\title{
METAL DIFFUSION AND \\ CHEMICAL PROCESSES \\ OF MONO AND BI-LAYER THIN FILMS
}

Małgorzata Pachecka 


\section{METAL DIFFUSION AND CHEMICAL \\ PROCESSES OF MONO AND BI-LAYER THIN \\ FILMS}

Małgorzata Pachecka 


\section{$\mathrm{PhD}$ committee}

\section{Chairman:}

Prof.dr.ir. J.W.M. Hilgenkamp University of Twente

\section{Supervisor:}

Prof.dr. F. Bijkerk

University of Twente

\section{Members:}

Prof.dr. F. Roozeboom

Eindhoven University of Technology

Prof.dr. W. van der Zande

Radboud University

Dr. A. Y. Kovalgin

University of Twente

Prof.dr. D. J. Gravesteijn

University of Twente

Cover: Delta value for the full spectral range obtained from in situ measurement of tin deposition on silicon wafer. Picture shows data obtained at 1 minute intervals during deposition.

Nederlandse titel:

Metaal diffusie en chemische oppervlakte processen van mono en bi-laag dunne films 


\section{METAL DIFFUSION AND CHEMICAL PROCESSES OF MONO AND BI-LAYER THIN FILMS}

\section{DISSERTATION}

to obtain

the degree of doctor at the University of Twente, on the authority of the rector magnificus, prof.dr. T.T.M. Palstra, on account of the decision of the graduation committee, to be publicly defended

on Friday the 13 of July 2018 at 14.45 hours

by

\section{Małgorzata Pachecka}

born on the 22 April 1987

in Siedlce, Poland 
This dissertation has been approved by:

Supervisor: prof.dr. F. Bijkerk

ISBN: 978-90-365-4568-6

CMałgorzata Pachecka (2018) 


\section{This thesis is based on the following publications:}

\section{Chapter 2:}

Pachecka, M.; Sturm, J. M.; van de Kruijs, R. W. E.; Lee, C. J.; Bijkerk, F., Electronegativity-Dependent Tin Etching from Thin Films. AIP Adv. 2016, 6, 075222.

\section{Chapter 3:}

Pachecka, M.; Lee, C. J.; Sturm, J. M.; Bijkerk, F., Tin Etching from Metallic and Oxidized Scandium Thin Films. AIP Adv. 2017, 7, 085107.

\section{Chapter 4:}

Pachecka, M.; Lee, C. J.; Sturm, J. M.; Bijkerk, F., Metal Diffusion Properties of Ultra-Thin High-k Sc $\mathrm{S}_{3}$ Films. AIP Adv. 2017, 7, 105324.

\section{Chapter 5:}

Pachecka, M.; Sturm, J. M.; Lee, C. J.; Bijkerk, F., Adsorption and Dissociation of $\mathrm{CO}_{2}$ on Ru(0001). J. Phys. Chem. C 2017, 121, 6729-6735.

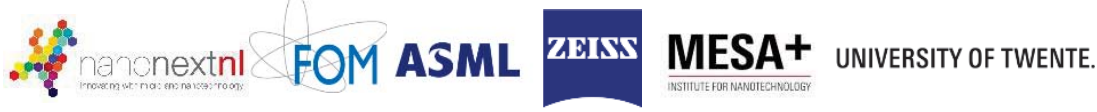

This work has been executed in the Industrial Focus Group XUV Optics as a part of the MESA+ Institute for Nanotechnology and the University of Twente (www.utwente.nl/mesaplus/xuv). It has been supported by NanoNextNL, a micro and nanotechnology consortium of the Government of the Netherlands and 130 partners. We acknowledge the support of ASML, Carl Zeiss SMT AG, Malvern Panalytical, SolMates, TNO, and Demcon, as well as the Province of Overijssel and the Foundation FOM. This work is additionally supported by the research programme Controlling photon and plasma induced processes at EUV optical surfaces (CP3E) of the Stichting voor Fundamenteel Onderzoek der Materie (FOM) with financial support from the Nederlandse Organisatie voor Wetenschappelijk Onderzoek (NWO). 



\section{Contents}

Chapter 1 Introduction........................................................... 1

1.1. Semiconductor motivated thin film materials research......... 1

1.1.1. Tin contamination control .......................................... 2

1.1.2 Hydrogen penetration control.................................... 4

1.2. High-k dielectrics applications .............................................. 4

1.3. Surface chemistry - electronegativity.................................... 5

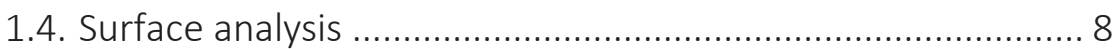

1.4.1. Spectroscopic ellipsometry....................................... 8

1.4.2. Low-energy ion scattering and $x$-ray photoelectron spectroscopy............................................................... 10

1.4.3. Reflection-absorption infrared spectroscopy ............ 11

1.4.4. Temperature programed desorption ........................ 12

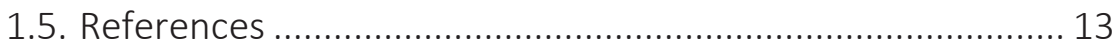

Chapter 2 Electronegativity-dependent tin etching from thin films................................................................ 19

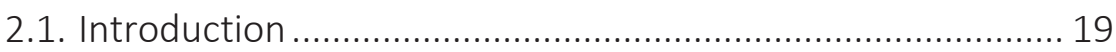

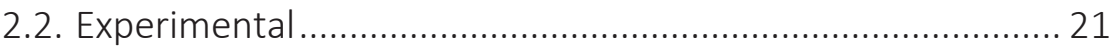

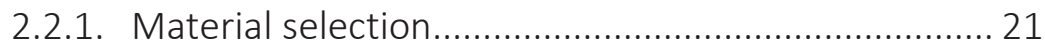

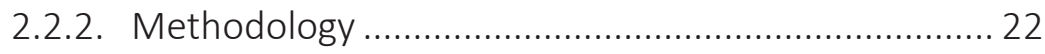

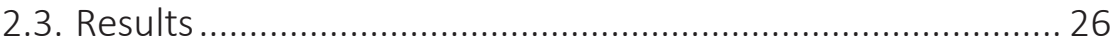

2.3.1. Tin deposition and etching in situ monitored with

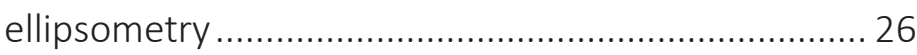

2.3.2. Electronegativity dependent Sn etching ................... 30

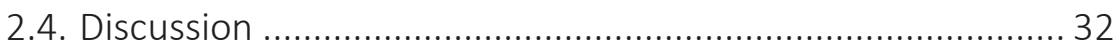

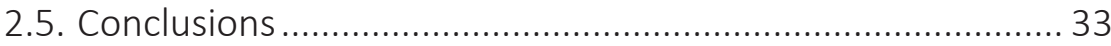




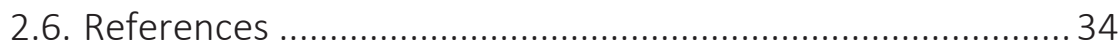

Chapter 3 Tin etching from metallic and oxidized Scandium thin films................................................................. 36

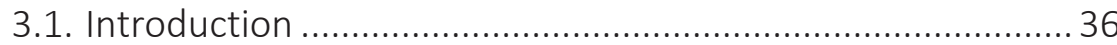

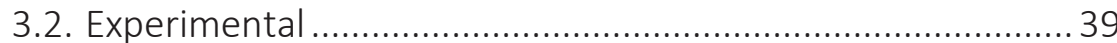

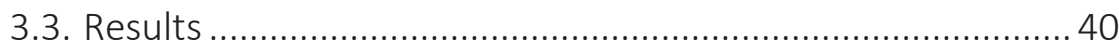

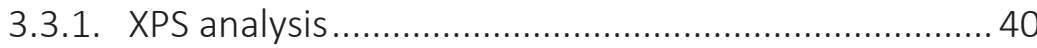

3.3.2. Sn deposition and etching measured with in-situ ellipsometry ............................................................. 43

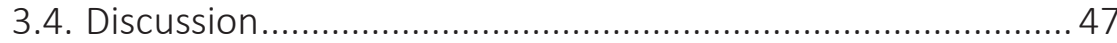

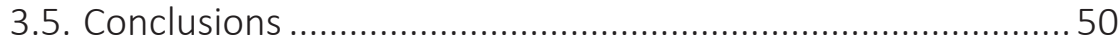

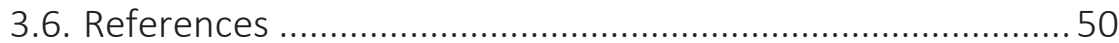

Chapter 4 Metal diffusion properties of ultra-thin high-k $\mathrm{Sc}_{2} \mathrm{O}_{3}$ films......................................................................... 54

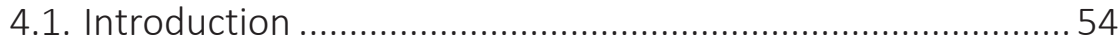

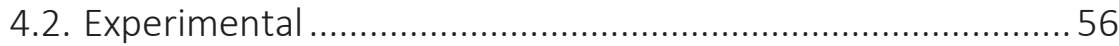

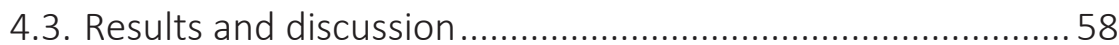

4.3.1. As deposited sample analysis -LEIS........................... 58

4.3.2. Tin deposition and etching - in situ ellipsometry

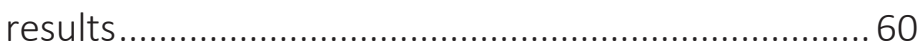

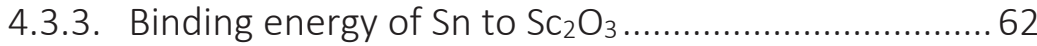

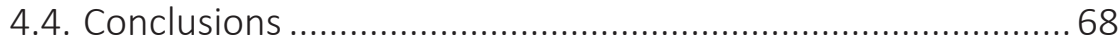

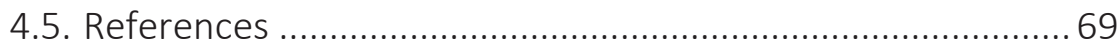

Chapter 5 Adsorption and dissociation of $\mathrm{CO}_{2}$ on $\mathrm{Ru}(0001) \ldots . .71$

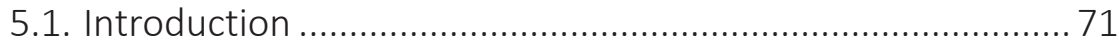

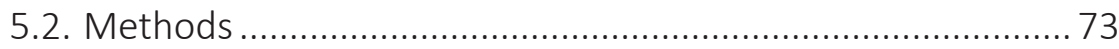




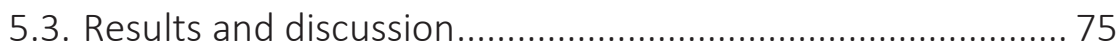

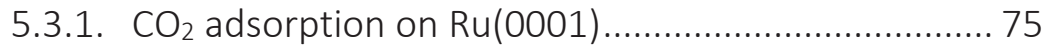

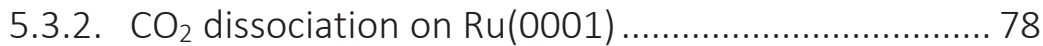

5.3.3. CO adsorption from the residual background gasses on

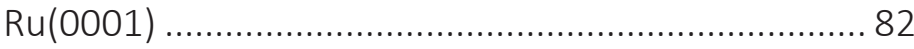

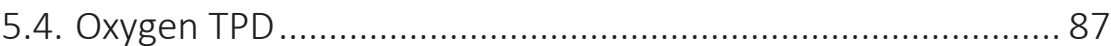

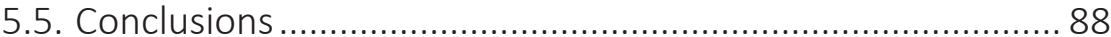

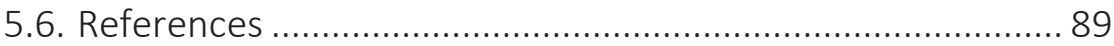

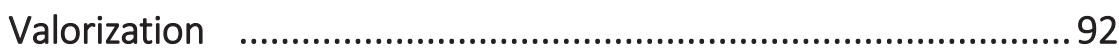

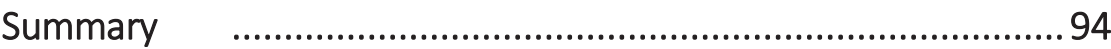

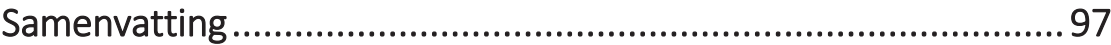

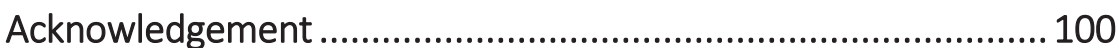

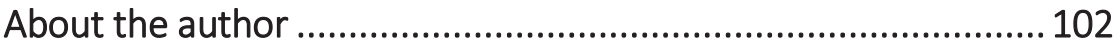





\section{Chapter 1}

\section{Introduction}

\subsection{Semiconductor motivated thin film materials research}

This thesis deals with two examples of materials research as motivated by modern semiconductor developments. The research concerns physical and chemical studies of thin film systems as used for optics and high-k dielectrics.

In thin-film applications, diffusion, and surface binding play key roles in the longevity of the film. For instance, the interface between the gate material and its surroundings plays a role in determining the capacitance and charge mobility. The stability of that interface, which is influenced by diffusion, will influence the lifetime and performance of an electronic device. Likewise, optical coatings must adhere to substrate surfaces, but, at the same time, the coating should not allow atmospheric contaminants, such as dirt, or oil to bind strongly. If this is not achieved, the coating performance will decay with time because contaminants cannot be cleaned.

In this thesis, surface binding and diffusion has been studied in model systems to investigate how the surface and the underlying thin-film changes surface binding. We show that for metal-metal interactions, surface binding strength can be predicted using a simple electronegativity model. In later work, we show that metaldielectric binding is strongly influenced by the underlying thin-film with electron diffusion and tunneling playing a role in controlling the surface-binding strength. 
The difference between conventional optical lithography (DUV) and EUVL is the use of very short wavelength light, and has required new research across the entire technology spectrum. ${ }^{1-15}$ New types of plasma light sources, based on $\operatorname{tin}^{16}$ are required to generate the short wavelength EUV light, and wafers must be exposed under vacuum to minimize EUV intensity losses by gaseous absorption, and to avoid contamination or oxidation of the optical elements.

EUV optics are reflective multilayer optics, consisting of artificial Bragg crystals with periodicity of half of the $13.5 \mathrm{~nm}$ wavelength. A stack of thin layers of alternating materials (with high and low refractive index) is created and reflected waves from all interfaces add up constructively. In practice 50-70 bilayers of Mo and Si have a reflectance of around $70 \%$, close to the theoretical maximum. ${ }^{1,13,17-18}$

Under EUV exposure, the optics may be subject to recoverable and non-recoverable reflectivity losses due to contamination. Thus, the MLM is terminated with a material that is more resistant to the environment (physical and chemical processes), while, at the same time, maximizing the mirror's reflectivity. Although not the only relevant surface binding process, ${ }^{11}, 19$ the focus of this thesis is mostly on understanding metal-metal and metal-dielectric surface processes, using tin as a model material.

\subsubsection{Tin contamination control}

Plasma facing mirror surfaces and any surfaces that are within the diffusion range of $\mathrm{Sn}$ particles and vapor may be contaminated with Sn. ${ }^{20}$ Any Sn particles on the mirror surface can also decrease its reflectivity. For instance, the presence of $1 \mathrm{~nm} \mathrm{Sn}$ on a mirror results in a reflection loss of $10 \% .{ }^{9,20}$

In order to prevent the optics from losing reflectivity and to enhance the mirror's lifetime, in situ mirror cleaning technologies may be used to maintain the optics performance. ${ }^{1}$ Carbon can be 
removed by atomic hydrogen etching. Oxidation is more problematic. But, for a Ru-terminated mirror, as long as a monolayer or less of oxide is formed, oxidation can be reversed by exposure to atomic hydrogen. ${ }^{21} \mathrm{Sn}$ can also be removed from mirror surfaces using hydrogen etching. ${ }^{20}$ Atomic hydrogen reacts readily with $\mathrm{Sn}$ (see equation $1-1$ ), in the +4 oxidation state, to form stannane $\left(\mathrm{SnH}_{4}\right)$, which is volatile at room temperature:

$$
\mathrm{Sn}+4 \mathrm{H}^{\cdot} \rightarrow \mathrm{Sn} \mathrm{H}_{4} \uparrow
$$

Stannane is unstable and decomposes slowly at room temperature to give metallic tin. Moreover, the dissociation of $\mathrm{SnH}_{4}$ can be accelerated by the presence of catalytically active surfaces (metallic $\mathrm{Sn}$ catalyzes the dissociation of $\mathrm{SnH}_{4}$ ). ${ }^{22}$ Transition metals may also catalyze the dissociation of stannane. ${ }^{23-24}$ On the other hand, the addition of a small amount of oxygen considerably slows the dissociation due to the formation of a non-catalyzing tin oxide film.

Although Sn can be etched rapidly by atomic hydrogen, the etching process was found to be incomplete when Sn was deposited on a Ru surface. Sn etching from a Ru surface can be improved by adding $\mathrm{Si}_{3} \mathrm{~N}_{4} \cdot{ }^{20}$

There have been numerous empirical studies on $\mathrm{Sn}$ removal from thin metal layers like $\mathrm{Ru}, \mathrm{Mo}, \mathrm{Si}, \mathrm{Pd}, \mathrm{Au}, \mathrm{Si}_{3} \mathrm{~N}_{4}, \mathrm{SiO}_{2}{ }^{9}, 15,20,25-26$ However, no systematic investigation has been performed, and the previous studies had little predictive power for the materials not directly investigated. To predict lifetime, the physics and chemistry of Sn etching must be understood in order to ensure that etching is complete and that the process does not damage the surface of the optical element.

In this thesis, we propose electronegativity as a factor that can be used to determine if $\mathrm{Sn}$ is etchable from a given material. We show that electronegativity is highly predictive in the case of metals. 


\subsubsection{Hydrogen penetration control}

In this thesis, we initiated the study of the application of catalytic surface reactions with carbon species to control hydrogen penetration. In principle carbon monoxide is the ideal species, since it strongly adsorbs to metallic surfaces, and is known to react directly with hydrogen to produce volatile hydrocarbons (via the Fischer-Tropsch reaction). ${ }^{27}$ However, even though a low partial pressure of CO may be sufficient to protect mirror surfaces, the sheer volume of the EUVL vacuum vessel requires dangerous amounts of $\mathrm{CO}$ to be available in a fabrication facility. Thus, it was decided to investigate carbon dioxide $\left(\mathrm{CO}_{2}\right)$ as a possible candidate for consuming hydrogen at the surface layer. Carbon dioxide may either directly react with hydrogen in a reverse water gas shift reaction, or indirectly via partial dissociation followed by a FischerTropsch reaction. In both cases, hydrogen would be consumed, thereby preventing hydrogen from penetrating into the mirror. Although the $\mathrm{CO}_{2}$ absorption has been studied on many materials, such as $\mathrm{Ph}, \mathrm{Pd}, \mathrm{Pt}, \mathrm{Fe}, \mathrm{Cu}, \mathrm{Re}, \mathrm{Ni}, \mathrm{Al}$ and $\mathrm{Mg}, \mathrm{CO}_{2}$ adsorption on $\mathrm{Ru}$ has not been investigated. ${ }^{28}$ In this thesis we studied $\mathrm{CO}_{2}$ adsorption and dissociation on single crystalline Ru.

\subsection{High-k dielectrics applications}

In semiconductor manufacturing processes, silicon dioxide $\left(\mathrm{SiO}_{2}\right)$ has been used as a gate oxide material. In order to continue the miniaturization of integrated circuit features, the implementation of high-k gate dielectrics, among several other strategies is required. ${ }^{29-30}$ As transistors have decreased in size, the thickness of the $\mathrm{SiO}_{2}$ gate dielectric has steadily decreased to increase the gate capacitance and, thereby, drive current. The reduction in current raises device performance and reduces power consumption, both desirable attributes. However, decreasing the thickness of $\mathrm{SiO}_{2}$ also leads to higher leakage currents due to tunneling, which increases 
power consumption, and reduces device reliability. Replacing the silicon dioxide gate dielectric with an alternative material that has a higher $\mathrm{k}$ value allows increased gate capacitance without the associated leakage effects. ${ }^{31-33}$ The gate oxide material must satisfy several criteria: in addition to the electronic function of a gate dielectric, the gate oxide material must maintain a high dielectric constant, and serve as a diffusion barrier against diffusion of material from the top electrode. Hence, it is also of importance to know the diffusion-barrier behavior. ${ }^{34}$ Group III based dielectrics, such as scandium oxide $\left(\mathrm{SC}_{2} \mathrm{O}_{3}\right)$, have been studied as possible candidate for high-k dielectric applications. ${ }^{29}$ Although the electronic properties of $\mathrm{Sc}_{2} \mathrm{O}_{3}$ were widely studied, the diffusionbarrier properties have not been investigated. ${ }^{31-33}$ In this thesis, diffusion studies were carried out. We used $\mathrm{Sn}$ to test if $\mathrm{Sc}_{2} \mathrm{O}_{3}$ layers of various thicknesses act as a diffusion barrier. Moreover we estimated electron tunneling rates for layers in the range of $0.7-1.5 \mathrm{~nm}$.

\subsection{Surface chemistry - electronegativity}

To understand the behavior of Sn at a surface, we use the concept of electronegativity. Electronegativity, $\chi$ (chi), is one of the three most important factors (electronegativity, electron affinity, ionization energy) which influence the type of bond between two atoms. ${ }^{35}$ Electronegativity is a parameter that was introduced by Linus Pauling (in 1932) as a measure of the power of an atom to attract electrons to itself when it is part of a compound. ${ }^{36}$ In Pauling's relative scale, valence-bond arguments were used to suggest that an appropriate numerical scale of electronegativities could be defined in terms of bond dissociation energies, $E_{d}$. Pauling proposed that the difference in electronegativities (equation 1-2) could be calculated based on:

$$
\mathrm{E}_{\mathrm{d}}(\mathrm{A}-\mathrm{B})=\frac{1}{2}\left[\mathrm{E}_{\mathrm{d}}(\mathrm{A}-\mathrm{A})+\mathrm{E}_{\mathrm{d}}(\mathrm{B}-\mathrm{B})\right]+a\left(\mathrm{\chi}_{(\mathrm{A})}-\chi_{(\mathrm{B})}\right)
$$


Where $E_{d}$ are the dissociation energies of the $A-B, A-A$ and $B-B$, $\chi_{(A)}$ and $\chi_{(B)}$ are the electronegativities of $A$ and $B$, respectively, and $a$ is equal to 96.5 when all energies are expressed in $\mathrm{kJ} \mathrm{mol}^{-1}\left(1 \mathrm{eV}=96.5 \mathrm{~kJ} \mathrm{~mol}^{-1}\right)$. As only differences in electronegativity are defined, it is necessary to choose an arbitrary reference point in order to construct a scale. Hydrogen was chosen as the reference with an electronegativity of 2.2, as it forms covalent bonds with a large variety of elements. ${ }^{36}$ The periodic table with the electronegativities values is presented in Figure 1-2. Electronegativity generally increases from left to right on the periodic table and from bottom to top. Metals are the least electronegative of the elements. An important application of electronegativity is in the prediction of the polarity of a chemical bond (Figure 1-1).

It was found that the greater the difference in electronegativities between elements, the greater the polar nature of the bond. ${ }^{35}$ In this thesis, relative electronegativities are used to successfully predict the success or failure of Sn etching from different surfaces.

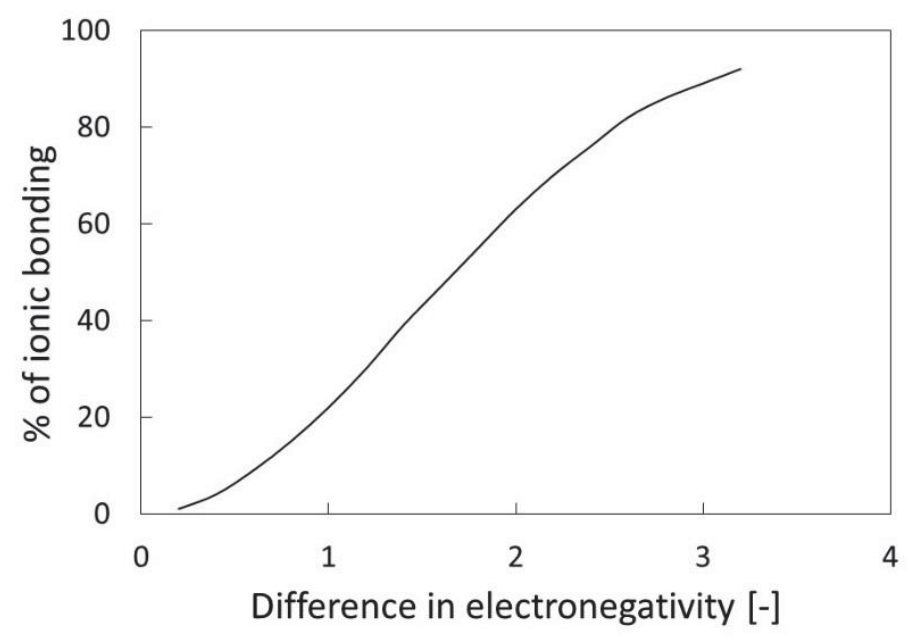

Figure 1-1. Percentage of ionic bond in chemical bond as a function of difference in electronegativity between the atoms. 


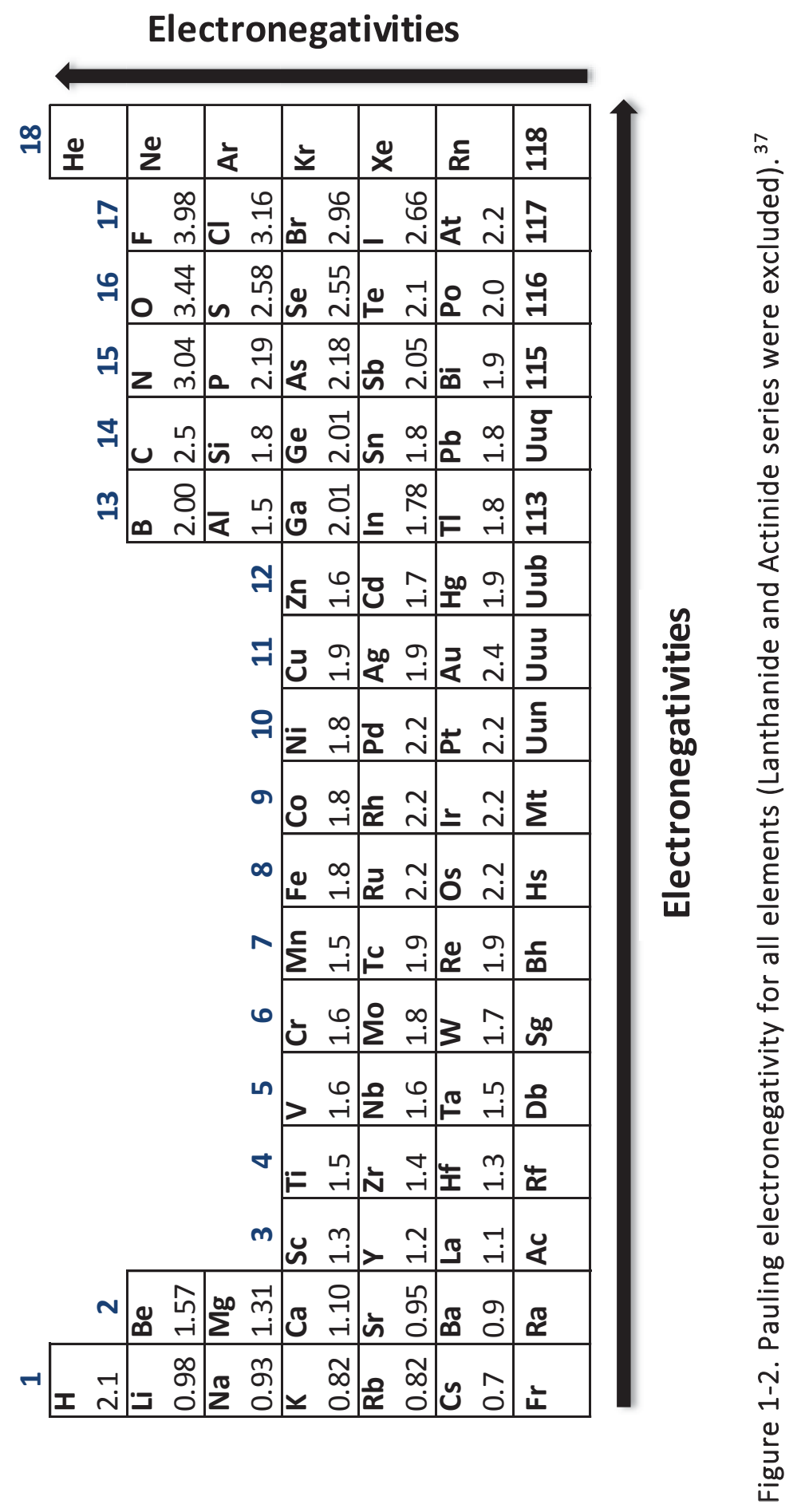




\subsection{Surface analysis}

Most of the techniques for surface analysis are used in vacuum to reduce scattering of electrons and/or ions by gas phase molecules. Measuring in vacuum also allows the influence of the ambient on the surface to be controlled. ${ }^{38}$ Many surface analysis techniques are not surface specific, so surface sensitivity plays an important role. The surface sensitivity depends on the escape depth of the detected probe. Moreover, the possibility of surface damage during analysis and influence of the incident electrons, photons or ions on the results must be taken into account. ${ }^{38}$ Many surface studies have been performed using scanning tunneling microscopy (STM), low energy electron diffraction (LEED), and X-ray photoelectron spectroscopy (XPS). STM can provide an information on the surface morphology, however it can be challenging to resolve some chemical reactions. ${ }^{39-41}$ LEED is sensitive to ordered overlayer structures and XPS is sensitive to chemical changes at the surface, but, the relatively high energy of the electron and X-Ray irradiation can lead to surface modifications that may be difficult to separate from the changes of interest. ${ }^{42-47}$ For surface adhesion and etching, studies, we have used X-ray fluorescence (XRF), X-ray photoelectron spectroscopy (XPS), scanning electron microscopy (SEM) and ellipsometry, which, taken together, give a very good overview of the surface chemistry and morphology changes during various experiments. ${ }^{25,}$,2-48 XRF has even higher elemental sensitivity than XPS, but no chemical sensitivity and cannot distinguish between surface and buried elements. Some of the techniques used in this thesis are described in more details below.

\subsubsection{Spectroscopic ellipsometry}

Spectroscopic ellipsometry was originally used in the work of Paul Drude in the $19^{\text {th }}$ century, when he used a polarized light in a reflection configuration to study the optical properties and 
thickness of very thin metallic films. ${ }^{49-53}$ In ellipsometry, polarized light is used to characterize the optical properties of materials. $49,51,53$ The change in polarization is represented by an amplitude ratio, $\Psi$, and a phase difference, $\Delta .{ }^{50}$ Together, these quantities determine the complex reflectance ratio (equation 1-3) ,$\rho$, according to:

$$
\rho=\tan (\Psi) \mathrm{e}^{\mathrm{i} \Delta}
$$

In general, the measured values for $\psi$ and $\Delta$ cannot be used to directly calculate the dielectric properties of the individual layers that comprise the sample (though the effective dielectric properties can be directly calculated). Instead, $\psi$ and $\Delta$ must be combined with modeling, which can provide layer thicknesses and material properties, making it an excellent tool for contact free determination of thickness and optical constants of films of all kinds. ${ }^{50,53-59}$ To create a proper model for measured samples, it is usually required that the structure/composition of the sample is already known to a certain extent. Such information may be obtained from a different measurement technique e.g. TEM or XPS, or from knowledge of how the sample was created 49, 51

Ellipsometry can yield information about layers with a sensitivity below a single atomic layer ${ }^{54}$, moreover, no reference measurement is necessary. By measuring two independent values at each wavelength, this technique provides more information than other optical techniques, such as conventional reflectometry. ${ }^{49}$ The maximum film thickness that can be measured with ellipsometry is limited to the coherence length of the light source. Thus, transparent or low absorbing thin films, with thickness ranging from less than a nanometer to several micrometers, can be measured with ellipsometry. ${ }^{49}$

Besides high sensitivity, ellipsometry has the advantage of being non-destructive and contactless. Additionally, ellipsometry can be used in an external configuration, which means that vacuum is not 
necessary, and with calibration, the instrument can probe the sample via optical ports, rather than being placed in the vacuum chamber. ${ }^{49}$ Ellipsometry measurements are also very fast (in a typical commercial instrument, a full spectrum can be collected every 3 seconds), providing data with high temporal resolution and allowing for the characterization of a sample in "real-time". A spectroscopic ellipsometer is also relatively easy to use and requires no sample preparation. ${ }^{54}$

\subsubsection{Low-energy ion scattering and x-ray photoelectron spectroscopy}

During low-energy ion scattering (LEIS) measurement sample surface is exposed with noble gas ions ( $\mathrm{He}+, \mathrm{Ne}+, \mathrm{Ar}+$, or $\mathrm{Kr}+$ ) in the range of 0.5 to $10 \mathrm{keV}$ and an incident angle of $<60^{\circ}$ with respect to the surface normal . ${ }^{60-62}$ Energy of the scattered ions depends only on the mass of the surface atoms. Elastic binary collision at the sample surface is characteristic for each element and is shown as a peak in LEIS spectrum, with a characteristic energy for each element. Moreover surface concentration of specific element is proportional to the peak intensity. ${ }^{62}$ Thus, due to high surface sensitivity, surface atomic composition can be determined with this technique. LEIS can also be used for the analysis of much deeper layers by using it in combination with sputter depth profiling. Moreover, the detection limit, for example, for light elements from Li to $O$ can reach $\leq 1 \%$. ${ }^{60,62}$ With LEIS, rough amorphous insulating samples as well as conducting flat single crystals can be analyzed. This flexibility allows LEIS to be used for studying important processes like adhesion, catalysis, diffusion, film growth, and electron emission for a wide variety of materials. ${ }^{62}$ The only restriction for the measurements is that measured samples must be put into vacuum for analysis. ${ }^{62}$

An alternative to LEIS is X-ray photoelectron spectroscopy (XPS). ${ }^{61-62}$ The sample in XPS is irradiated with monochromatic soft 
X-ray radiation. This energy is absorbed by the sample, which emits photoelectrons. The energy difference between incident radiation and emitted photoelectrons is used to calculate the binding energy of the electrons. XPS allows the sample elements and their atomic concentrations to be determined and the chemical states can, in many cases, be determined from small changes in the measured binding energy. ${ }^{63}$ In situ XPS has elemental sensitivities in the parts per thousand range, and is often directly sensitive to the average chemical changes in the top $\sim 5-10 \mathrm{~nm}$ of the surface layer, limited by the escape depth of the photoelectrons. ${ }^{42-47}$ Electrons generated deeper in the solid may escape, but on the way out they collide with other atoms and lose energy, therefore, they are not use for analysis. The surface sensitivity can be significantly increased by irradiating the surface at grazing incidence. However, in a grazing incidence geometry, less X-Ray radiation is absorbed, reducing the electron emission intensity, and increasing the time of XPS scans, which also reduces the temporal resolution of dynamic measurements. ${ }^{38}$

Similarly to the case of LEIS, XPS measurements require high vacuum ( $10^{-8} \mathrm{mbar}$ ) or ultra-high vacuum, making it inappropriate for in situ measurements of processes when relatively high pressures may be required for a surface process (e.g., deposition or etching processes). ${ }^{63}$

\subsubsection{Reflection-absorption infrared spectroscopy}

With reflection-absorption infrared spectroscopy (RAIRS), the infrared spectrum of light, reflected from a (normally metallic) sample surface, covered with a thin layer, is examined. Infraredfrequency dependent absorption by the thin layer is used to characterize the layer. Such absorption bands correspond to the normal ro-vibrational modes of molecules, and can provide detailed information about the geometric structure of the molecules and the force constant of bonds, both within molecules 
and between the molecules and the underlying metal surface. ${ }^{64}$ The growth and decay of vibrational modes can be studied in situ. Depending on the species of chemical in the adsorbed layer, the sensitivity of RAIRS can be lower than a monolayer of coverage (down to a few percent of a monolayer). Thus, RAIRS is used for studying reactions, molecular adsorption, surface phase transitions, and/or lateral inter-molecular interactions. Moreover, RAIRS is very suitable for studying catalytic reactions under a wide range of pressure conditions. ${ }^{64-66}$

RAIRS has excellent energy resolution $\left(<2 \mathrm{~cm}^{-1}\right)$ which is useful for separating multiple peaks, phase transitions, lateral interactions and dynamics of coupling. Furthermore, due to the low energy of the radiation in RAIRS, in situ studies are highly unlikely to modify the surface during measurement. ${ }^{64}$ Beside the fact that it is a straightforward instrument to use, RIARS is not restricted to vacuum conditions, making it highly versatile.

The fact that the signal is weak, owing to the small number of absorbing molecules, is one of the limitations of this technique. Moreover, RAIRS only excites out-of-plane vibrational modes of the dipole moments via constructive interference. While the in-plane surface vibrational modes are suppressed by the metal surface due to destructive interference effects. This limits the technique in quantifying the coverage. ${ }^{64-65,67-68}$

\subsubsection{Temperature programed desorption}

In temperature programed desorption (TPD) spectroscopy it is possible to detect elements and components at the surface by measuring the temperature at which molecules desorb from the surface. This is achieved via controlled surface heating at a constant rate and use of a mass spectrometer positioned close to the surface. Depending on the mass spectrometer, TPD allows several masses to be detected at the same time. TPD provides a direct measurement of the surface binding energy, and allows for an 
absolute measure of surface coverage. Analyzed species on the surface are desorbed during measurements, thus it a technique that significantly changes the surface chemical composition during the measurement. ${ }^{66,69-71}$ Residual background gases will prevent the TPD from being measured, thus the measurements require UHV.

By combining TPD and RAIRS, it is often possible to draw more quantitative conclusions from the results than from both techniques separately.

\subsection{References}

1. Kemp, K.; Wurm, S., Euv Lithography. C. R. Physique 2006, 7, 875886.

2. Fiedorowicz, H.; Bartnik, A.; Jarocki, R.; Kostecki, J.; Krzywiński, J.; Mikołajczyk, J.; Rakowski, R.; Szczurek, A.; Szczurek, M., Compact Laser Plasma Euv Source Based on a Gas Puff Target for Metrology Applications. J. Alloy. Compd. 2005, 401, 99-103.

3. Development of Sn-Fueled High-Power Dpp Euv Source for Enabling Hvm. 2008.

4. Cleaning of Tin Debris by Reactive Ion Etching in a DischargeProduced Euv Plasma Source. 2009.

5. Chen, J., et al., Detection and Characterization of Carbon Contamination on Euv Multilayer Mirrors. Opt. Express 2009, 17, 16969-16979.

6. Kostera, N., et al., Molecular Contamination Mitigation in Euvl by Environmental Control. Microelectron. Eng. 2002, 61-62, 65-76.

7. Hou, K.-C.; George, S.; Mordovanakis, A. G.; Takenoshita, K.; Nees, J.; Lafontaine, B.; Richardson, M.; Galvanauskas, A., High Power Fiber Laser Driver for Efficient Euv Lithography Source with Tin-Doped Water Droplet Targets. Opt. Express 2008, 16, 965-974.

8. Louis, E.; Yakshin, A. E.; Tsarfati, T.; Bijkerk, F., Nanometer Interface and Materials Control for Multilayer Euv-Optical Applications. Prog. Surf. Sci. 2011, 86, 255-294.

9. Mackay, R. S.; Klunder, D. J. W.; van Herpen, M. M. J. W.; Banine, V. Y.; Gielissen, K., Debris Mitigation and Cleaning Strategies for Sn- 
Based Sources for Euv Lithography. Proc. of SPIE 2005, 5751, 943951.

10. Madey, T. E.; Faradzhev, N. S.; Yakshinskiy, B. V.; Edwards, N. V., Surface Phenomena Related to Mirror Degradation in Extreme Ultraviolet (Euv) Lithography. Appl. Surf. Sci. 2006, 253, 1691-1708.

11. Mertens, B., Progress in Euv Optics Lifetime Expectations. Microelectron. Eng. 2004, 73-74, 16-22.

12. Motai, K.; Oizumi, H.; Miyagaki, S.; Nishiyama, I.; Izumi, A.; Ueno, T.; Namiki, A., Cleaning Technology for Euv Multilayer Mirror Using Atomic Hydrogen Generated with Hot Wire. Thin Solid Films 2008, 516, 839-843.

13. Paret, V.; Boher, P.; Geyl, R.; Vidal, B.; Putero-Vuaroqueaux, M.; Etienne Quesnel , E.; Robic, J.-Y., Characterization of Optics and Masks for the Euv Lithography. Microelectron. Eng. 2002, 61-62, 145-155.

14. Graham, S.; Steinhaus, C.; Clift, M.; Klebanoff, L.; Bajt, S., Atomic Hydrogen Cleaning of Euv Multilayer Optics. Proc. of SPIE 2003, 5037, 460-469.

15. van Herpen, M. M. J. W.; Klunder, D. J. W.; Soer, W. A.; Moors, R.; Banine, V., Sn Etching with Hydrogen Radicals to Clean Euv Optics. Chem. Phys. Lett. 2010, 484, 197-199.

16. Banine, V.; Moors, R., Plasma Sources for Euv Lithography Exposure Tools. J. Phys. D: Appl. Phys. 2004, 37, 3207-3212.

17. Oestreich, S.; Klein, R.; Scholze, F.; Jonkers, J.; 3, E. L., E.; Yakshin, A.; Görts, P.; Ulm, G.; Haidl, M.; Bijkerk, F., Multilayer Reflectance During Exposure to Euv Radiation. SPIE 2000, 4146.

18. Bakshi, V., Euv Lithography; SPIE Press, 2009.

19. Dolgov, A.; Lopaev, D.; Lee, C. J.; Zoethout, E.; Medvedev, V.; Yakushev, O.; Bijkerk, F., Characterization of Carbon Contamination under Ion and Hot Atom Bombardment in a Tin-Plasma Extreme Ultraviolet Light Source. Appl. Surf. Sci. 2015, 353, 708-713.

20. Soer, W. A.; van Herpen, M. M. J. W.; Jak, M. J. J.; Gawlitza, P.; Braun, S.; Salashchenko, N. N.; Chkhalo, N. I.; Banine, V. Y., AtomicHydrogen Cleaning of Sn from Mo/Si and Dlc/Si Extreme Ultraviolet Multilayer Mirrors. J. Micro/Nanolith. MEMS MOEMS 2012, 11, 021118-1.

21. Dolgov, A.; Abrikosov, A.; Lee, C. J.; Krivtsun, V. M.; Yaskushev, O.; Lopaev, D.; van Kaampen, M.; Bijkerk, F., Plasma-Assisted Oxide 
Removal from Ruthenium Coated Euv Optics. J. Appl. Phys. 2017, submitted.

22. Tamaru, K., The Thermal Decomposition of Tin Hydride. J. Phys. Chem. 1956, 60, 610-612.

23. Faradzhev, N.; Sidorkin, V., Hydrogen Mediated Transport of Sn to Ru Film Surface. J. Vac. Sci. Technol., A 2009, 27, 306.

24. Masel, R. I., Principles of Adsorption and Reaction on Solid Surfaces; John Wiley \& Sons, 1996.

25. Ugur, D.; Storm, A. J.; Verberk, R.; Brouwer, J. C.; Sloof, W. G., Decomposition of Snh4 Molecules on Metal and Metal-Oxide Surfaces. Appl. Surf. Sci. 2014, 288, 673-676.

26. Ugur, D.; Storm, A. J.; Verberk, R.; Brouwer, J. C.; Sloof, W. G., Generation and Decomposition of Volatile Tin Hydrides Monitored by in Situ Quartz Crystal Microbalances. Chem. Phys. Lett. 2012, 552, 122-125.

27. Craxford, S. R., On the Mechanism of the Fischer-Tropsch Reaction. Trans. Faraday Soc. 1946, 42.

28. Solymosi, F., The Bonding, Structure and Reactions of Co2 Adsorbed on Clean and Promoted Metal Surfaces. J. Mol. Catal. 1991, 65, 337358.

29. Klenov, D. O.; Edge, L. F.; Schlom, D. G.; Stemmer, S., Extended Defects in Epitaxial Sc2o3 Films Grown on (111) Si. Appl. Phys. Lett. 2005, 86, 051901.

30. Zhao, C., et al., Ternary Rare-Earth Metal Oxide High-K Layers on Silicon Oxide. Appl. Phys. Lett. 2005, 86, 132903.

31. Sivasubramani, P., et al., Thermal Stability of Lanthanum Scandate Dielectrics on Si(100). Appl. Phys. Lett. 2006, 89, 242907.

32. Luo, B., et al., Surface Passivation of Algan/Gan Hemts Using MbeGrown Mgo or Sc203. Solid-State Electron. 2002, 46.

33. Mehandru, R., et al., Algan/Gan Metal-Oxide-Semiconductor High Electron Mobility Transistors Using Sc[Sub 2]O[Sub 3] as the Gate Oxide and Surface Passivation. Appl. Phys. Lett. 2003, 82, 2530.

34. Shannon, R. D., Dielectric Polarizabilities of Ions in Oxides and Fluorides. J. Appl. Phys. 1993, 73, 348-366.

35. Atkins, P. W.; de Paula, J., Atkins's Physical Chemistry, 7 ed.; Oxford University Press, 2002. 
36. Pauling, L., The Nature of the Chemical Bond. Iv. The Energy of Single Bonds and the Relative Electronegativity of Atoms. JACS 1932, 54, 3570-3582.

37. Atkins, P. W., Physical Chemistry, Third ed.; Oxford University Press, 1986.

38. Surface Analysis the Principal Techniques, 2 ed.; John Wiley \& Sons Ltd, 2009.

39. Eren, B.; Zherebetskyy, D.; Patera, L. L.; Wu, C. H.; Bluhm, H.; Africh, C.; Wang, L.-W.; Somorjai, G. A.; Salmeron, M., Activation of Cu(111) Surface by Decomposition into Nanoclusters Driven by Co Adsorption. Surf. Sci. 2016, 351, 475-478.

40. Mongeot de, F. B.; Scherer, M.; Gleich, B.; Kopatzki, E.; Behm, R. J., Co Adsorption and Oxidation on Bimetallic Pt/Ru(0001) Surfaces - a Combined Stm and Tpd/Tpr Study. Surf. Sci. 1998, 411, 249-262.

41. Onishi, H.; Iwasawa, Y., Reconstruction of Tio,( 110) Surface: Stm Study with Atomic-Scale Resolution. Surf. Sci. 1994, 313, 783-789.

42. Kong, D.; Zhu, J.; Ernst, K.-H., Low-Temperature Dissociation of Co2 on a Ni/Ceo2(111)/Ru(0001) Model Catalyst. J. Phys. Chem. C 2016, 120, 5980-5987.

43. Wambach, J.; Illing, G.; Freund, H. J., Co2 Activation and Reaction with Hydrogen on $\mathrm{Ni}$ ( 110): Formate Formation. Chem. Phys. Lett. 1991, 184, 239-244.

44. Behner, H.; Spiess, W.; Wedler, G.; Borgmann, D.; Freund, H. J., Electron Energy Loss Study of the Electronically Excited States of Adsorbedco2: Case Study Co2/Fe. Surf. Sci. 1987, 184, 335-344.

45. Diemant, T.; Schuttler, K. M.; Behm, R. J., Ag on Pt(111): Changes in Electronic and Co Adsorption Properties Upon Ptag/Pt(111) Monolayer Surface Alloy Formation. Chem. Phys. Chem. 2015, 16, 2943-2952.

46. Wang, W.; Li, L.; Zhou, Q.; Pan, J.; Zhang, Z. L.; Tok, E. S.; Yeo, Y.-C., Tin Surface Segregation, Desorption, and Island Formation During Post-Growth Annealing of Strained Epitaxial Ge1-Xsnx Layer on Ge(001) Substrate. Appl. Surf. Sci. 2014, 321, 240-244.

47. Böttcher, A.; Niehus, H., Formation of Subsurface Oxygen at Ru(0001). J. Chem. Phys. 1999, 110, 3186-3195.

48. Braginsky, O. V., et al., Removal of Amorphous $\mathrm{C}$ and $\mathrm{Sn}$ on Mo:Si Multilayer Mirror Surface in Hydrogen Plasma and Afterglow. J. Appl. Phys. 2012, 111, 093304. 
49. Garcia-Caurel, E.; de Martino, A.; Gaston, J.-P.; Yan, L., Application of Spectroscopic Ellipsometry and Mueller Ellipsometry to Optical Characterization. Appl. Spectrosc. 2013, 67.

50. Handbook of Ellipsometry; Willam Andrew, Springer, 2005.

51. Partovi, F., Theoretical Treatment of Ellipsometry. J. Opt. Soc. Am. 1962, 52.

52. Drude, P., Ueber Die Gesetze Der Reflexion Und Brechung Des Lichtes an Der Grenze Absorbirender Krystalle. Annalen der Physik 1887, 268.

53. McCrackin, F. L.; Passaglia, E.; Stromberg, R. R.; L., S. H., Measurement of the Thickness and Refractive Index of Very Thin Films and Teh Optical Properties of Surfaces by Ellipsometry. J. Res. Natl. Bur. Stand. Sec. A 1963, 67A, 363-377.

54. Chen, J.; Louis, E.; Harmsen, R.; Tsarfati, T.; Wormeester, H.; van Kampen, M.; van Schaik, W.; van de Kruijs, R. W. E.; Bijkerk, F., In Situ Ellipsometry Study of Atomic Hydrogen Etching of Extreme Ultraviolet Induced Carbon Layers. Appl. Surf. Sci. 2011, 258, 7-12.

55. Chen, J.; Lee, C. J.; Louis, E.; Bijkerk, F.; Kunze, R.; Schmidt, H.; Schneider, D.; Moors, R., Characterization of Euv Induced Carbon Films Using Laser-Generated Surface Acoustic Waves. Diam. Relat. Mater. 2009, 18, 768-771.

56. Chen, J.; Louis, E.; Wormeester, H.; Harmsen, R.; van de Kruijs, R. W. E.; Lee, C. J.; van Schaik, W.; Bijkerk, F., Carbon-Induced Extreme Ultraviolet Reflectance Loss Characterized Using Visible-Light Ellipsometry. Meas. Sci. Technol. 2011, 22, 105705.

57. Aspnes, D. E., Spectroscopic Ellipsometry-a Perspective. J. Vac. Sci. Technol. A 2013, 31, 058502.

58. Synowicki, R. A., Spectroscopic Ellipsometry Characterization of Indium Tin Oxide Film Microstructure and Optical Constants. Thin Solid Films 1998, 313-314, 394-397.

59. Oates, T. W. H.; Wormeester, H.; Arwin, H., Characterization of Plasmonic Effects in Thin Films and Metamaterials Using Spectroscopic Ellipsometry. Prog. Surf. Sci. 2011, 86, 328-376.

60. Brongersma, H. H.; Oosterhoff, L. J., High Resolution Singlet-Triplet Excitation Spectra by Low Energy Electron Impact Spectroscopy. Chem. Phys. Lett. 1967, 1. 
61. Brongersma, H. H.; Buck, T. M., Low-Energy Ion Scattering (Leis) for Composition and Structure Analysis of the Outer Surface. Nucl. Instrum. Methods 1978, 149.

62. Brongersma, H. H., Low-Energy lon Scattering In: Characterization of Materials; J. wiley \& Sons, 2012.

63. Watts, J. F.; Wolstenholme, J., An Introduction to Surface Analysis by Xps and Aes; John Wiley \& Sons, 2005.

64. Greenler, R. G., Design of a Reflection-Absorption Experiment for Studying the Ir Spectrum of Molecules Adsorbed on a Metal Surface. J. Vac. Sci. Technol., 1975, 12, 1410-1417.

65. Barros, R. B.; Garcia, A. R.; Ilharcoand, L. M., The Decomposition Pathways of Methanol on Clean Ru(0001), Studied by ReflectionAbsorption Infrared Spectroscopy (Rairs). J. Phys. Chem. B 2001, 105, 11186-11193.

66. Sturm, J. M.; Lee, C. J.; Bijkerk, F., Reactions of Ethanol on Ru(0001). Surf. Sci. 2013, 612, 42-47.

67. Mendelsohn, R.; Mao, G.; Flach, C. R., Infrared Reflection-Absorption Spectroscopy: Principles and Applications to Lipid-Protein Interaction in Langmuir Films. Biochim. Biophys. Acta. 2010, 1798, 788-800.

68. Pearce, H. A.; Sheppard, N., Possible Importance of a "Metal-Surface Selection Rule" in the Interpretation of the Infrared Spectra of Molecules Adsorbed on Particulate Metals; Infrared Spectra from Ethylene Chemisorbed on Silica-Supported Metal Catalysts. Surf. Sci. 1976, 59, 205-217.

69. Liu, Z. M.; Zhou, Y.; Solymosi, F.; White, J. M., Vibrational Study of Co2- on K-Promoted Pt(111). J. Phys. Chem. 1989, 93, 4383-4385.

70. Liu, F.; Sturm, J. M.; Lee, C. J.; Bijkerk, F., Extreme Uv Induced Dissociation of Amorphous Solid Water and Crystalline Water Bilayers on Ru(0001). Surf. Sci. 2016, 646, 101-107.

71. Liu, Z. M.; Zhou, Y.; Solymosi, F.; White, J. M., Spectroscopic Study of K-Induced Activation of Co, on Pt( 111). Surf. Sci. 1990, 245, 289-304. 


\section{Chapter 2}

\section{Electronegativity-dependent tin}

\section{etching from thin films}

The influence of a thin film substrate material on the etching of a thin layer of deposited tin (Sn) by hydrogen radicals was studied. The amount of remaining Sn was quantified for materials that cover a range of electronegativities. We show that, for metals, the etching depends on the relative electronegativity of the surface material and Sn. Tin is chemically etched from surfaces with an electronegativity smaller than Sn, while incomplete Sn etching is observed for materials with an electronegativity larger than Sn. Furthermore, the amount of remaining $\mathrm{Sn}$ increases as the electronegativity of the surface material increases. We speculate, that, due to Fermi level differences in the material's electronic structure, the energy of the two conduction bands shift such that the availability of electrons for binding with hydrogen is significantly reduced.

\subsection{Introduction}

A hot Sn plasma emitting at a target wavelength of $13.5 \mathrm{~nm}$ is used as an EUV (extreme ultraviolet) source for photolithography applications. ${ }^{1}$ Tin materials, in the form of debris resulting from the plasma, can be deposited on mirrors and consequently decreases the mirror reflectivity. ${ }^{2-4}$

Reactive hydrogen species are able to form the volatile hydride stannane $\left(\mathrm{Sn}+4 \mathrm{H}^{\circ} \rightarrow \mathrm{SnH}_{4} \uparrow\right)$, which can subsequently be removed from the surface. ${ }^{4}$ Stannane slowly decomposes (at $35^{\circ} \mathrm{C}$ ) 
to metallic Sn and hydrogen ${ }^{5}$, which reduces the effective etchrate due to re-deposition.

Successful Sn etching using hydrogen atoms will depend on the surface material. ${ }^{3} 7$ For example, the cleaning rate of the last few $\mathrm{nm}$ of Sn from a Si surface is almost twice as fast as that from a Ru surface. ${ }^{7}$ This disparity in etching rate increases for $\mathrm{Sn}$ layers that become thinner than $2 \mathrm{~nm}$. A possible explanation for this disparity is $\mathrm{Sn}$ re-deposition on the surface, due to the decomposition of Sn hydride. Metallic surfaces like $\mathrm{Ni}, \mathrm{Ru}, \mathrm{Rh}$ or Au effectively catalyze the decomposition of $\mathrm{SnH}_{4}{ }^{7}$ During the etching process, the substrate becomes more exposed, which favors Sn decomposition and re-deposition, and may lead to a dynamic equilibrium between $\mathrm{SnH}_{4}$ formation and decomposition. However, the amount of Sn remaining after hydrogen etching is significantly more than a monolayer, which cannot be fully explained by enhanced re-deposition due to catalytic activity. ${ }^{7}$

Aside from environmental factors, such as hydrogen flow rate and substrate temperature, an additional factor that contributes to the etching of Sn is the surface material's electronic structure, which has remained relatively unstudied as a factor. Experimental studies on the influence of electronic structure are challenging because surface states depend intrinsically on the local geometry of the surface material where the $\mathrm{Sn}$ atoms adsorb. As a first step towards quantifying the influence of surface electronic structure, we use a proxy that may allow some general principles to be revealed. Because electronegativity provides a simple empirical model for binding strength (and, indirectly, the changes to electronic structure), we propose here to use electronegativity as a proxy for electronic structure.

The electron distribution in a bond in a diatomic molecule containing different atoms is not symmetrical between the atoms 8 , the degree to which this redistribution occurs can be described by a single parameter, called the electronegativity. ${ }^{9}$ The probability 
density of an electron pair, shared between two elements, has a maximum that is located closer to the more electronegative element. The more electronegative element acquires a partial negative charge, and the molecule may also acquire a dipole moment.

When electrons are shared by two metallic atoms in a bulk material, a metallic bond may be formed. The electrons that participate in metallic bonds are delocalized, thus, metallic bonds have no dipole moment. An interface between two metals acquires a potential difference, however, that depends on the difference between their Fermi levels. At thermodynamic equilibrium, the Fermi level is constant across the interface, meaning that the energy of the two conduction bands must smoothly shift to be coincident at the interface. ${ }^{10}$ This modifies the electronic structure of the Sn near the interface, and changes the availability of electrons for bond formation with, in our case, hydrogen atoms. Due to this change in charge availability, the relative electronegativities of the surface material and the Sn may be used to predict the degree to which electrons are available for bonding. This allows the success or failure of Sn etching from a thin metallic surface material to be predicted. Specifically, we hypothesize that Sn can be fully chemically etched from surfaces with electronegativity lower than Sn, while incomplete Sn etching is expected for materials with electronegativity higher than Sn.

\subsection{Experimental}

\subsubsection{Material selection}

From all chemical elements, 15 were chosen for further study (see Table 2-1). The chosen surface materials belong to different groups and periods in the periodic table.

As stated, electronegativity is a measure of the ability of an atom in a molecule to draw bonding electrons to itself. The most 
commonly used electronegativity is a relative scale of electronegativity, developed by Linus Pauling in $1932 .{ }^{11}$ In this scale, electronegativity differences are defined by differences in bond dissociation energies with hydrogen set to an arbitrary reference point value of 2.1.

Elements with electronegativities, $\chi$, higher and lower than Sn $(\chi=1.8)$ were chosen. It should be noted that $\mathrm{Sn}$ has a rather high electronegativity, limiting the number of appropriate materials with an electronegativity higher than Sn. Finally, to avoid cases dominated by excessively fast oxidation, elements from the first and second groups were excluded. Furthermore, elements that were known to react strongly with hydrogen, such as Pd and Co, were excluded. Within these restrictions, it was desirable to choose elements that covered as broad a range of the periodic table as possible. The aim was to include a large range of possible electronegativities. Elements from groups 3-14, consisting of transition metals, metalloids, other metals and non-metals were chosen for further investigation.

\subsubsection{Methodology}

Thin films of chosen materials, with the average thickness of $5 \mathrm{~nm}$, were deposited onto silicon wafers $(10 \times 10 \times 0.5 \mathrm{~mm})$ by magnetron sputtering or electron-beam deposition. The film thickness was monitored during deposition using a quartz microbalance. After deposition, the samples were removed from the chamber and exposed to ambient conditions. Grazing incidence $x$-ray reflection measurements were performed to extract accurate layer thicknesses. The deposition method, and XRR derived layer thicknesses are shown in Table 2-1. The uncertainty in the film thickness was estimated to be $10 \%$.

X-ray photoelectron spectroscopy (XPS) (Thermo Scientific Theta Probe) analysis showed that for many materials a surface oxide layer forms upon exposure to ambient conditions. For most of the 
materials that we chose, the oxide layer is usually self-limiting at atmospheric pressure and room temperature, resulting in a socalled native oxide layer with a thickness of few nanometers at most. 12

Table 2-1.Electronegativity values, deposition method, thickness of surface material and native oxide thickness on each sample for test materials used in this work.

\begin{tabular}{|c|c|c|c|c|c|c|c|c|c|c|c|c|c|c|c|c|c|c|}
\hline Element & Sc & Ta & $\mathrm{Ti}$ & $\mathrm{Nb}$ & V & $\mathrm{Cr}$ & $\mathrm{Al}$ & W & Mo & $\mathrm{Si}$ & $\underset{\text { wafer }}{\mathrm{Si}}$ & $\mathrm{Ag}$ & B & Ru & $\mathrm{Au}$ & C & Sn & $\mathrm{H}$ \\
\hline Type of metal & TR & TR & TR & $\mathrm{TR}$ & TR & $\mathrm{TR}$ & OM & TR & TR & $\mathrm{ML}$ & $\mathrm{ML}$ & TR & $\mathrm{ML}$ & TR & TR & NM & OM & NM \\
\hline 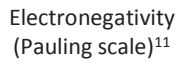 & 1.3 & 1.5 & 1.5 & 1.6 & 1.6 & 1.6 & 1.5 & 1.7 & 1.8 & 1.8 & 1.8 & 1.9 & 2 & 2.2 & 2.4 & 2.5 & 1.8 & 2.1 \\
\hline $\begin{array}{l}\text { Method of } \\
\text { deposition on } \\
\text { silicon wafer }\end{array}$ & EB & MS & MS & MS & $\mathrm{EB}$ & MS & $\mathrm{EB}$ & MS & MS & MS & - & $E B$ & MS & MS & EB & MS & - & - \\
\hline Thickness [nm] & 5.5 & 6.7 & 6.6 & 5.7 & 5.5 & 8 & 5.5 & 7 & 5.5 & 4.7 & 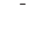 & 5.5 & 4.4 & 17.5 & 5.6 & 5.1 & - & - \\
\hline $\begin{array}{c}\text { Native oxide }[\mathrm{nm}] \\
\text { XPS }\end{array}$ & 3.6 & 3.2 & 3.2 & 3.5 & 4.7 & 1.5 & 2.2 & 2.3 & 2.5 & 1.3 & 1.3 & - & $\sim 0.9$ & 0.8 & - & $\sim 0.5$ & - & - \\
\hline
\end{tabular}

TR - transition metal, $\mathrm{ML}$ - metalloids, $\mathrm{OM}$ - other metal, NM - non metal, MS - magnetron sputtering, EB - e-beam, "-" for native oxide means that presence of oxide cannot be determined

Tin deposition and etching experiments were performed in a vacuum chamber (Figure 2-1b) with a base background pressure of $10^{-9} \mathrm{mbar}\left(10^{-7} \mathrm{~Pa}\right)$, which increases to $10^{-8} \mathrm{mbar}$ during $\mathrm{Sn}$ deposition. The samples described in Table 2-1 were not subjected to further preparation and were placed directly in the vacuum chamber. The sample was held upside down on a movable sample holder, $4 \mathrm{~cm}$ above the exit port of an evaporation source. The temperature of the sample was monitored using a Pt-100 temperature sensor, installed under the sample (Figure 2-1a).

Tin (Umicore) with a bulk density of $7.3 \mathrm{~g} / \mathrm{cm}^{3}$ was evaporated from an Effusion Cell EF $40 \mathrm{C} 1$ (PREVAC) evaporator operated at $980^{\circ} \mathrm{C}$. The $\mathrm{Sn}$ deposition rate was calibrated using a quartz microbalance (INFICON XTM/2 Deposition Monitor). It was found that the evaporation rate as measured using the quartz microbalance (QMB) at $980^{\circ} \mathrm{C}$ was approximately $0.4 \mathrm{~nm} / \mathrm{min}$. 
In a typical experiment, $8 \mathrm{~nm}$ of $\mathrm{Sn}$ was deposited. During deposition, the sample temperature remains lower than $55^{\circ} \mathrm{C}$, and, after deposition the sample is allowed to cool to room temperature. The influence of a surface temperature on mobility of Sn was additionally checked and no mobility of Sn was observed below $150{ }^{\circ} \mathrm{C}$. Tin deposition and etching (see below) on the sample surface was monitored with spectroscopic ellipsometry (J.A. Woollam Co., M-2000, spectral range 245-1689 nm) at an angle of incidence of $76.4^{\circ}$ (with respect to the surface normal).

Tin was etched with atomic hydrogen $\left(\mathrm{H}^{\circ}\right)$, which was generated using a hot $\left(2000{ }^{\circ} \mathrm{C}\right)$ tungsten filament (placed $3 \mathrm{~cm}$ from the sample holder). In order to achieve sufficient $\mathrm{H}^{\prime}$ flux with a stable flow rate, the hydrogen (purity $99.999 \%$ ) pressure during exposure was fixed at $8 \cdot 10^{-2}$ mbar. The hydrogen radical flux at the surface was measured to be $10^{17} \mathrm{at} /\left(\mathrm{cm}^{2 \cdot} \mathrm{s}\right) \cdot{ }^{13}$ To prevent the sample from heating excessively, the filament was operated at a duty cycle of 0.5 with a period of $10 \mathrm{~min}$, and a shield was placed between the filament and the sample.

a)

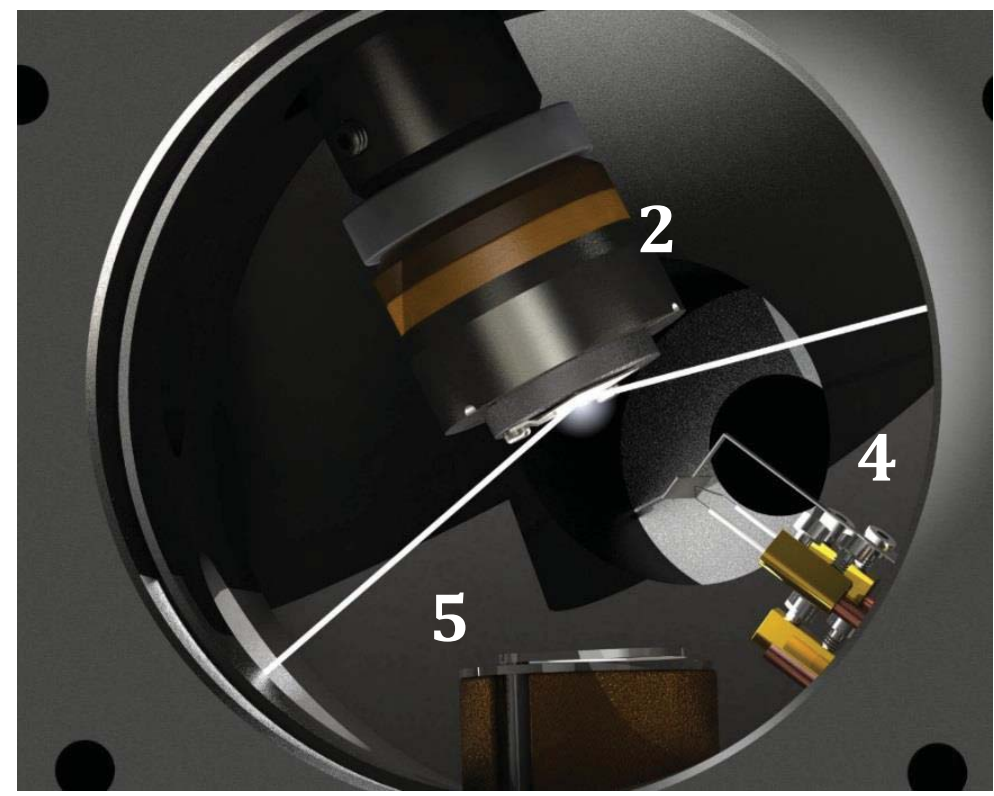


b)

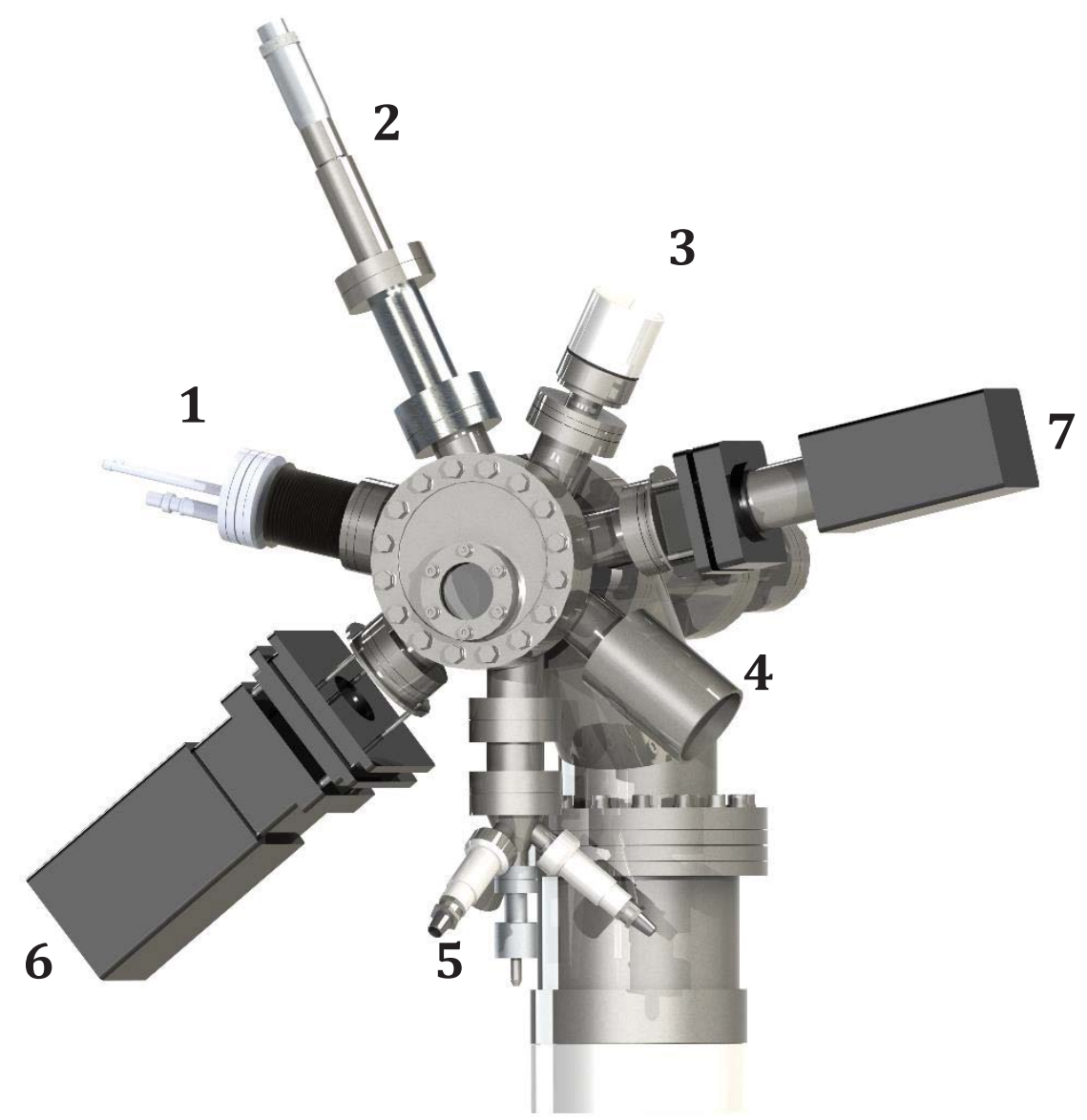

Figure 2-1. Experimental set up inside (a) of vacuum chamber (b), 1-Quartz microbalance, 2-sample holder, 3-pressure gauge, 4tungsten filament ( $H$ radical generator), 5-effusion cell, 6,7elllipsometer detector and source, respectively.

Selected samples were removed from the deposition chamber before exposure to hydrogen radicals, allowing $S n$ layer thickness analysis using X-ray fluorescence. X-ray fluorescence (XRF) (PW2400 chemium anode sequential XRF-spectrometer) has a detection limit for $\mathrm{Sn}$ of $0.01 \mathrm{\mu g} / \mathrm{cm}^{2}(0.014 \mathrm{~nm})$. Other samples were analyzed after hydrogen etching. 


\subsection{Results}

\subsubsection{Tin deposition and etching in situ monitored with ellipsometry}

Although the absolute thickness of the $\mathrm{Sn}$ layer is relevant, the total amount of remaining $\mathrm{Sn}$ after etching is the parameter of interest. To avoid uncertainties on the amount of deposited Sn, we use XRF and determine the layer thickness using the bulk density of $\mathrm{Sn}$ $\left(7.287 \mathrm{~g} / \mathrm{cm}^{3}\right)$. The average thickness of the Sn layer on the samples before etching was measured to be $7.7 \pm 0.9 \mathrm{~nm}$ (Table 2-2). XPS measurements could not detect the underlying material, indicating that the layers were closed to within a few percent. The Sn etching experiments do not include exposure to ambient, and the etching experiments were performed less than one hour after deposition, thus we do not expect Sn oxidation. Therefore, for the hydrogen etching measurements, the initial etching is dominated by the chemistry of $\mathrm{Sn}$ and hydrogen, while further into the etch process, the substrate starts to play a role.

Table 2-2. Deposited Sn thickness (XRF) for all surface materials.

\begin{tabular}{lllllllllllllllll}
\hline Element & $\mathrm{Sc}$ & $\mathrm{Ta}$ & $\mathrm{Ti}$ & $\mathrm{Nb}$ & $\mathrm{V}$ & $\mathrm{Cr}$ & $\mathrm{Al}$ & $\mathrm{W}$ & $\mathrm{Mo}$ & $\mathrm{Si}$ & $\begin{array}{c}\mathrm{Si} \\
\text { wafer }\end{array}$ & $\mathrm{Ag}$ & $\mathrm{B}$ & $\mathrm{Ru}$ & $\mathrm{Au}$ & $\mathrm{C}$ \\
\hline $\begin{array}{l}\text { Sn } \\
\text { thickness } \\
{[\mathrm{nm}]}\end{array}$ & 7.58 & 7.74 & 7.95 & 8.43 & 7.25 & 7.62 & 7.18 & 7.8 & 7.88 & 7.21 & 8.6 & 7.25 & 8 & 7.95 & 7.18 & 7.42 \\
\hline
\end{tabular}

During Sn deposition and hydrogen radical etching, the surface was monitored in situ with spectroscopic ellipsometry. These measurements were primarily used to distinguish the end point for Sn etching by monitoring the ellipsometric angles Psi (not shown) and Delta (see Figure 2-2 for Delta). For a sample where complete Sn etching was observed (confirmed afterwards with XRF measurements), e.g., crystalline silicon (Figure 2-3a), it can be seen that, after 120 minutes of hydrogen etching, the Delta value for a wavelength of $530 \mathrm{~nm}$, which shows the largest Delta modulation, nearly returns to the value it had prior to Sn deposition, and is 
stable thereafter (end point of etching). This is typical for the entire Delta (Figure 2-2) and Psi (not shown) spectrum for surfaces from which Sn could be etched completely. The similarity of the initial and final Psi and Delta spectra also means that the surface is very close to its original state after etching. It is most likely that the small differences in the Psi and Delta spectra are due to a very slight change in sample alignment during etching.

The Ru surface is an example of incomplete Sn etching, which can be clearly seen from the ellipsometry measurements (Figure 2-3b). After 100 min of etching, the Delta value is stable, but it has not returned to the value it had prior to $\mathrm{Sn}$ deposition. It is clear that $\mathrm{Sn}$ remains on the sample surface (confirmed with XRF measurements, see below).

Although the ellipsometry measurements can be used to estimate the Sn layer thickness during deposition and etching, this process proved to be unreliable. The as-deposited Sn surface is rather rough ${ }^{3}$, and the surface roughness is expected to change during etching, which influences the interpretation of the ellipsometry data during etching, but not at the end point of etching. For some samples, the ellipsometry measurements showed evidence that the $\mathrm{Sn}$ and hydrogen radicals interacted with the underlying surface, changing its optical properties as well. As a result of these factors, a reliable model fit could not be obtained. Therefore, to quantify the amount of Sn remaining on the surface after etching, XRF measurements were performed. 
a)

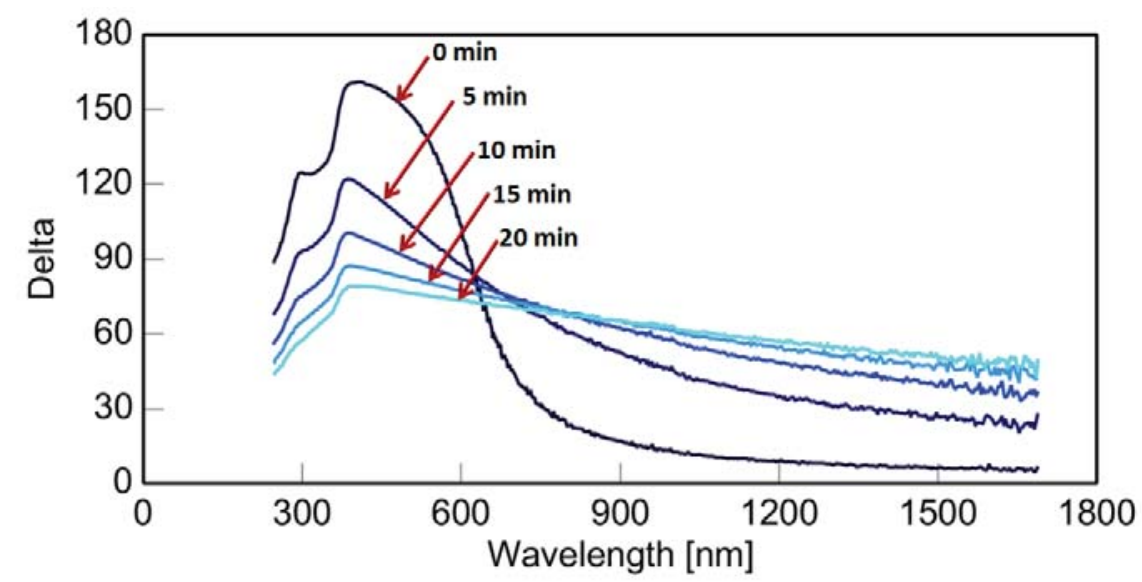

b)

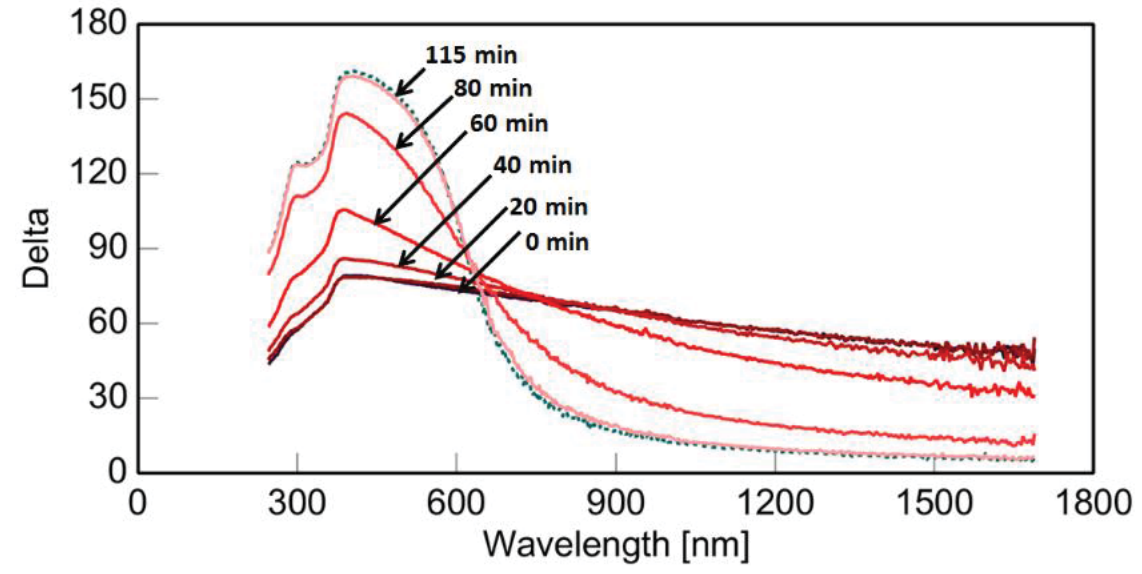

Figure 2-2. Delta as a function of wavelength during Sn deposition (a) and hydrogen radical etching (b) on a silicon wafer. Delta values for a clean silicon wafer are presented as a dashed line in Figure 2$2 b$. 
a)

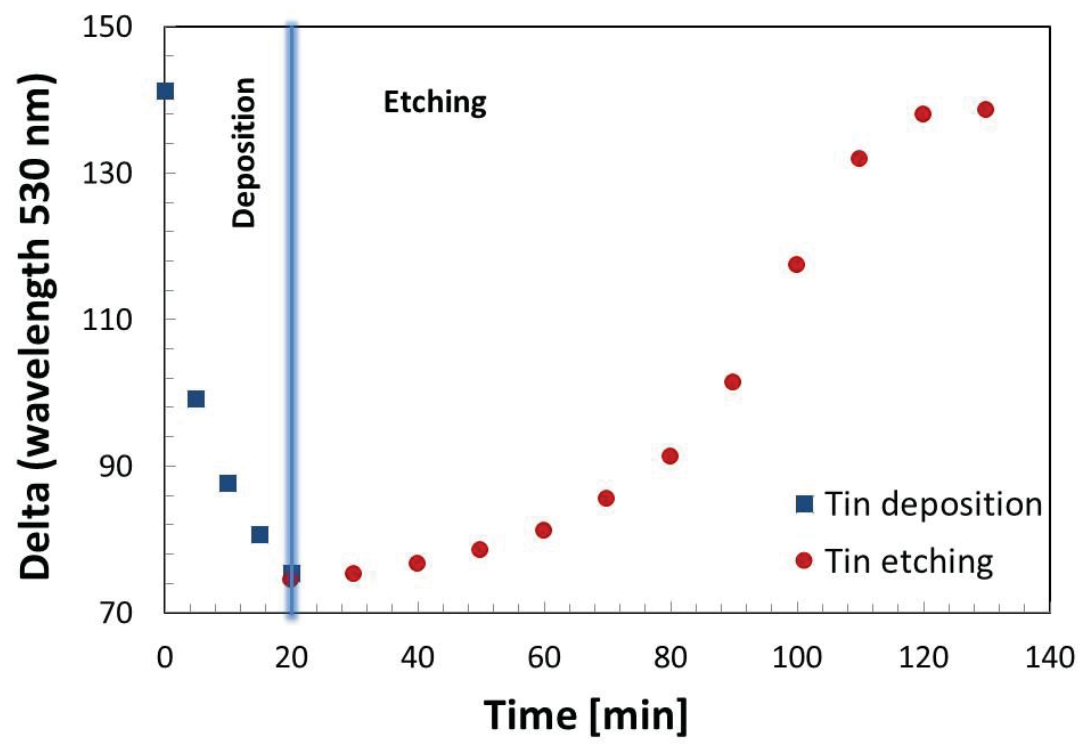

b)

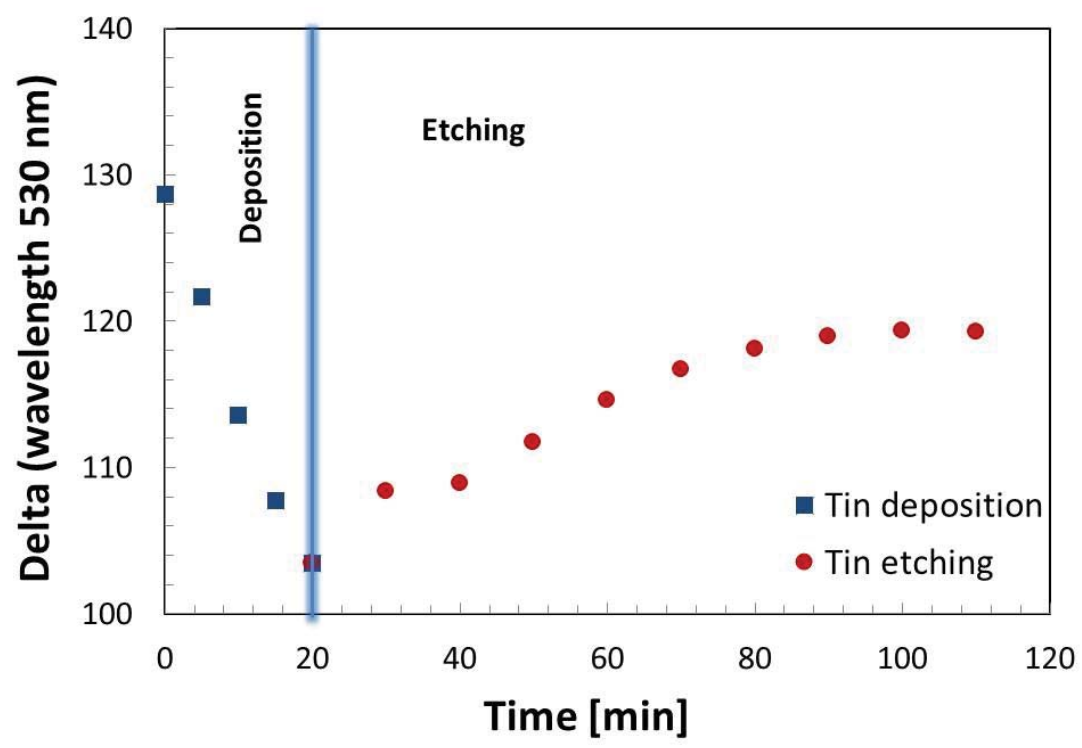

Figure 2-3. Delta value for $530 \mathrm{~nm}$ during $\mathrm{Sn}$ deposition and hydrogen radical etching for a) silicon wafer and b) Ru layer. 


\subsubsection{Electronegativity dependent Sn etching}

Figure 2-4 shows the Sn layer thickness derived from XRF after etching as a function of difference in electronegativity between the surface material and Sn. The surface materials can be divided in two groups in terms of complete and incomplete Sn etching.

The first group includes surface materials that have electronegativity values that are lower or equal to $\operatorname{Sn}\left(\boldsymbol{\chi}_{\mathrm{Sn}_{\mathrm{n}}} \boldsymbol{\chi}_{\mathrm{M}} \geq 0\right)$. For these materials, $\mathrm{Sn}$ is completely etched (less than $0.08 \mathrm{~nm}$ of $\mathrm{Sn}$ on the surface) with two exceptions, where $0.4 \mathrm{~nm}$ and $0.14 \mathrm{~nm}$ of $\mathrm{Sn}$ remain on the Mo and $\mathrm{W}$ surfaces. For these materials, it is possible that the re-deposition plays a role, especially just after the etch is terminated. ${ }^{3}$

The second group consists of surface materials that have an electronegativity value higher than that of $S n\left(\chi_{S_{n}}-\chi_{M}<0\right)$. In this group incomplete $\mathrm{Sn}$ etching is observed. Moreover, the thickness of the remaining $\mathrm{Sn}$ increases for smaller electronegativity values, indicating that $\mathrm{Sn}$ is more strongly bound to these surfaces. It is remarkable that we find a simple linear relationship between the Sn thickness and electronegativity for $\boldsymbol{\chi}_{\mathrm{Sn}}-\boldsymbol{\chi}_{\mathrm{M}}<0$. A possible explanation for this result (see below) is that the surface material modifies the electronegativity of the first few layers of the Sn. For this to occur, the two layers should not be significantly intermixed. To determine if the Sn intermixes with the surface layer, angle resolved XPS analysis was performed on the etched Ru sample. This showed minimal intermixing between $\mathrm{Ru}$ and $\mathrm{Sn}$. For $\mathrm{Au}$ and $\mathrm{Ag}$, angle resolved XPS was inconclusive.

The XPS spectra, however, show that, for $\mathrm{Ag}$, the $\mathrm{Sn} 3 \mathrm{~d}_{5 / 2}$ spectral line shifts from $484.78 \mathrm{eV}$ ( $\mathrm{Sn}$ as deposited) to $484.91 \mathrm{eV}$ (after etching with $\mathrm{H}^{*}$ ), while the expected chemical shift (CS) for $\mathrm{Sn} 3 \mathrm{~d}_{5 / 2}$ spectral line upon Ag-Sn alloy formation is $1 \mathrm{eV} .{ }^{14,15}$ Likewise, the $\mathrm{Ag} 3 \mathrm{~d}_{5 / 2}$ spectral line shifts from $368.22 \mathrm{eV}$ (Ag as deposited) to $368.32 \mathrm{eV}$ (after etching with $\mathrm{H}^{\circ}$ ), which is also less than the 
expected $1 \mathrm{eV}$ shift. These measurements confirm that Ag and $\mathrm{Sn}$ do not significantly intermix.

In contrast, the XPS spectra for $\mathrm{Sn}$ and $\mathrm{Au}$ are suggestive of intermixing. The expected CS for the $A u \mathrm{ff}_{7 / 2}$ spectral line upon Au$\mathrm{Sn}$ alloy formation is $0.45-1.1 \mathrm{eV}{ }^{16}$, while for the $\mathrm{Sn} 3 \mathrm{~d}_{5 / 2}$ spectral line the expected CS is $0.1-0.4 \mathrm{eV}$. The $S n 3 d_{5 / 2}$ spectral line after etching with $\mathrm{H}^{\prime}$ was measured to be $485.29 \mathrm{eV}$, a CS of $0.34 \mathrm{eV}$, while the Au $4 \mathrm{f}_{7 / 2}$ spectral line shifts from $84.06 \mathrm{eV}$ to $84.6 \mathrm{eV}$ $(0.4 \mathrm{eV})$. These results are consistent with intermixing.

Two notable exceptions from the second group are carbon and boron. It is known from the literature that carbon can be successfully etched from silicon using hydrogen reactive species. ${ }^{17}$, 18 Thus, because the Sn layer grows in islands ${ }^{3}$, hydrogen radicals also have access to the underlying carbon surface before the $\mathrm{Sn}$ is completely removed. An XPS analysis of a carbon sample before and after $\mathrm{Sn}$ deposition and etching confirmed that the carbon layer thickness was reduced by approximately $25 \%$ during Sn etching. As a result, the etching process may remove carbon from around the $\mathrm{Sn}$, allowing the $\mathrm{Sn}$ to also be etched. It is also possible that hydrogen radicals may react to create more complex organometallic volatiles, which effectively allows $\mathrm{S} n$ to be etched together with carbon.

Boron can be etched by hydrogen radicals, but only at elevated temperatures. ${ }^{19}$ XPS analysis confirmed that boron was not etched during hydrogen radical exposure, eliminating both the possibility of boron hydride formation and of volatile metallo-complexes. This illustrates that, although electronegativity is generally predictive (especially for the first group), detailed electronic structure also plays a role.

Our results show that the etch rate, near the interface between two materials, can be suppressed or enhanced, depending on the electronegativity difference. The suppression is sometimes sufficient to prevent the last few nanometers of material from 
being etched, as seen in Figure 2-4. It should be noted that, for Ag and Ru this certainly includes $\mathrm{Sn}$ that is not in direct contact with the surface material.

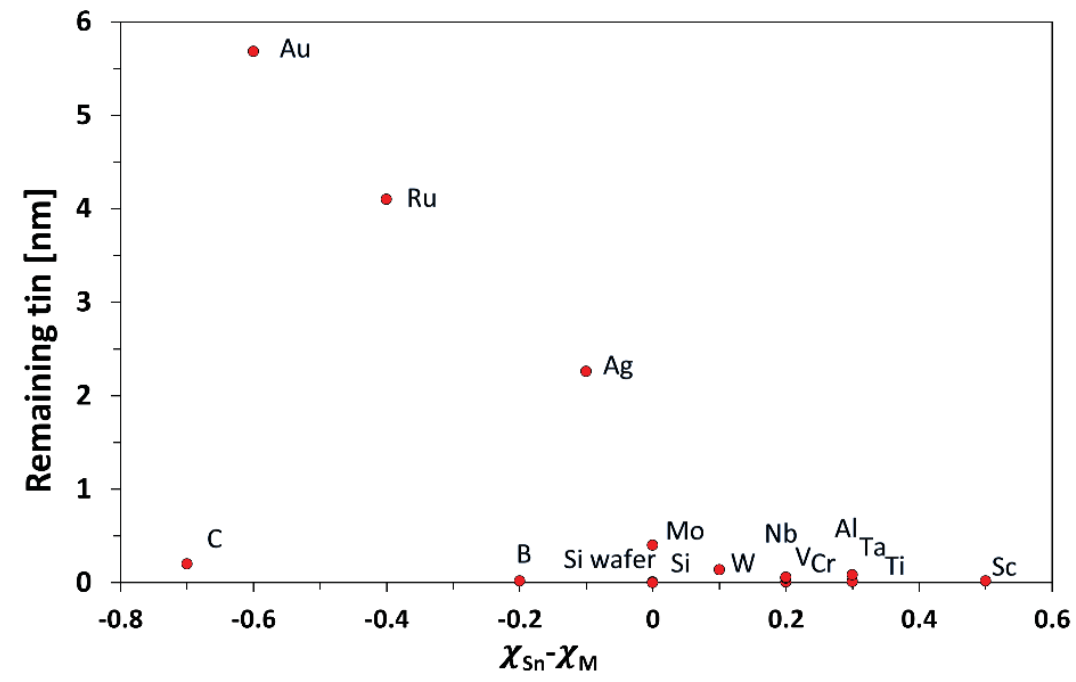

Figure 2-4. Remaining $\mathrm{Sn}$ after etching with hydrogen radicals as a function of difference in electronegativity between $\mathrm{Sn}$ and the surface material.

\subsection{Discussion}

During etching, an electron must be donated for hydrogen to form a stable bond. However, for Sn, bound to a highly electronegative surface, the valence electrons have probably been donated to surrounding atoms, making it impossible for Sn hydride to form.

Electronegativity also explains why the remaining thickness of Sn increases as the electronegativity difference becomes more negative. Analogous to the case for oxides, ${ }^{20}$ the effective electronegativity of $\mathrm{S} n$ at the interface is increased when it binds to a strongly electronegative surface (and, likewise, decreased when it binds to a weakly electronegative surface). Thus, the first monolayer of Sn donates its electrons, which are delocalized and are more likely to be found in the surface material. In doing so, the 
monolayer of $\mathrm{Sn}$ becomes more electronegative because it is now electron poor. However, it is not as electronegative as the original surface. Similarly, the second monolayer of Sn donates electrons to the first Sn layer, becoming slightly more electronegative. This process continues, until, at some layer thickness, the electronegativity of the uppermost $S n$ returns to its natural value. For $\mathrm{Ru}$ and $\mathrm{Ag}$, where XPS confirms that there is minimal intermixing, this screening length is indicated by the thickness of the remaining $\mathrm{Sn}$ (4.1 and $2.3 \mathrm{~nm}$ ), while for $\mathrm{Au}$, it is likely that a similar screening length is present, however, intermixing precludes quantification.

\subsection{Conclusions}

The remaining amount of $\mathrm{Sn}$ after etching with hydrogen radicals depends on the substrate onto which Sn was deposited. Transition metals with electronegativity values that are lower than or equal to Sn $\left(\chi_{S_{n}-} \chi_{M} \geq 0\right)$ can be fully etched from $S n$. The remaining $S n$ thickness is found to be less than $0.08 \mathrm{~nm}$ on Sc, Ta, Ti, Nb, V, Cr, Al, and Si surfaces.

Incomplete Sn etching was observed when Sn was initially deposited onto materials with an electronegativity value higher than that of $\mathrm{Sn}\left(\boldsymbol{\chi}_{\mathrm{Sn}-} \boldsymbol{\chi}_{\mathrm{M}}<0\right)$. Moreover, the thickness of the remaining $\mathrm{Sn}$ increases with more negative electronegativity differences. This indicates that, not only is Sn bound more strongly to the underlying surface material, but, near the interface, the Sn Sn bonds are stronger than those found in bulk Sn.

It is known that, even though electrons are delocalized in a metal bond, the continuity of the Fermi level requires that the energy levels and occupancy of the electronic states changes within a few nanometers of the interface. These changes make the Sn surface (when it is within a few nanometers of the surface material) less reactive and more difficult to etch, and can even prevent etching 
all together. This raises an interesting new approach to surface passivation that warrants further investigation.

\subsection{References}

1. Banine, V.; Moors, R., Plasma Sources for Euv Lithography Exposure Tools. Journal of Physics D: Applied Physics 2004, 37, 3207-3212.

2. Mertens, B., et al., Progress in Euv Optics Lifetime Expectations. Microelectronic Engineering 2004, 73-74, 16-22.

3. Soer, W. A.; van Herpen, M. M. J. W.; Jak, M. J. J.; Gawlitza, P.; Braun, S.; Salashchenko, N. N.; Chkhalo, N. I.; Banine, V. Y., AtomicHydrogen Cleaning of Sn from Mo/Si and Dlc/Si Extreme Ultraviolet Multilayer Mirrors. J. Micro/Nanolith. MEMS MOEMS 2012, 11, 021118-1.

4. La Fontaine, B. M.; Sporre, J.; Lofgren, R. E.; Ruzic, D. N.; Khodykin, O. V.; Myers, D. W.; Naulleau, P. P., Development of an in-Situ Sn Cleaning Method for Extreme Ultraviolet Light Lithography</Title>. 2011, 7969, 796929-796929-9.

5. Tamaru, K., The Thermal Decomposition of Tin Hydride. 1955.

6. Ugur, D.; Storm, A. J.; Verberk, R.; Brouwer, J. C.; Sloof, W. G., Decomposition of Snh4 Molecules on Metal and Metal-Oxide Surfaces. Appl. Surf. Sci. 2014, 288, 673-676.

7. van Herpen, M. M. J. W.; Klunder, D. J. W.; Soer, W. A.; Moors, R.; Banine, V., Sn Etching with Hydrogen Radicals to Clean Euv Optics. Chemical Physics Letters 2010, 484, 197-199.

8. Atkins, P. W., Physical Chemistry, 3 ed.; Oxford ssPrUniversit, 1986.

9. McNaught, A. D.; Wilkinson, A., Iupac. Compendium of Chemical Terminology, 2 ed.; Blackwell Scientific Publications: Oxford, UK, 1997.

10. Kittel, C.; Kroemer, H., Thermal Physics, 2 ed.; W. H. Freeman and Company: New York, 1980.

11. Pauling, L., The Nature of the Chemical Bond. Iv. The Energy of Single Bonds and the Relative Electronegativity of Atoms. Journal of the American Chemical Society 1932, 54, 3570-3582.

12. Song, S.; Placido, F., Investigation on Initial Oxidation Kinetics of Al, $\mathrm{Ni}$, and Hf Metal Film Surfaces. Chinese Optics Letters 2010, 8, 8790. 
13. Graham, S.; Steinhaus, C.; Clift, M.; Klebanoff, L.; Bajt, S., Atomic Hydrogen Cleaning of Euv Multilayer Optics. SPIE 2003, 5037, 460469.

14. Hegde R.I., S. S. R., Badrinarayanan S., Sinha A.P.B., A Study of Dilute Tin Alloys by X-Ray Photoelectron Spectroscopy. Journal of Electron Spectroscopy and Related Phenomena 1981, 24, 19-25.

15. Hegde, R. I., Core Level Binding-Energy Shifts in Dilute Tin Alloys. Surf. Interface Anal. 1982, 4, 204-207.

16. Friedman, R. M.; Hudis, J.; PerIman, M. L.; Watson, R. E., Electronic Behavior in Alloys - Au-Sn. Phys. Rev. B 1973, 8, 2433-2440.

17. Chen, J.; Louis, E.; Harmsen, R.; Tsarfati, T.; Wormeester, H.; van Kampen, M.; van Schaik, W.; van de Kruijs, R.; Bijkerk, F., In Situ Ellipsometry Study of Atomic Hydrogen Etching of Extreme Ultraviolet Induced Carbon Layers. Applied Surface Science 2011, 258, 7-12.

18. Braginsky, O. V., et al., Removal of Amorphous C and Sn on Mo:Si Multilayer Mirror Surface in Hydrogen Plasma and Afterglow. Journal of Applied Physics 2012, 111, 093304.

19. Muetterties, E. L., Boron Hydride Chemistry; Academic Press: New York, San Francisko, London, 1975.

20. Campet, G.; Portier, J.; Subramanian, M. A., Electronegativity Versus Fermi Energy in Oxides: The Role of Formal Oxidation State. Materials Letters 2004, 58, 437-438. 


\section{Chapter 3}

\section{Tin etching from metallic and}

\section{oxidized Scandium thin films}

The role of oxide on Sn adhesion to Sc surfaces was studied with insitu ellipsometry, X-ray photoelectron spectroscopy and secondary electron microscopy. Sn etching with hydrogen radicals was performed on metallic Sc, metallic Sc with a native oxide, and a fully oxidized Sc layer. The results show that Sn adsorbs rather weakly to a non-oxidized Sc surface, and is etched relatively easily by atomic hydrogen. In contrast, the presence of native oxide on Sc allows Sn to adsorb more strongly to the surface, slowing the etching. Furthermore, thinner layers of scandium oxide result in weaker Sn adsorption, indicating that the layer beneath the oxide plays a significant role in determining the adsorption strength. Unexpectedly, for $\mathrm{Sn}$ on $\mathrm{Sc}_{2} \mathrm{O}_{3}$, and, to a lesser extent, for $\mathrm{Sn}$ on Sc, the etch rate shows a variation over time, which is explained by surface restructuring, temperature change, and hydrogen adsorption saturation.

\subsection{Introduction}

In previous work, it was demonstrated that the formation of stannane $\left(\mathrm{SnH}_{4}\right)$, and, as a result, the successful etching of tin ( $\mathrm{Sn}$ ) from a metallic surface could be predicted by the electronegativity $(x)$ difference between the surface material and tin. ${ }^{1}$ Sn can be successfully etched from surfaces consisting of metals with electronegativity values lower than or equal to Sn. Incomplete Sn etching was predicted for metals that have electronegativity values 
higher than that of Sn. ${ }^{1}$ However, in that publication, all metals, except gold and silver were strongly oxidized (the presence of oxide on $\mathrm{Ag}$ could not be determined). Notably, metals with high electronegativities form weak oxides, while those with low electronegativity form strong oxides (e.g., scandium and aluminium), leaving open the question of the role of oxidation in tin adhesion.

Although in many conditions a metallic surface is oxidized, this is not universally true. In some cases, the native oxide layer can be removed by hydrogen reactive species, changing the surface properties. ${ }^{2}$ Furthermore, in many applications, such as extreme ultraviolet lithography (EUVL), space applications, and ultra-high vacuum (UHV) science, the environmental conditions may be sufficiently reducing, removing, at least temporarily, the surface oxide, and exposing the bare metal to surface processes. ${ }^{2,3}$

It is known that the presence of oxide on EUVL optics causes a reduction of reflectivity 2,4 , thus optics with oxide-free surfaces would be beneficial in terms of optical performance. Because of the difficulties in preparing oxide-free metallic surfaces, there is limited published data on tin adsorption to non-noble, oxide free metal surfaces. To our knowledge, the role of oxide in tin etching from oxidized metals has only been studied in the context of molybdenum (Mo) and silicon (Si) 5, which have the same electronegativity as tin. However, it is unclear if Mo or Si are representative for low electronegativity materials. Furthermore, Mo oxide has a relatively low dissociation temperature ${ }^{6}$, making it more likely that the etch process (and perhaps even the tin deposition process) will result in the reduction of the top layer of molybdenum oxide. ${ }^{7-12}$ Of the transition metals, scandium (Sc) has the lowest electronegativity, representing a relatively extreme case, and making it an ideal test case. By studying Sn adsorption and etching from Sc, and combining that with already published data on noble metals and Mo, it will be possible to conclude if the 
electronegativity difference is indeed the main predictor of the energy of adhesion between tin and the surface. Furthermore, by comparing etching from oxidized and metallic surfaces, it will be possible to determine if the oxide layer plays a significant role in $\mathrm{Sn}$ adhesion.

Previous surface adhesion and etching studies have used X-ray fluorescence (XRF), X-ray photoelectron spectroscopy (XPS), scanning electron microscopy (SEM) and ellipsometry, which, taken together, give a very good overview of the surface chemistry and morphology changes during various experiments. ${ }^{13-20}$ Of these, ellipsometry measurements, combined with modeling, provide layer thickness and material properties, making it an excellent tool for contact free determination of thickness and optical constants of films of all kinds. ${ }^{21-26}$ Ellipsometry can yield information about layers even down to a single atomic layer ${ }^{21}$, moreover, no reference measurement is necessary. Ellipsometry measurements are also very fast, providing high resolution temporal data. In situ XPS, on the other hand, has elemental sensitivities in the parts per thousand range, and is often directly sensitive to the average chemical changes in the top $\sim 5-10 \mathrm{~nm}$ of the surface layer, limited by the escape depth of the photoelectrons ${ }^{15-20}$. However, XPS scans take much longer, limiting the temporal resolution of dynamic measurements. Moreover, XPS requires high vacuum $\left(10^{-8} \mathrm{mbar}\right.$ ) or ultra-high vacuum, making it inappropriate for in situ measurements due to the relatively high pressure during etching. XRF has even higher elemental sensitivity than XPS, but no chemical sensitivity and cannot distinguish between surface and buried elements. Thus, in our study we use in situ ellipsometry to study Sn deposition and etching. XPS and SEM were used for ex situ analysis. In this paper we study the role of native scandium oxide on the adhesion between Sn and Sc. 


\subsection{Experimental}

Three types of samples, each of $1 \times 1 \mathrm{~cm}$ size, were prepared: $20 \mathrm{~nm}$ $\mathrm{Sc}, 3 \mathrm{~nm}$ and $5 \mathrm{~nm} \mathrm{Sc} \mathrm{O}_{3} / \mathrm{Sc} \mathrm{Sc}_{2} \mathrm{O}_{3}$ (see Figure 3-1(a), (b) and (c) for details). Scandium oxidizes very rapidly in ambient conditions, creating a native oxide layer. To prevent Sc from oxidizing during deposition and sample handling, the $\mathrm{Si}$ wafer substrates were covered with $5 \mathrm{~nm}$ of amorphous Si to protect the deposited Sc layer from oxidizing via interaction with the native $\mathrm{SiO}_{2}$ layer on the Si wafer. After the Sc layer was deposited, it was protected from oxidation with a $5 \mathrm{~nm}$ thick amorphous carbon (C) layer. It is known that $C$ can be etched from many surfaces with reactive hydrogen species $21,27-29$, thus the $\mathrm{C}$ layer is removed in-situ before $\mathrm{Sn}$ is deposited on top of this sample (see Figure 3-1(a)). For the $5 \mathrm{~nm}$ $\mathrm{Sc}_{2} \mathrm{O}_{3} / \mathrm{Sc}$ and $3 \mathrm{~nm} \mathrm{Sc} \mathrm{O}_{3}$ samples, Sc was deposited directly on the Si wafer, which had a native oxide layer of approximately $1.3 \mathrm{~nm} .{ }^{1}$ To obtain a $\mathrm{Sc}_{2} \mathrm{O}_{3}$ top surface, these samples were exposed to ambient, letting a native oxide layer to form. After deposition, the samples were characterized with angle resolved (AR) XPS.

a)

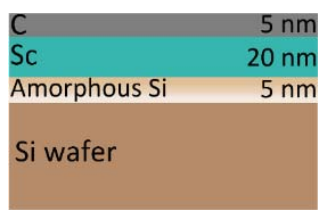

b)

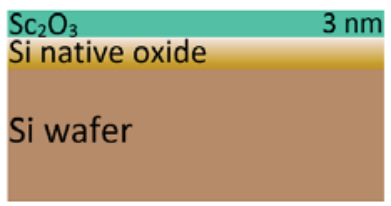

c)

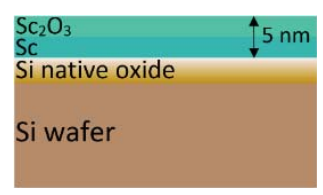

Figure 3-1. Composition of the samples used in this work: (a) $20 \mathrm{~nm}$ $\mathrm{Sc}$, (b) $3 \mathrm{~nm} \mathrm{Sc} \mathrm{O}_{3}$, (c) $5 \mathrm{~nm} \mathrm{Sc} \mathrm{O}_{3} / \mathrm{Sc}$.

Tin deposition and etching takes place in an apparatus that has been described in detail elsewhere. ${ }^{1}$ Briefly, experiments are performed in two different manners: for oxidized samples, approximately $8 \mathrm{~nm}$ of $\mathrm{Sn}$ is evaporated onto the sample at a rate of $0.4 \mathrm{~nm} / \mathrm{min}$ and, immediately afterwards, etched with hydrogen radicals $\left(H^{*}\right)$. For the metallic Sc sample, the $C$ coating is first 
removed (determined by ellipsometry) using $\mathrm{H}^{\cdot}$ etching, after which, $8 \mathrm{~nm}$ of $\mathrm{Sn}$ is deposited, followed by $\mathrm{H}^{\prime}$ etching. In all cases, the $\mathrm{H}^{\prime}$ flux is generated by passing a molecular hydrogen flow (100 $\mathrm{sccm}$ ) over a tungsten (W) filament that is heated to $2000{ }^{\circ} \mathrm{C}$. The hydrogen radical flux that was measured to be $10^{17}$ at $/ \mathrm{s} \cdot \mathrm{cm}^{2}$ at the sample surface, which was obtained from the carbon etching rate following the method used in ref. 14. The filament was operated in 5 min cycles to avoid excessively heating of the sample surface. In situ ellipsometry was used to monitor Sn deposition and etching. After $\mathrm{Sn}$ deposition and etching experiments, the samples were analyzed ex situ with XPS, as well as SEM with energy selective backscatter detector (SEM-ESB) and high efficiency secondary electron detector (SEM HE-SE2).

\subsection{Results}

\subsubsection{XPS analysis}

Keeping the Sc layer of the $20 \mathrm{~nm}$ Sc sample type free of native oxide is crucial, thus, directly after deposition, a sample was analyzed by XPS with sputter depth profiling. From the elemental depth profile, presented in Figure 3-2, it can be seen that the Sc layer is not completely oxygen free. However, the ratio of $\mathrm{O}$ to $\mathrm{Sc}$ in the layer is about 3:20, which is considerably less than the stoichiometric ratio for $\mathrm{Sc}_{2} \mathrm{O}_{3}$. To verify that the carbon layer prevented oxidation, a sample was kept in ambient for 2 months. Subsequent XPS measurements showed that the ratio of O to Sc did not change in that time.

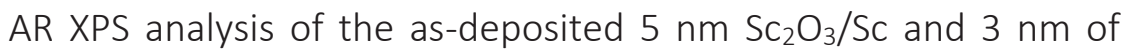
$\mathrm{Sc}_{2} \mathrm{O}_{3}$ samples were performed to determine the depth of oxidation of the Sc layers. The fit for the thicknesses of the oxide layers was found to have an uncertainty smaller than $0.1 \mathrm{~nm}$. In the case of $3 \mathrm{~nm} \mathrm{Sc}_{2} \mathrm{O}_{3}$, the deposited Sc was almost fully oxidized, with

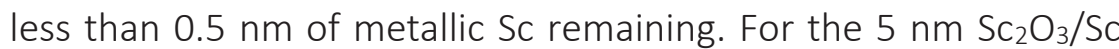


sample, the native oxide thickness was found to be $3.6 \mathrm{~nm}$, in agreement with previous work ${ }^{1}$, while the remaining $1.7 \mathrm{~nm}$ was elemental Sc. In both cases, the fit to the AR-XPS data indicates that there is some intermixing between $\mathrm{Sc}$ and $\mathrm{Si}$. This intermixing may also explain the remaining metallic scandium found in the $3 \mathrm{~nm}$ $\mathrm{Sc}_{2} \mathrm{O}_{3}$ sample, since it was expected that the Sc layer would be fully oxidized in this case. Moreover, the surfaces of both samples were found to have a small amount of carbon and carbonate species due to exposure to ambient.

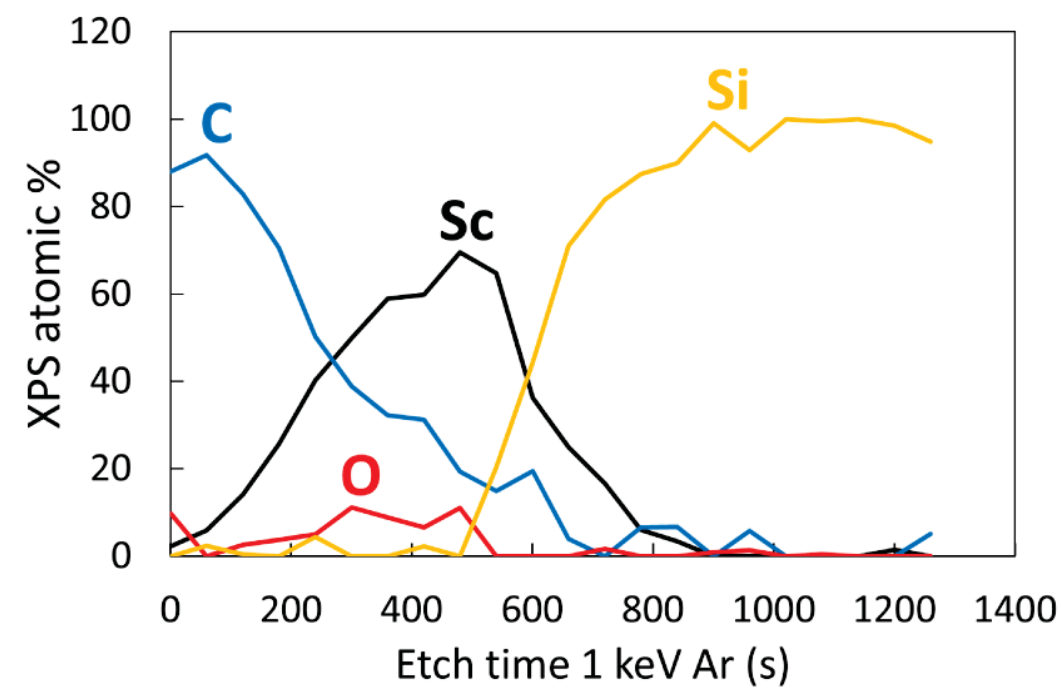

Figure 3-2. Sputter depth profile of as deposited $20 \mathrm{~nm}$ Sc sample.

The protective layer of carbon on $20 \mathrm{~nm}$ Sc sample type was removed directly before $\mathrm{Sn}$ deposition and etching experiments. After in-situ ellipsometry monitoring of $C$ removal (see details below) the sample was measured ex-situ with XPS (see Figure 3-3). 


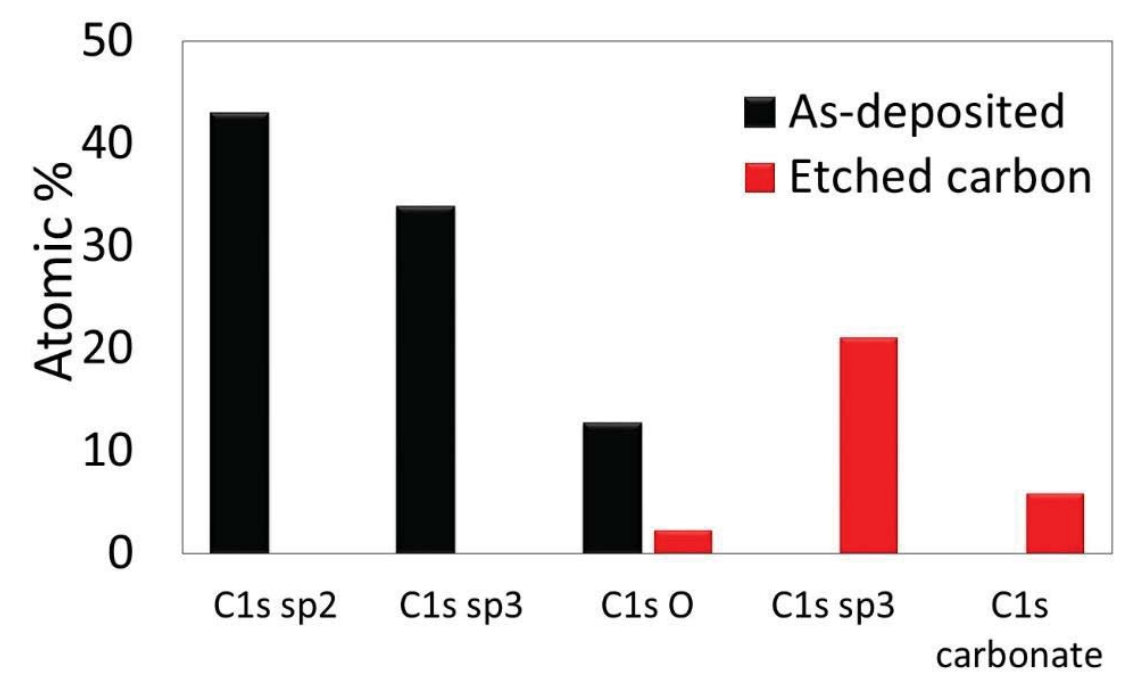

Figure 3-3. XPS analysis: atomic \% of different carbon species on the as-deposited sample and after carbon etching, for a $20 \mathrm{~nm} \mathrm{Sc}$ sample. As deposited carbon corresponds to magnetron sputtered carbon, while the carbon detected after etching is consistent with carbon that is deposited during sample handling and exposure to ambient.

The carbon layer, which was deposited with magnetron sputtering, is characterized by a high percentage of amorphous $\mathrm{C}$, dominated by $\mathrm{sp}^{2}$ and $\mathrm{sp}^{3}$ bonding. In contrast, the $\mathrm{C}$ found on the etched sample has mostly $\mathrm{sp}^{3}$ bonded carbon and a small amount of carbonate, indicating that it is from a different source. The former is typical for magnetron deposited amorphous carbon, while the latter is consistent with atmospheric carbon contamination. From this, and the relative peak intensities of the underlying material, we conclude that the amorphous $\mathrm{C}$ was completely etched by $\mathrm{H}$ before the Sn was deposited. 


\subsubsection{Sn deposition and etching measured with in- situ ellipsometry}

The in situ ellipsometry time-series data for Sn deposition and etching from the $20 \mathrm{~nm}$ Sc sample are shown in Figure 3-4. The different stages of etching and deposition are indicated by different colors for the delta value, taken at a wavelength of $513 \mathrm{~nm}$. Carbon etching is indicated by a black solid line, Sn deposition by a blue dashed line, and $\mathrm{Sn}$ etching by a red solid line. The five minute duty cycle of the $\mathrm{H}^{\prime}$ generator is visible during the $\mathrm{C}$ etching. After approximately 115 minutes of $\mathrm{C}$ etching, the delta value is constant, indicating that $\mathrm{C}$ etching is complete. The success of $\mathrm{C}$ etching was confirmed by ex situ XPS measurements (see above). Following $C$ etching, $8 \mathrm{~nm}$ of $\mathrm{Sn}$ was deposited on the surface (see blue dashed line, Figure 3-4). Afterwards, the sample was again exposed to $\mathrm{H}^{\circ}$ (in 5 minutes cycles) to etch the $\mathrm{Sn}$ (see red solid line in Figure 3-4). After two cycles of $5 \mathrm{~min}$, the value of delta returns to that of metallic Sc, which suggests complete Sn etching. An XPS analysis, performed after $\mathrm{Sn}$ etching, failed to detect any $\mathrm{Sn}$, indicating that the amount of remaining $\mathrm{Sn}$ is below the sensitivity of our XPS analysis (<0.2 at.\%).

The $\mathrm{Sc}_{2} \mathrm{O}_{3}$ terminated samples were directly covered with

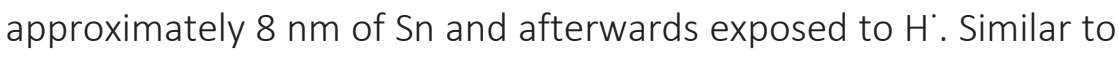
the case for $20 \mathrm{~nm}$ Sc sample, the ellipsometry time-series data (see Figure 3-5) show that $\mathrm{Sn}$ is completely removed. Delta values return to a slightly higher value (indicated on the Figure 3-5 as a dashed lines for each sample) than before $\mathrm{Sn}$ deposition due to removal of surface contamination. However, the etch rate of $\mathrm{Sc}_{2} \mathrm{O}_{3}$ terminated samples is much slower than $20 \mathrm{~nm}$ Sc sample, as can be seen by the total etch time. Furthermore, the etch rate for the $5 \mathrm{~nm} \mathrm{Sc} \mathrm{O}_{3} / \mathrm{Sc}$ sample is slower than for $3 \mathrm{~nm} \mathrm{Sc} \mathrm{O}_{3}$. The different etch behavior for each of the three sample types is discussed in section 3-4 discussion. 


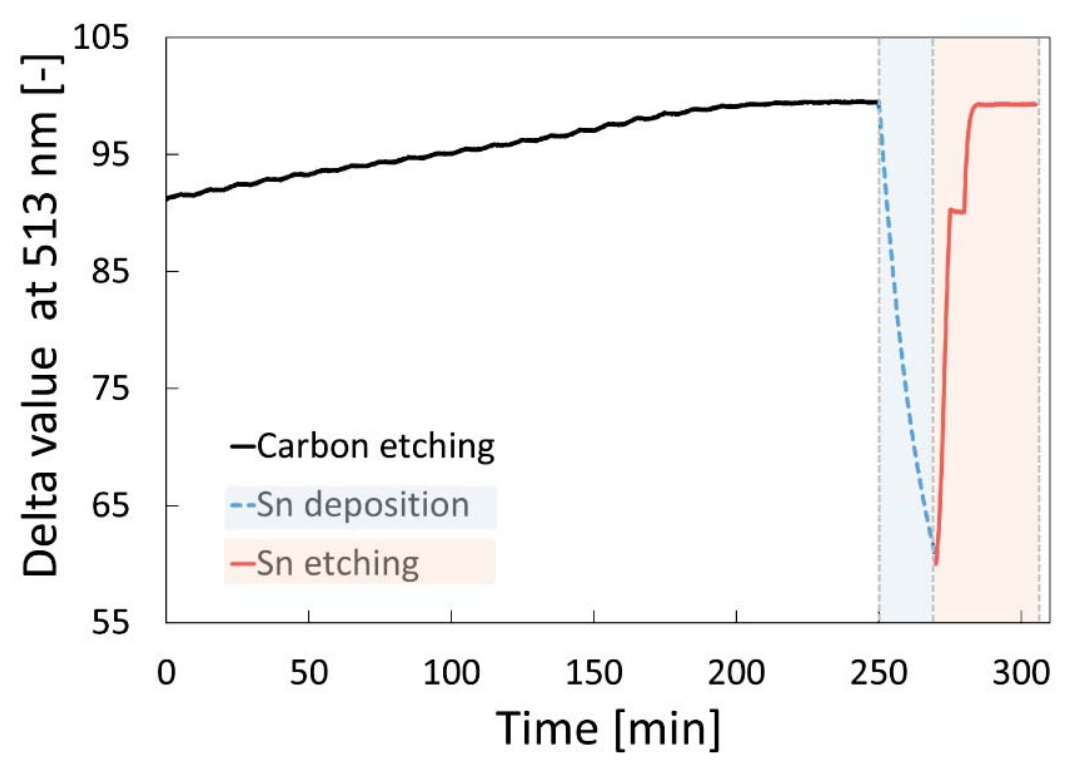

Figure 3-4. Delta value at $513 \mathrm{~nm}$ from in situ ellipsometry measurement during carbon etching, $\mathrm{Sn}$ deposition and $\mathrm{Sn}$ etching on $20 \mathrm{~nm}$ Sc sample type.

On closer inspection, it can be seen that the etch rate changes substantially during etching. To highlight this, we use the change in delta with time to estimate the etch rate. In this thickness range, the changes in delta are nearly linear with Sn thickness, thus, the change in slope provides a direct measure of the change in etch rate, which is presented in Figure 3-6. Delta value changes, corresponding to the deposition of $1 \mathrm{~nm} \mathrm{Sn}$ on the sample, were calculated to be $6.6^{\circ}, 6.5^{\circ}$ and $4.9^{\circ}$ for $3 \mathrm{~nm} \mathrm{Sc} \mathrm{O}_{3}, 5 \mathrm{~nm} \mathrm{Sc} \mathrm{O}_{3} / \mathrm{Sc}$ and $20 \mathrm{~nm} \mathrm{Sc}$, respectively. In Figure 3-6, Delta values corresponding to the moments the filament was off have been removed. 


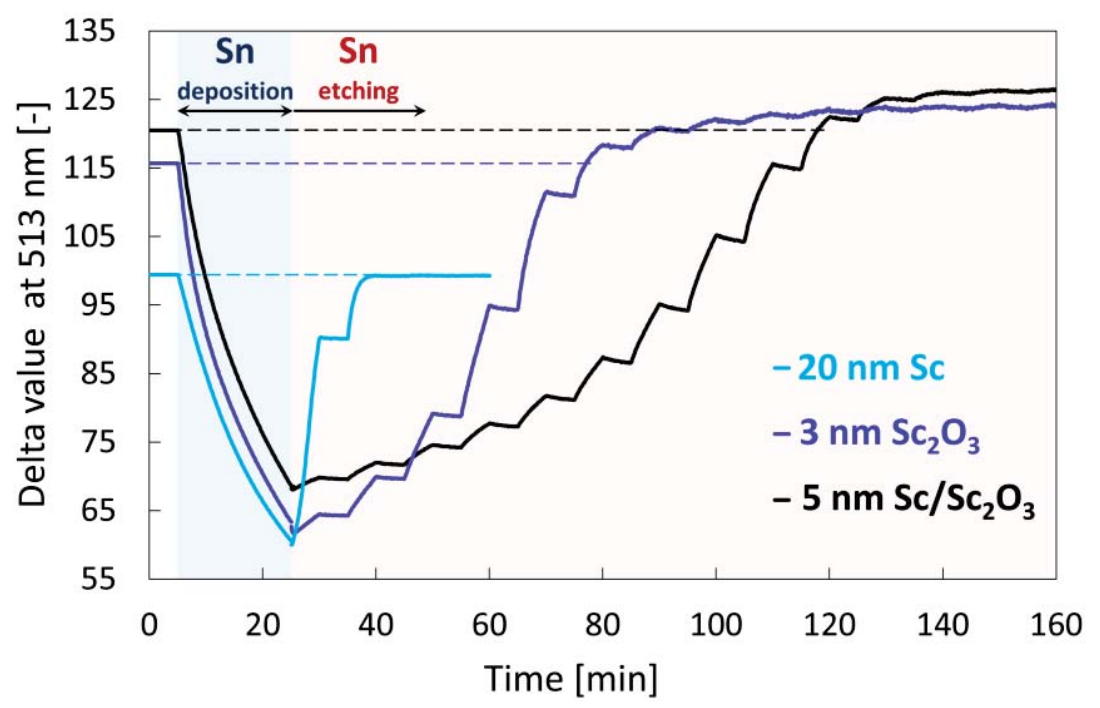

Figure 3-5. Delta value at $513 \mathrm{~nm}$ from in-situ ellipsometry measurement during experiments for $20 \mathrm{~nm} \mathrm{Sc}, 3 \mathrm{~nm} \mathrm{Sc}{ }_{2} \mathrm{O}_{3}$ and 5 $\mathrm{nm} \mathrm{Sc} / \mathrm{Sc}_{2} \mathrm{O}_{3}$ sample types.

The etching rate changes over the whole etching process, as well as over a single $5 \mathrm{~min}$ cycle. The $20 \mathrm{~nm}$ Sc sample has the highest average $\mathrm{Sn}$ etching rate at $0.82 \mathrm{~nm} / \mathrm{min}$, while $\mathrm{Sc}_{2} \mathrm{O}_{3}$ terminated samples have a lower average etching rate, which was calculated to be $0.31 \mathrm{~nm} / \mathrm{min}$ for $3 \mathrm{~nm}$ of $\mathrm{Sc}_{2} \mathrm{O}_{3}$, and $0.19 \mathrm{~nm} / \mathrm{min}$ for $5 \mathrm{~nm}$ $\mathrm{SC}_{2} \mathrm{O}_{3} / \mathrm{SC}$.

We speculate that these findings may be qualitatively be explained as follows. Initially, the etch rate increases with time, which may be due to an increase of the Sn surface area. The presence of the Sc

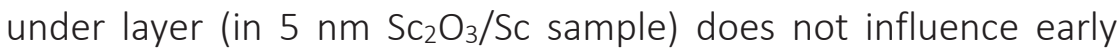
etching, but does influence the early stages of $\mathrm{Sn}$ deposition. As a result, the three samples may have different initial Sn surface areas and, consequently, different etch rates. For all the samples, the maximum etch rate appears after more than half of the initial Sn thickness has been etched. As expected, at late etch times, the etch rate falls simply because the small amount of $\mathrm{Sn}$ remaining on the 
surface, and the etch rate is proportional to the surface coverage of $\mathrm{Sn}$.

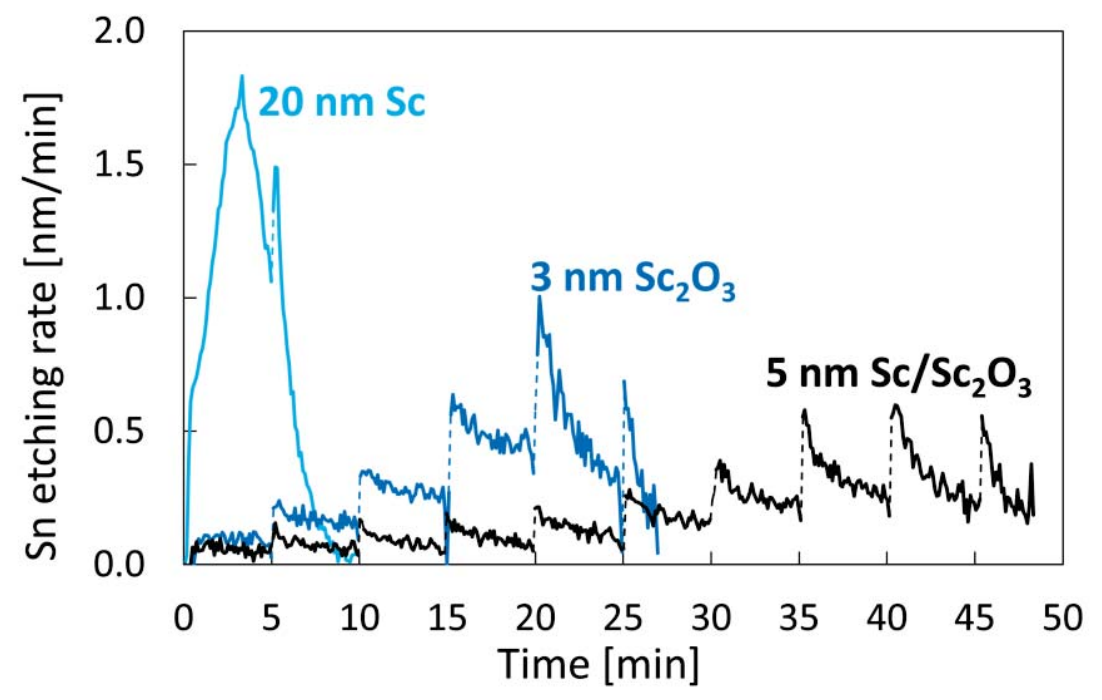

Figure 3-6. Tin etching rate for $\mathrm{Sc}, 5 \mathrm{~nm} \mathrm{Sc} / \mathrm{Sc}_{2} \mathrm{O}_{3}$, and $3 \mathrm{~nm}$ of $\mathrm{Sc}_{2} \mathrm{O}_{3}$ samples. The dashed lines represents the step between the $5 \mathrm{~min}$ etching cycles.

The decay in the etch rate over a single 5 minute period is most likely due to the temperature change of the sample. Sporre et al. showed that sample temperature has significant influence on the etch rate for temperatures over $60{ }^{\circ} \mathrm{C} .{ }^{30}$ Likewise, it is expected from the modeling in ref. 31 that the etch rate rapidly decreases with increasing temperature, but that the onset of the decrease begins at a lower temperature. ${ }^{31}$ Higher temperatures decrease the residence time of hydrogen at the surface, thus the surface coverage is lower and, therefore, the etch rate goes down. Apart from the first etch cycle, which begins at room temperature, the temperature of the sample increases over a 5 min period from approximately 30 to $60{ }^{\circ} \mathrm{C}$. The $30{ }^{\circ} \mathrm{C}$ temperature change in this temperature range can cause a decrease in the etching rate of up to $30 \%{ }^{31}$, which approximately fits the changes in etch rate that are observed during a single etch cycle. The temperature 
dependence does not significantly influence Sn etching from the Sc terminated sample, since the etching process is very rapid and most of the deposited $\mathrm{Sn}$ is removed in a single etch cycle.

After Sn deposition and etching experiments, the sample surfaces were analyzed with SEM HE-SE2 and SEM-ESB. For all samples, after $\mathrm{Sn}$ deposition and etching, the surface is uniform and free of any features. SEM-ESB analysis shows that there are no traces of Sn, confirming the ellipsometry and XPS analysis.

\subsection{Discussion}

Even though complete $\mathrm{Sn}$ etching is achieved on all three samples, the etch rate is significantly slower for a thin scandium oxide layer, and even slower for a Sc oxide terminated scandium layer. It is postulated here that the differences in etch rate are due to the differences in electron distribution in the different systems.

The fastest etching rate was observed for the $20 \mathrm{~nm}$ metallic Sc sample. In this case the top outer-most layers consists of two metals, Sn and Sc, thus there is only a small barrier for electron transfer (contact potential of $0.85 \mathrm{eV}^{32}$, due to the metal-metal junction). When $\mathrm{Sn}$ is deposited, on a metallic Sc surface, electrons will be shared between those two metals. The more electronegative element attracts electrons to itself, which, in our case, is $S_{n}\left(\chi_{s n}=1.8, \chi_{s c}=1.3\right)^{1}$. When reactive hydrogen species arrive at the surface, the $\mathrm{Sn}$ can easily form $\mathrm{SnH}_{4}$, and $\mathrm{Sn}$ etching proceeds at a rate limited only by the accessibility of $\mathrm{Sn}$ to hydrogen radicals.

The situation changes when the Sc layer is oxidized. Due to the manner in which the scandium was oxidized, the oxide layer is likely to have a relatively large number of defect states in the bandgap that can accept electrons. ${ }^{33-35}$ Electrons from the Sn layer diffuse via tunneling to these defect states, taking into account that the reaction of atomic $\mathrm{H}$ at the surface can generate hot electrons with energies in the eV range. ${ }^{36}$ The defect states effectively trap 
electrons in the scandium oxide, slowing their return to the $\mathrm{Sn}$

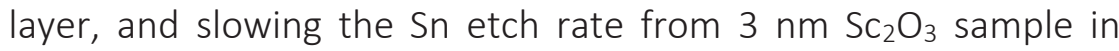
comparison to $20 \mathrm{~nm}$ Sc sample.

Although the etch rate of both samples with $\mathrm{Sc}_{2} \mathrm{O}_{3}$ is slower than the case for metallic Sc, it can be clearly seen that there is also a

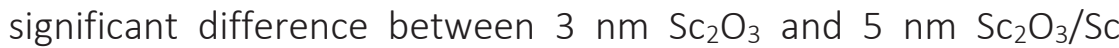
samples. In the case of a $\mathrm{Sc}_{2} \mathrm{O}_{3}$ layer, separating $\mathrm{Sn}$ and Sc $(5 \mathrm{~nm}$ $\mathrm{Sc}_{2} \mathrm{O}_{3} / \mathrm{Sc}$ ), the electrons that diffuse into the defects in the oxide layer may end up in states that are above the equilibrium Fermi level, may decay to a lower energetic state by tunneling into the Sc layer. In this way, the metallic Sc acts as a reservoir for electrons, while tunneling back to the Sn layer must either occur directly, or via defect states. Low lying defect states must first be vacated by Sn etching before they can accept electrons from Sc, while high lying states are energetically unfavorable. Furthermore, the difference in work functions between Sn and Sc creates a driving potential that favors the diffusion of electrons from Sn to Sc, which can be clarified by treating this structure as a metal-insulator-metal tunnel device (MIM) (see Figure 3-7 (b)). MIMs consist of a sandwich with a metal back electrode, an insulating oxide layer and metal top layer. The thin insulator layer (of a few nanometers) acts as high-pass filter for carrier transport. ${ }^{37-39}$ Although the transport is hindered or suppressed through the band gap of an insulator, (hot) electrons and holes may tunnel through the oxide barrier due to its small thickness and presence of local states in the band gap. ${ }^{39}$ Tunneling from a metal through a thin insulator to metal has been extensively studied for different material compositions. ${ }^{37-41}$ The difference in schematic band diagrams for $20 \mathrm{~nm} \mathrm{Sc}, 3 \mathrm{~nm} \mathrm{~S} \mathrm{C}_{2} \mathrm{O}_{3}$ and $5 \mathrm{~nm} \mathrm{Sc} \mathrm{O}_{3} / \mathrm{Sc}$ samples is presented in Figure 3-7 (a), (b) and (c). For drawing those diagrams, we used work function values for $\mathrm{Si}, \mathrm{Sc}$ and $\mathrm{Sn}$ of $4.85 \mathrm{eV}, 3.5 \mathrm{eV}$ and $4.35 \mathrm{eV}$, respectively ${ }^{42}$, while electron affinities were taken to be equal to $0.9 \mathrm{eV}$ for $\mathrm{SiO}_{2}{ }^{43}$, and $0.85 \mathrm{eV}$ for $\mathrm{Sc}_{2} \mathrm{O}_{3}{ }^{44}$. Band gaps for $\mathrm{Sc}_{2} \mathrm{O}_{3}, \mathrm{SiO}_{2}$ and $\mathrm{Si}$ are: $6.3 \mathrm{eV}{ }^{45}$, 
$9 \mathrm{eV}{ }^{46}$ and $1.11 \mathrm{eV}^{47}$, respectively. The values of work function, electron affinities and band gaps are indicated on a relative scale on the diagrams below.

a)

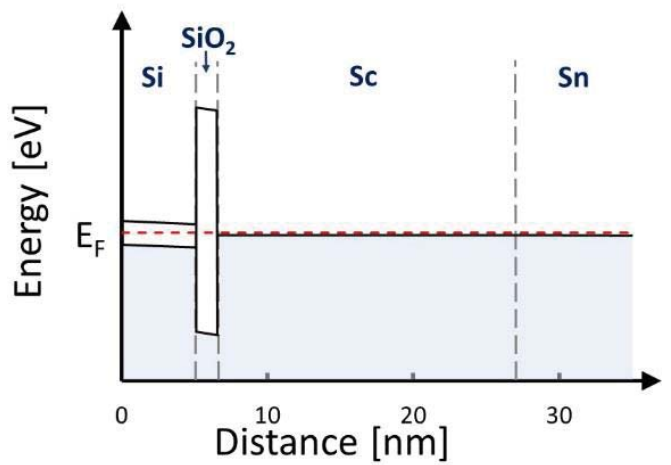

b)

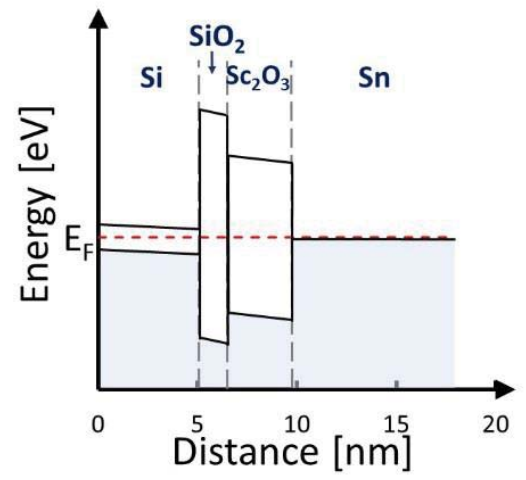

c)

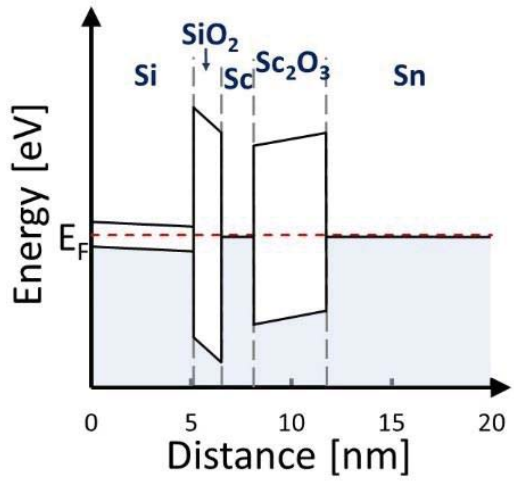

Figure 3-7. Energy band diagram over the layers for tested samples: (a) $20 \mathrm{~nm} \mathrm{Sc}$, (b) $3 \mathrm{~nm} \mathrm{Sc} \mathrm{O}_{3}$, (c) $5 \mathrm{~nm} \mathrm{Sc}_{2} \mathrm{O}_{3} / \mathrm{Sc}$.

The work function difference between Sc and Sn leads to a built-in electric field over the $\mathrm{Sc}_{2} \mathrm{O}_{3}$ layer that makes tunnelling from $\mathrm{Sc}$ to $\mathrm{Sn}$ less favourable than the reverse. Electrons that tunnel through the oxide barrier must return when $\mathrm{Sn}$ is etched from the surface, thus the existence of the barrier still allows to etch $\mathrm{Sn}$ but at the same time significantly slows down the etch rate in comparison to $3 \mathrm{~nm} \mathrm{Sc} \mathrm{O}_{3}$ and $20 \mathrm{~nm}$ Sc samples. 


\subsection{Conclusions}

In conclusion, we have shown that tin can be fully etched from a metallic Sc surface as predicted by Pachecka et al. ${ }^{1}$, as well from Sc thin films with complete and incomplete oxidation. Furthermore, our results show that the presence of $\mathrm{Sc}_{2} \mathrm{O}_{3}$ on a $\mathrm{Sc}$ thin film significantly slows the etch rate. The etch rate was found to change during the whole etch process, as well as over individual five minutes cycles. Changes in the surface area of the Sn layer (in between etch cycles) may account for rate changes between etch cycles, while temperature increases and possible saturation of the surface with hydrogen probably account for changes during an etch cycle. For Sn etching from oxidized Sc, trapping of electrons in defects of the $\mathrm{Sc}_{2} \mathrm{O}_{3}$ layer lowers the etching rate compared to metallic Sc surface. This effect is strengthened when Sc metal is present below the $\mathrm{Sc}_{2} \mathrm{O}_{3}$, due to the built-in electric field over the oxide generated by the difference in work function between Sc and Sn.

\subsection{References}

1. M. Pachecka, J. M. Sturm, R. W. E. van de Kruijs, C. J. Lee and F. Bijkerk, AIP Advances 6 (7), 075222 (2016).

2. D. Ugur, A. J. Storm, R. Verberk, J. C. Brouwer and W. G. Sloof, Microelectron. Eng. 110, 60-65 (2013).

3. D. Ugur, A. J. Storm, R. Verberk, J. C. Brouwer and W. G. Sloof, J. Phys. Chem. C 116 (51), 26822-26828 (2012).

4. B. Mertens, Microelectron. Eng. 73-74, 16-22 (2004).

5. W. A. Soer, M. M. J. W. van Herpen, M. J. J. Jak, P. Gawlitza, S. Braun, N. N. Salashchenko, N. I. Chkhalo and V. Y. Banine, J. Micro/Nanolith. MEMS MOEMS 11 (2), 021118-021111 (2012).

6. L. Kihlborg and A. Magneli, Acta Chem. Scand. 9, 471-476 (1955).

7. J.-G. Choi and L. T. Thompson, Appl. Surf. Sci. 93, 143-149 (1996).

8. T. Leisegang, A. A. Levin, J. Walter and D. C. Meyer, Cryst. Res. Technol. 40 (1-2), 95-105 (2005). 
9. P. A. Spevack and N. S. McIntyre, J. Phys. Chem. 97, 11020-11030 (1993).

10. J. Sloczynski, React. Solid. 7, 83-88 (1989).

11. M. J. Kennedy and S. C. Bevan, JLCM 36, 23-30 (1974).

12. W. V. Schulmeyer and H. M. Ortner, Int. J. Refract. Met. H. 20, 261269 (2002).

13. D. Ugur, A. J. Storm, R. Verberk, J. C. Brouwer and W. G. Sloof, Appl. Surf. Sci. 288, 673-676 (2014).

14. O. V. Braginsky, A. S. Kovalev, D. V. Lopaev, E. M. Malykhin, T. V. Rakhimova, A. T. Rakhimov, A. N. Vasilieva, S. M. Zyryanov, K. N. Koshelev, V. M. Krivtsun, M. van Kaampen and D. Glushkov, J. Appl. Phys. 111 (9), 093304 (2012).

15. D. Kong, J. Zhu and K.-H. Ernst, J. Phys. Chem. C 120, 5980-5987 (2016).

16. J. Wambach, G. Illing and H. J. Freund, Chem. Phys. Lett. 184, 239244 (1991).

17. H. Behner, W. Spiess, G. Wedler, D. Borgmann and H. J. Freund, Surf. Sci. 184, 335-344 (1987).

18. T. Diemant, K. M. Schuttler and R. J. Behm, Chem. Phys. Chem. 16 (14), 2943-2952 (2015).

19. W. Wang, L. Li, Q. Zhou, J. Pan, Z. L. Zhang, E. S. Tok and Y.-C. Yeo, Appl. Surf. Sci. 321, 240-244 (2014).

20. A. Böttcher and H. Niehus, J. Chem. Phys. 110, 3186-3195 (1999).

21. J. Chen, E. Louis, R. Harmsen, T. Tsarfati, H. Wormeester, M. van Kampen, W. van Schaik, R. van de Kruijs and F. Bijkerk, Applied Surface Science 258 (1), 7-12 (2011).

22. J. Chen, C. J. Lee, E. Louis, F. Bijkerk, R. Kunze, H. Schmidt, D. Schneider and R. Moors, Diam. Relat. Mater. 18 (5-8), 768-771 (2009).

23. J. Chen, E. Louis, H. Wormeester, R. Harmsen, R. W. E. van de Kruijs, C. J. Lee, W. van Schaik and F. Bijkerk, Meas. Sci. Technol. 22 (10), 105705 (2011).

24. D. E. Aspnes, J. Vac. Sci. Technol. A 31 (5), 058502 (2013).

25. R. A. Synowicki, Thin Solid Films 313-314, 394-397 (1998).

26. T. W. H. Oates, H. Wormeester and H. Arwin, Prog. Surf. Sci. 86 (1112), 328-376 (2011). 
27. J. D. Blackwood and D. J. McCarthy, Australian Journal of Chemistry 20, 2003-2004 (1967).

28. A. Horn, A. Schenk, J. Biener, B. Winter, C. Lutterloh, M. Wittmann and J. Kuppers, Chemical Physics Letters 231, 193-198 (1994).

29. E. Despiau-Pujo, A. Davydova, G. Cunge, L. Delfour, L. Magaud and D. B. Graves, J. Appl. Phys. 113 (11), 114302 (2013).

30. P. P. Naulleau, J. R. Sporre, D. Elg, D. N. Ruzic, S. N. Srivastava, I. V. Fomenkov and D. C. Brandt, 8679, 86792H (2013).

31. J. Sporre, D. Elg, D. Andruczyk, T. Cho, D. N. Ruzic, S. Srivastava and D. C. Brandt, Proc. of SPIE 8322, 83222L-83222L-83211 (2012).

32. C. D. Hodgman, R. C. Weast and S. M. Selby, Handbook of Chemistry and Physics, 46 ed. (The Chemical Rubber Co., Cleveland (Ohio), 1965).

33. D. Liu, S. J. Clark and J. Robertson, Appl. Phys. Lett. 96 (3), 032905 (2010).

34. T. V. Perevalov, O. E. Tereshenko, V. A. Gritsenko, V. A. Pustovarov, A. P. Yelisseyev, C. Park, J. H. Han and C. Lee, J. Appl. Phys. 108 (1), 013501 (2010).

35. H. Nishikawa, E. Watanabe, D. Ito and Y. Ohki, Phys. Rev. Lett. 72 (13), 2101-2104 (1994).

36. D. Diesing and E. Hasselbrink, Chem. Soc. Rev. 45 (13), 3747-3755 (2016).

37. J. G. Simmons, J. Phys. D: Appl. Phys. 4, 613-657 (1971).

38. J. G. Simmons, J. Appl. Phys. 34 (6), 1793-1803 (1963).

39. P. Thissen, B. Schindler, D. Diesing and E. Hasselbrink, New J. Phys. 12 (11), 113014 (2010).

40. L. A. Kasprzak, R. B. Laibowitz and M. Ohring, J. Appl. Phys. 48 (10), 4281-4286 (1977).

41. T. E. Hartman, J. Appl. Phys. 35 (11), 3283-3294 (1964).

42. J. Speight, Lange's Handbook of Chemistry, Sixteenth Edition ed. (McGraw-Hill Education, 2005).

43. Materials and Reliability Handbook for Semiconductor Optical and Electron Devices. (Springer, 2013).

44. P. S. P., C. R. Abernathy and F. Ren, Gallium Nitride Processing for Electronics, Sensors and Spintronics. (Springer, 2006). 
45. A. V. Emeline, G. V. Kataeva, V. K. Ryabchuk and N. Serpone, J. Phys. Chem. B 103, 9190-9199 (1999).

46. E. Vella, F. Messina, M. Cannas and R. Boscaino, Phys. Rev. B 83 (17), 174201 (2011).

47. B. G. Streetman and S. Banerjee, Solid State Electronic Devices, 5th ed. (Prentice Hall, 2006). 


\section{Chapter 4}

\section{Metal diffusion properties of}

\section{ultra-thin high-k $\mathrm{Sc}_{2} \mathrm{O}_{3}$ films}

The diffusion barrier properties of $\mathrm{Sc}_{2} \mathrm{O}_{3}$ against metal diffusion were studied. Tin and ruthenium were used as probe materials to study the barrier properties of $\mathrm{Sc}_{2} \mathrm{O}_{3}$ in thickness ranges that are of relevance for gate materials. Tin deposition and hydrogen radical etching from $\mathrm{SC}_{2} \mathrm{O}_{3}$ layers of 0.5-1.5 nm thickness, deposited on $\mathrm{Ru}$, show that these $\mathrm{Sc}_{2} \mathrm{O}_{3}$ layers effectively block the diffusion of $\mathrm{Sn}$ into Ru. We show that $\mathrm{Sn}$ adhesion and etching depends strongly on the thickness of the $\mathrm{Sc}_{2} \mathrm{O}_{3}$ film. The etch-rate is found to be inversely proportional to the $\mathrm{Sc}_{2} \mathrm{O}_{3}$ layer thickness, which we attribute to $\mathrm{Sc}_{2} \mathrm{O}_{3}$ becoming a more effective charge transfer barrier at larger thicknesses.

\subsection{Introduction}

Group III based dielectrics, such as scandium oxide $\left(\mathrm{SC}_{2} \mathrm{O}_{3}\right)^{1}$ and rare earth scandates ${ }^{2}$ e.g. $\mathrm{LaSCO}_{3}$ have been studied as possible candidates for high-k dielectric applications, due to their possession of a suitably large optical band gap (5-6 eV). Moreover, $\mathrm{Sc}_{2} \mathrm{O}_{3}$ has a high dielectric constant $(\varepsilon=13)$ in comparison to $\mathrm{SiO}_{2}$ $(\varepsilon=4.5) .^{3}$ Scandium oxide, doped with lanthanum, has been investigated as a high-k gate material for silicon-based integrated circuits. ${ }^{4}$ However, much of the interest in $\mathrm{Sc}_{2} \mathrm{O}_{3}$ has been in applications in AlGaN/GaN devices. Devices, based on AIGaN/GaN without passivation, show significant gate lag effects due to the presence of surface states in the region between the gate and drain 
contact. Moreover due to large polarization induced field and large conduction band offset, high current density can be achieved with AlGaN/GaN heterostructures. Scandium oxide has attractive band gap and thermal lattice properties for use on $\mathrm{GaN}^{5} \mathrm{~A} \mathrm{Sc}_{2} \mathrm{O}_{3}$ layer was shown to effectively mitigate the collapse in drain current through passivation of the surface traps. ${ }^{5-6}$ Additionally, it was demonstrated that $\mathrm{Sc}_{2} \mathrm{O}_{3}$ can be used simultaneously as a gate oxide and as a surface passivation layer for AlGaN/GaN high electron mobility transistors. ${ }^{7}$

However, the gate oxide material must satisfy several criteria: in addition to the electronic function of a gate dielectric, the gate oxide material must maintain a high dielectric constant, and serve as a diffusion barrier against diffusion of material from the top electrode. Furthermore, the gate dielectric must be as thin as possible, so a high resistance to diffusion is critical. Thus, in addition to the electronic properties of the gate, it is also of importance to understand the $\mathrm{Sc}_{2} \mathrm{O}_{3}$ diffusion-barrier behavior. The thermal stability of the high-k dielectric material is also of importance, thus, a dielectric material should show good thermal stability, at least at the processing temperatures of the device, and have a low coefficient of thermal expansion. ${ }^{4,8-9}$

In order to carry out diffusion studies, we use tin (Sn), a highly mobile metallic probe atom, to test if $\mathrm{Sc}_{2} \mathrm{O}_{3}$ layers of various thicknesses act as a diffusion barrier. Although $\mathrm{Sn}$ is not relevant for high-k dielectric applications we used it due to the fact that $\mathrm{Sn}$ has the advantage of forming a volatile hydride, which allows it to be removed from surfaces with hydrogen reactive species. ${ }^{10}$ Tin intermixes and/or binds strongly with highly electronegative materials, such as ruthenium (Ru), gold ( $\mathrm{Au})$, and silver (Ag). Furthermore, it has been shown that $\mathrm{Sn}$, after it diffuses into the aforementioned materials cannot be etched by atomic hydrogen 11-13, while $\mathrm{Sn}$ deposited onto $\mathrm{Sc}_{2} \mathrm{O}_{3}$ can be completely removed with atomic hydrogen. ${ }^{14}$ In this work, we study $\mathrm{Sc}_{2} \mathrm{O}_{3}$ barriers 
deposited on top of highly electronegative Ru surfaces, with in situ ellipsometry. The deposition and etching results are understood in the context of a metal-insulator-metal tunnel device.

\subsection{Experimental}

Ruthenium and scandium were deposited by direct current (DC) magnetron sputtering from targets with $99.95 \%$ and $99.5 \%$ purity, respectively. First, $4 \mathrm{~nm}$ of Ru was deposited onto a silicon wafer. On top of Ru, thin layers of scandium (Sc) with thicknesses of 0.5, 1, and $1.5 \mathrm{~nm}$ were deposited (see Table 4-1). An additional sample with $4 \mathrm{~nm}$ of $\mathrm{Ru}$, deposited on a silicon wafer, was used as a reference for analysis with low-energy ion scattering spectroscopy (LEIS) measurements (see below). Deposition was performed in a vacuum chamber with a base pressure of $3 \cdot 10^{-8} \mathrm{mbar}$ and a temperature of $22{ }^{\circ} \mathrm{C}$ inside the chamber. Samples were placed approximately $30 \mathrm{~cm}$ from the magnetron. The magnetron current during deposition was $1 \mathrm{~A}$ while magnetron voltage was $460 \mathrm{~V}$ and $410 \mathrm{~V}$ for Ru and Sc deposition, respectively. Argon pressure during sputtering was measured to be $7 \cdot 10^{-4}$ mbar during Ru deposition and $6 \cdot 10^{-4}$ mbar during Sc deposition. The deposition rates for $\mathrm{Ru}$ and Sc were 0.169 and $0.166 \mathrm{~nm} / \mathrm{s}$, respectively.

Table 4-1. Material and thicknesses composition of the samples. All materials were deposited on silicon wafer substrates.

\begin{tabular}{cccc}
\hline Material & \multicolumn{3}{c}{ Sample name } \\
\cline { 2 - 4 }$[\mathrm{nm}]$ & $0.5 \mathrm{Sc}_{2} \mathrm{O}_{3} / \mathrm{Ru}$ & $1 \mathrm{Sc}_{2} \mathrm{O}_{3} / \mathrm{Ru}$ & $1.5 \mathrm{Sc}_{2} \mathrm{O}_{3} / \mathrm{Ru}$ \\
\hline $\mathrm{Sc}$ & 0.5 & 1 & 1.5 \\
$\mathrm{Ru}$ & 4 & 4 & 4 \\
\hline
\end{tabular}

For many materials, oxidation of the layer is usually self-limiting at atmospheric pressure and room temperature, resulting in a socalled native oxide layer with a thickness of few nanometers at most. It was reported that $5.5 \mathrm{~nm} \mathrm{Sc}$, deposited on a silicon wafer, has a native oxide thickness of $3.6 \mathrm{~nm}$, while $3 \mathrm{~nm}$ of Sc is fully 
oxidized. ${ }^{11,14}$ Thus, Sc layers with a thickness below $3 \mathrm{~nm}$ can be expected to fully oxidize when exposed to ambient. However, to test thinner layers, the oxide layer should be terminated. Hence the Sc was deposited on Ru, a noble metal. Ruthenium does not oxidize easily, thus allowing a sharp interface between Ru and Sc native oxide to be created.

After deposition, all the samples were removed from the chamber and exposed to ambient conditions to form $\mathrm{Sc}_{2} \mathrm{O}_{3}$ layers. The properties of the deposited layers were then analyzed with LEIS, and $x$-ray photoelectron spectroscopy (XPS). Tin deposition and etching experiments were performed in an apparatus that has been described in detail elsewhere. ${ }^{11}$ Tin (Umicore) with a bulk density of $7.3 \mathrm{~g} / \mathrm{cm}^{3}$ and purity of $99.9 \%$ was evaporated from an Effusion Cell EF $40 \mathrm{C} 1$ (PREVAC) evaporator operated at $980^{\circ} \mathrm{C}$. The Sn deposition rate was calibrated using a quartz microbalance (INFICON XTM/2 Deposition Monitor). It was found that the evaporation rate as measured using the quartz microbalance (QMB) at $980^{\circ} \mathrm{C}$ was approximately $0.4 \mathrm{~nm} / \mathrm{min}$. Approximately 8 $\mathrm{nm}$ of tin was evaporated onto the sample and, immediately afterwards, etched with hydrogen radicals $\left(H^{\circ}\right)$. The $H^{\cdot}$ flux is generated by passing a molecular hydrogen flow (100 sccm) over a tungsten (W) filament that is heated to $2000^{\circ} \mathrm{C}$. The hydrogen radical flux was calculated to be $10^{17}$ at $/ \mathrm{s} \cdot \mathrm{cm}^{2}$ at the sample surface from the measured carbon etching rate, following the method used in ref. 15. The temperature of the sample was monitored using a Pt-100 temperature sensor, mounted on the backside of the sample. During hydrogen etching, the filament was operated in 5 min cycles to avoid excessive sample heating. As a result, the temperature modulations were less than $25^{\circ} \mathrm{C}$, and the maximum sensor temperature was always below $55{ }^{\circ} \mathrm{C}$. Thus, the surface temperature is unlikely to be more than $(55+5){ }^{\circ} \mathrm{C}$ than the sensor temperature. During Sn deposition and etching, the sample was monitored with in situ ellipsometry. After the Sn deposition 
and etching experiments, the samples were analyzed ex situ with XPS.

\subsection{Results and discussion}

\subsubsection{As deposited sample analysis -LEIS}

To ensure that the $\mathrm{Sc}_{2} \mathrm{O}_{3}$ layer forms a closed film, several samples were analyzed with LEIS. To remove surface contaminants, the samples were sputtered with a dose of $4 \cdot 10^{15} 3 \mathrm{keV} \mathrm{He} \mathrm{H}^{+}$ions $/ \mathrm{cm}^{2}$ before analysis. The LEIS spectra after sputtering are presented in Figure 4-1.

It can be seen that, even after mild sputtering of the surface contaminants, the only species present on the surface are Sc and O. No surface Ru was detected for any of the Sc layer thicknesses. This confirms that the prepared Sc native oxide thin layers are uniform and closed layers, thus allowing the oxide layers barrier properties to be studied.

For the different $\mathrm{Sc}_{2} \mathrm{O}_{3}$ thicknesses, there is a significant difference in the so-called tail signal from sub-surface Ru (especially in the energy range around $2100-2400 \mathrm{eV}$ ). This tail signal results from $\mathrm{He}$ ions that penetrate the sample (upon which they are neutralized), backscatter on sub-surface Ru atoms in the direction of the detector and are reionized when leaving the sample, such that they can be detected with the electrostatic analyzer. Due to stopping of ions in the sample, scattering on a Ru atom deeper inside the sample contributes to the tail signal at lower energy relative to the surface peak. The tail signal thus provides a depth profile of Ru in the sample. ${ }^{16}$ 


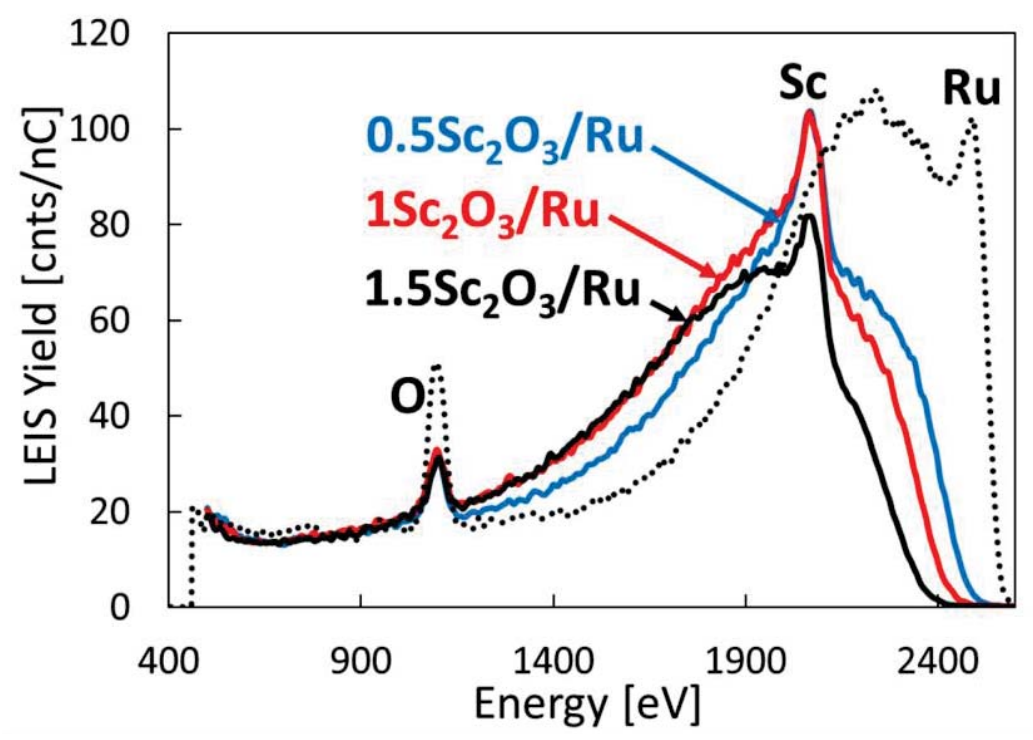

Figure 4-1. LEIS measurements after mild He sputtering for $0.5 \mathrm{Sc}_{2} \mathrm{O}_{3} / \mathrm{Ru}$ (blue solid line), $1 \mathrm{Sc}_{2} \mathrm{O}_{3} / \mathrm{Ru}$ (red solid line) and $1.5 \mathrm{Sc}_{2} \mathrm{O}_{3} / \mathrm{Ru}$ (black solid line). The dashed line is $4 \mathrm{~nm} \mathrm{Ru}$ on a silicon wafer, shown as a reference (after the same cleaning step).

For comparison a typical LEIS spectrum for Ru is also presented in Figure 4-1 as a black dashed line. For $0.5 \mathrm{~nm} \mathrm{Sc}$, the thinnest oxide studied, the high energy on-set of the tail signal from sub-surface Ru corresponds to the energy of the Ru surface peak (labelled as $\mathrm{Ru}$ ) of the $\mathrm{Ru}$ reference, which indicates that the $\mathrm{Sc}_{2} \mathrm{O}_{3}$ layer formed is only just closed, and that $\mathrm{Ru}$ is present from the $2^{\text {nd }}$ atomic layer. For thicker $\mathrm{Sc}_{2} \mathrm{O}_{3}$ layers, the tail and its onset shift to lower energies, which indicates that $\mathrm{Ru}$ is covered by a $\mathrm{Sc}_{2} \mathrm{O}_{3}$ layer free of Ru. Hence, we can conclude that the interface between the $\mathrm{Ru}$ and $\mathrm{SC}_{2} \mathrm{O}_{3}$ is rather sharp.

From the LEIS measurements, the final thickness values of the $\mathrm{Sc}_{2} \mathrm{O}_{3}$ layers were obtained, following the procedure described in ref. 16, using an effective stopping value for $3 \mathrm{keV} \mathrm{He}$ ions in $\mathrm{Sc}_{2} \mathrm{O}_{3}$ of $151 \mathrm{eV} / \mathrm{nm}$ film thickness extracted from SRIM software. ${ }^{17}$ The thicknesses of the top layer differ slightly from the target layer thicknesses. The measured thicknesses of the $\mathrm{Sc}_{2} \mathrm{O}_{3}$ layers of 
$0.5 \mathrm{Sc}_{2} \mathrm{O}_{3} / \mathrm{Ru}, 1 \mathrm{Sc}_{2} \mathrm{O}_{3} / \mathrm{Ru}$ and $1.5 \mathrm{Sc}_{2} \mathrm{O}_{3}$ sample were calculated to be $0.71 \mathrm{~nm}, 1.10 \mathrm{~nm}$ and $1.56 \mathrm{~nm}$, respectively, corresponding to a minor swelling of the nominal thicknesses deposited, due to oxidation.

\subsubsection{Tin deposition and etching - in situ ellipsometry results}

During $\mathrm{S} n$ deposition and etching experiments there is no exposure to ambient, and the etching experiments were performed less than 1 hour after Sn deposition, thus no Sn oxidation is expected. The ellipsometry Delta value at $513 \mathrm{~nm}$ is shown for all the samples in Figure 4-2. Tin deposition starts at 5 minutes, and finishes at 25 minutes, corresponding to a $\mathrm{Sn}$ layer that is $\sim 8 \mathrm{~nm}$ thick. Afterwards, $\mathrm{Sn}$ is etched, starting from 25 minutes, using hydrogen radicals. Etching is performed with the filament operated in 5 minutes cycles to maintain the sample below $55^{\circ} \mathrm{C}$. After etching is complete, Delta returns to its original value (apart from a small offset due to the removal of carbon contamination), indicating that $\mathrm{Sn}$ does not diffuse through the $\mathrm{Sc}_{2} \mathrm{O}_{3}$ layer. Remarkably, this is also true for the thinnest $\mathrm{SC}_{2} \mathrm{O}_{3}$ layer. The deposited $\mathrm{Sn}$ is fully removed from all tested samples, which was confirmed with the XPS measurements. This can be compared to Sn etching experiments on $\mathrm{Ru}$, where the remaining thickness of $\mathrm{Sn}$ was reported to be 4.1 $\mathrm{nm} .{ }^{11}$

It can be seen that the total etching time increases with increasing $\mathrm{Sc}_{2} \mathrm{O}_{3}$ thickness. The $\mathrm{Sn}$ etching time as a function of $\mathrm{Sc}_{2} \mathrm{O}_{3}$ thickness is presented in Figure 4-3. 


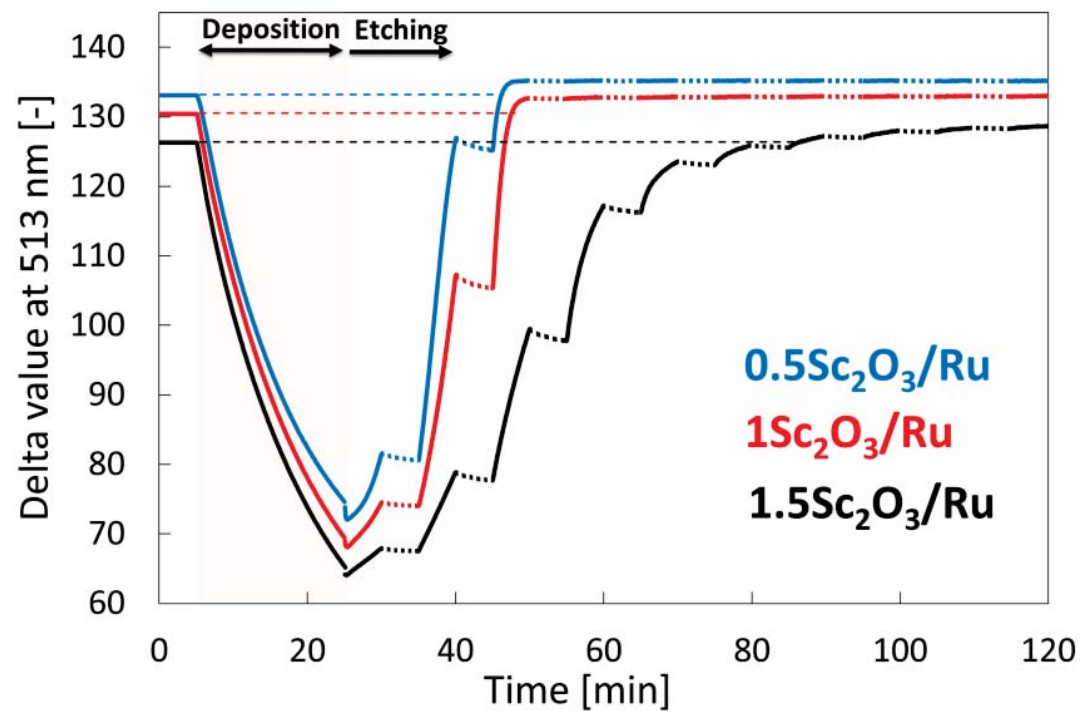

Figure 4-2. Delta value for $513 \mathrm{~nm}$ during $\mathrm{Sn}$ deposition and $\mathrm{Sn}$ etching. Deposition starts at $5 \mathrm{~min}$ and finishes at $25 \mathrm{~min}$. $\mathrm{H}^{*}$ etching starts at $25 \mathrm{~min}$ and proceeds in 5 minutes cycles with the filament ON (solid line) and OFF (dotted line).

The etch-rate is inversely proportional to the $\mathrm{Sc}_{2} \mathrm{O}_{3}$ layer thickness. Moreover, with increasing $\mathrm{Sc}_{2} \mathrm{O}_{3}$ thickness, the etching time converges to the value found for bulk $\mathrm{Sc}_{2} \mathrm{O}_{3}$, which is presented in Figure 4-3 as the point at $3 \mathrm{~nm} \mathrm{Sc} \mathrm{O}_{3}$ (obtained from ref. 14). It should be noted that, for this point, the Sc was deposited on a silicon wafer and full oxidation of the layer was achieved. ${ }^{14}$ For etching to be successful, tin hydride must be formed, and charge transfer from the Ru layer to the Sn layer must occur. Hot electrons are generated when atomic hydrogen reacts with $\mathrm{Sn}$, and these may tunnel through the oxide barrier, or get trapped in defect states in the oxide. The tunneling rate depends on the thickness of the $\mathrm{Sc}_{2} \mathrm{O}_{3}$ layer, and the potential difference between the work functions. Thus, the contribution of tunnelling to the etch rate may be estimated (see below). 


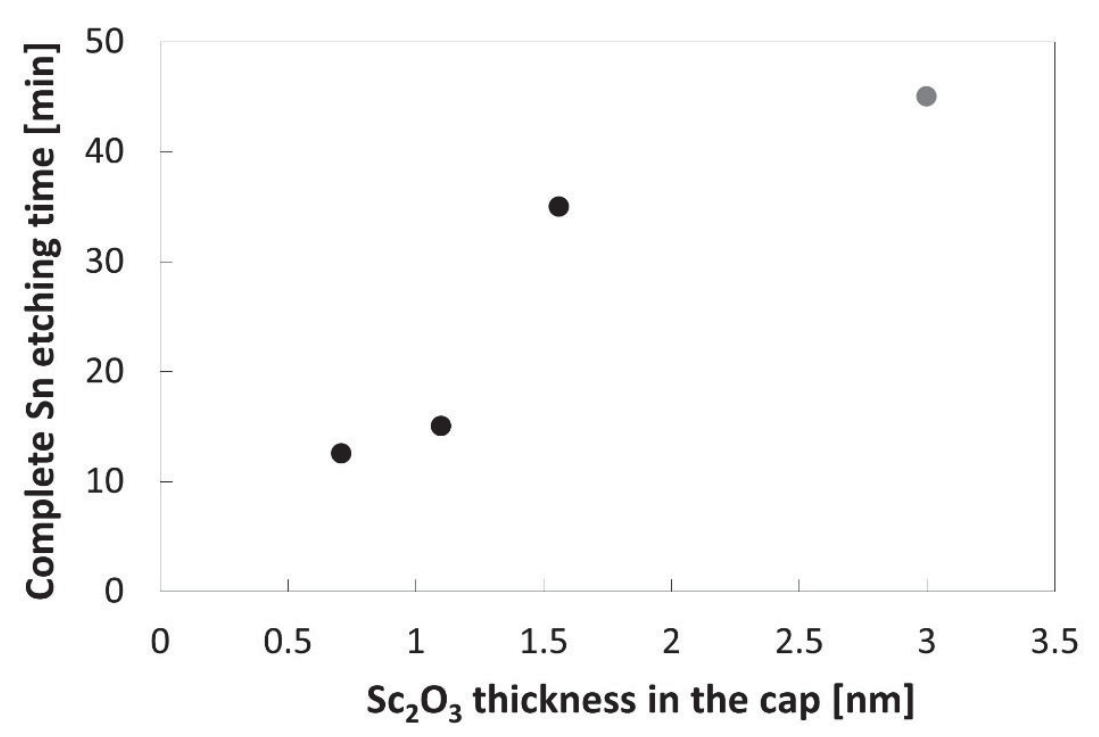

Figure 4-3. Sn etching time (time when filament was OFF is excluded) as a function of $\mathrm{Sc}_{2} \mathrm{O}_{3}$ thickness on top of $\mathrm{Ru}$. The point with $3 \mathrm{~nm} \mathrm{Sc} \mathrm{O}_{3}$ is taken from ref. 14. For this point, the $\mathrm{Sc}$ is deposited on a silicon wafer.

\subsubsection{Binding energy of $\mathrm{Sn}$ to $\mathrm{Sc}_{2} \mathrm{O}_{3}$}

The binding between $\mathrm{Sn}$ and $\mathrm{SC}_{2} \mathrm{O}_{3}$ can be understood in terms of charge transfer between the Ru and Sn layers. In this model, the $\mathrm{Ru} / \mathrm{SC}_{2} \mathrm{O}_{3} / \mathrm{Sn}$ structure acts as a metal-insulator-metal tunnel device (MIM) and we can compare the Sn etch rate from the tested samples. MIMs consist of a metal back electrode, an insulating oxide layer and metal top layer. The thin insulator layer acts as highpass filter for carrier transport. ${ }^{18-20}$ Charge transport is limited by the band gap of the insulator, but the small thickness of the oxide layer, and the presence of local defect states in the band gap allow (hot) electrons and holes to tunnel through the oxide barrier. ${ }^{20}$ Tunneling from a metal through a thin insulator to another metal has been extensively studied for different material combinations. ${ }^{18-22}$ Noting that the Fermi level remains constant across the interfaces, schematic band diagrams for the different 
thicknesses of $\mathrm{Sc}_{2} \mathrm{O}_{3}$ can be constructed (see Figure 4-4 (a), Figure 4-4 (b) and Figure 4-4 (c)). The work function values for Ru and Sn were taken to be $4.71 \mathrm{eV}$ and $4.35 \mathrm{eV}$, respectively ${ }^{23}$, while the electron affinity and band gap for $\mathrm{Sc}_{2} \mathrm{O}_{3}$ are reported to be $0.9 \mathrm{eV}^{24}$ and $6.3 \mathrm{eV} .{ }^{25}$ The values of the work function, electron affinities and band gap are indicated on a relative scale on the diagrams below.

a)

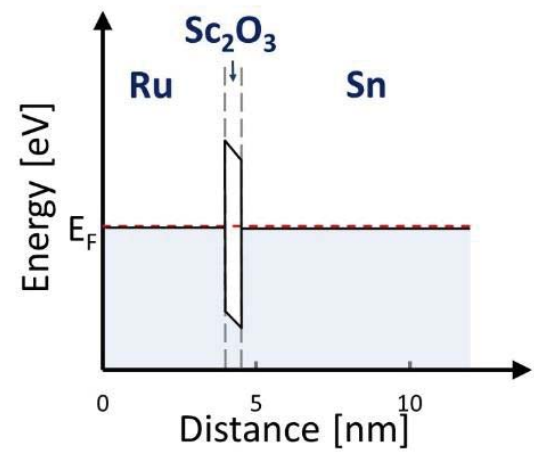

b)

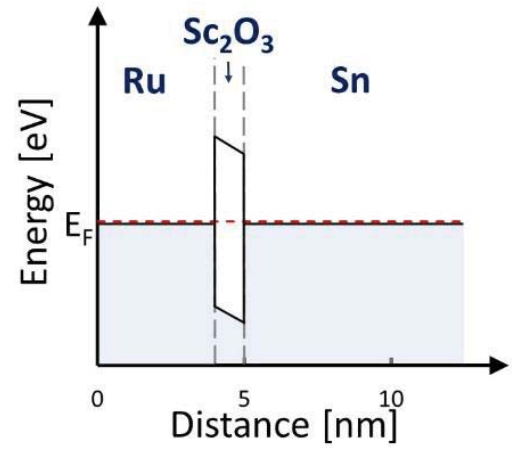

c)

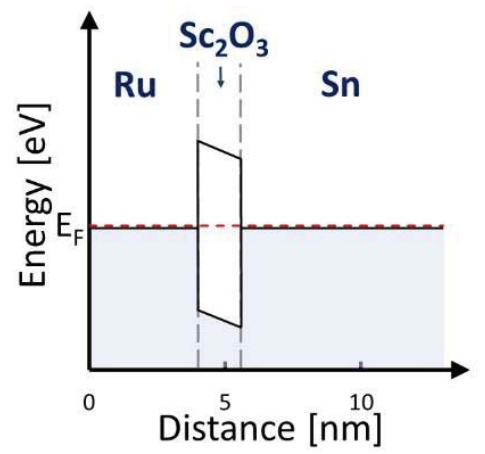

Figure 4-4. Energy band diagram over the layers for $0.5 \mathrm{Sc}_{2} \mathrm{O}_{3} / \mathrm{Ru}(\mathrm{a})$ $1 \mathrm{Sc}_{2} \mathrm{O}_{3} / \mathrm{Ru}(\mathrm{b})$, and $1.5 \mathrm{Sc}_{2} \mathrm{O}_{3} / \mathrm{Ru}(\mathrm{c})$.

The difference in work functions between $\mathrm{Sn}$ and Ru creates a driving potential that favors the diffusion of electrons from $\mathrm{Ru}$ to 
$\mathrm{Sn}$. The potential drop induces an electric field that varies from $0.51,0.33$ and $0.23 \mathrm{~V} / \mathrm{nm}$, depending on the $\mathrm{Sc}_{2} \mathrm{O}_{3}$ layer thickness. To estimate the relative tunnelling rates, we consider a plane wave solution to Schrödinger's equation, $\psi_{R u}=A_{1} e^{i k_{1} x}+B_{1} e^{-i k_{1} x}$, for an electron traveling in the $x$ direction in the Ru layer, orthogonal to the $\mathrm{Ru} / \mathrm{SC}_{2} \mathrm{O}_{3}$ interface. Setting the potential of the Ru layer to zero leads to: $k_{1}^{2}=K_{e} m_{e} / \hbar^{2}$, where $K_{e}$ is the kinetic energy of the electron, $m_{e}$ is the electron's mass, and $\hbar$ the reduced Planck's constant. The positive complex exponential represents the wave traveling towards the $\mathrm{Sc}_{2} \mathrm{O}_{3}$ barrier, while the negative complex exponential represents the reflected wave. In the $\mathrm{SC}_{2} \mathrm{O}_{3}$ layer, the wave function is given by $\psi_{S c O}=A_{2} e^{i k_{2} x}+B_{2} e^{-i k_{2} x}$, where the electron's momentum is given by $k_{2}^{2}=\left(K_{e}-V_{a}\right) m_{e} / \hbar^{2}$ and $V_{a}$ is the height of the potential barrier at the $\mathrm{Ru} / \mathrm{Sc}_{2} \mathrm{O}_{3}$ interface. The positive complex exponential represents the transmitted wave function, while the negative complex exponential represents a wave traveling from the $\mathrm{Sc}_{2} \mathrm{O}_{3}$ into the $\mathrm{Ru}$. In considering electron tunneling from Ru to $\mathrm{Sn}$, we set $B_{2}=0$. To satisfy Schrödinger's equation both the wave function, and it's first derivative must be continuous across the interface. This leads to the following expression for the transmitted and reflected amplitudes, $A_{2}$ and $B_{1}$, respectively.

$$
\mathrm{B}_{1}=\mathrm{A}_{1} \frac{\mathrm{ik}_{1}-\mathrm{k}_{2 \mathrm{r}}}{\mathrm{k}_{2 \mathrm{r}}+\mathrm{ik} \mathrm{k}_{1}}
$$

and

$$
\mathrm{A}_{2}=\mathrm{A}_{1} \frac{\mathrm{i} 2 \mathrm{k}_{1}}{\mathrm{k}_{2 \mathrm{r}}+\mathrm{ik}_{1}}
$$

where we have assumed that $V_{a}>K_{e}$ and $k_{2 r}$ indicates that the momentum should be evaluated at the $\mathrm{Ru} / \mathrm{SC}_{2} \mathrm{O}_{3}$ interface.

Inside the $\mathrm{SC}_{2} \mathrm{O}_{3}$, the electron's momentum becomes complex, leading to an exponentially decaying wave function. As before, the wave function and its derivative should be continuous at the $\mathrm{Sc}_{2} \mathrm{O}_{3} / \mathrm{Sn}$ barrier, giving: 


$$
\begin{aligned}
& \mathrm{B}_{2 \mathrm{~s}}=\mathrm{A}_{2} \frac{\mathrm{ik}_{1}-\mathrm{k}_{2 \mathrm{~s}}}{\mathrm{k}_{2 \mathrm{~s}}+\mathrm{ik}_{1}} \mathrm{e}^{-\overline{\mathrm{k}_{2}} \mathrm{t}} \\
& \mathrm{A}_{3}=\mathrm{A}_{2} \frac{\mathrm{i} 2 \mathrm{k}_{1}}{\mathrm{k}_{2 \mathrm{~s}}+\mathrm{ik} \mathrm{k}_{1}} \mathrm{e}^{-\overline{\mathrm{k}_{2}} \mathrm{t}}
\end{aligned}
$$

where $B_{2 s}$ is the reflection coefficient from the $\mathrm{Sc}_{2} \mathrm{O}_{3} / \mathrm{Sn}$ interface, and $k_{2 s}$ is the electron momentum, evaluated at the $\mathrm{Sc}_{2} \mathrm{O}_{3} / \mathrm{Sn}$ interface. The bar indicates that the average momentum in the $\mathrm{Sc}_{2} \mathrm{O}_{3}$ layer should be used. Furthermore, we have also assumed that the potential difference between the Sn layer and the Ru layer is the same as the work function difference between the two materials. From Equations 4-2 and 4-4 the amplitude of the electron wave function in the $\mathrm{Sn}$ layer can be estimated as:

$$
A_{3}=-\frac{4 k_{1}^{2} e^{-\overline{\overline{k_{2}}} t}}{\left(\mathrm{k}_{2 \mathrm{r}}+\mathrm{ik}_{1}\right)\left(\mathrm{k}_{2 \mathrm{~s}}+\mathrm{ik}_{1}\right)}
$$

while the transmission probability can be estimated as $1 /\left(\left|A_{3}^{2}\right|\right)$, which is shown as a function of the layer thickness (Figure 4-5 (b)) for $1 \mathrm{eV}$ electrons, and as a function of electron energy (Figure 4-5 (a)) for a barrier thickness of $0.7 \mathrm{~nm}$. Note that for thermal electrons $\left(K_{e} \sim 0.025 \mathrm{eV}\right)$, the transmission probability is orders of magnitude lower than for electrons with an energy of $1 \mathrm{eV}$. This implies that the electron flux due to tunneling is negligible for thermal electrons.

In deriving equations 4-1 to $4-5$, we have assumed that $B_{2}$ is negligible. We confirm this by combining equations $4-2$ and $4-3$ to calculate the probability density of the $B_{2}$ term, due to reflection from the $\mathrm{Sc}_{2} \mathrm{O}_{3} / \mathrm{Sn}$ interface. For a layer thickness of $0.7 \mathrm{~nm}, B_{2}$ is two orders of magnitude less than $A_{2}$, indicating that tunneling due to reflected electrons is, indeed, negligible.

To estimate if tunneling is significant, the transmission probabilities in Figure 4-5 (a) and (b) should be compared to the total number of 
electrons that need to traverse the barrier and the integrated atomic hydrogen flux. The number of Sn atoms (per unit surface area) is $3 \times 10^{16} \mathrm{~cm}^{-2}$, thus, the total charge transfer per unit area is $9 \times 10^{16} \mathrm{~cm}^{-2}$ (assuming $\mathrm{SnH}_{3}$ is the dominant etch product). The atomic hydrogen dose is simply the fluence (flux integrated over the etch time), which varies from $7.5 \times 10^{17} \mathrm{~cm}^{-2}$ to $2.1 \times 10^{20} \mathrm{~cm}^{-2}$. Every hydrogen radical may excite a hot electron that tunnels across the barrier. According to ref. 20 these electrons have an energy smaller than $2 \mathrm{eV}$, thus, we consider the case of electrons with an energy of $1 \mathrm{eV}$. For the case of $1 \mathrm{eV}$ electrons, the total expected tunneling charge per unit area ranges from $7.8 \times 10^{16} \mathrm{~cm}^{-2}$ to $2.7 \times 10^{13} \mathrm{~cm}^{-2}$, which, for the thinnest layer is comparable to the required charge transfer per unit area. Thus, using this data, tunneling between $\mathrm{Sn}$ and Ru predicts an etch time of $860 \mathrm{~s}$ compared to the measured $750 \mathrm{~s}$, which is in good agreement. For thermal electrons, the maximum tunneling charge transfer per unit area is only $1.2 \times 10^{14} \mathrm{~cm}^{-2}$ for the thinnest barrier, indicating that only hot electrons can contribute significantly to etching via tunneling.

Reversing the calculation above, we estimate in Figure 4-6 the contribution of charge transfer between the $\mathrm{Sn}$ and Ru layers to $\mathrm{Sn}$ etching. The tunneling contribution drops off very rapidly, leaving charge diffusion via defects as the dominant mechanism for most layer thicknesses. This explains the sensitivity for the change of the layer thickness in the etching process. Although the model can take the electron's effective mass into account by replacing $m_{e}$ with the effective mass, there are, to our knowledge, no reported values of the effective mass of electrons in $\mathrm{Sc}_{2} \mathrm{O}_{3}$ or $\mathrm{Ru}$. The tunneling probability is most sensitive to the effective mass of the $\mathrm{Sc}_{2} \mathrm{O}_{3}$ layer. For $1 \mathrm{eV}$ electrons with effective masses down to 0.5 , tunneling is still restricted to the thinnest layer $(0.71 \mathrm{~nm})$. However, for $1 \mathrm{eV}$ electrons with effective masses $\sim 0.1$, tunneling is efficient for thicknesses up to $1.5 \mathrm{~nm}$. 
a)

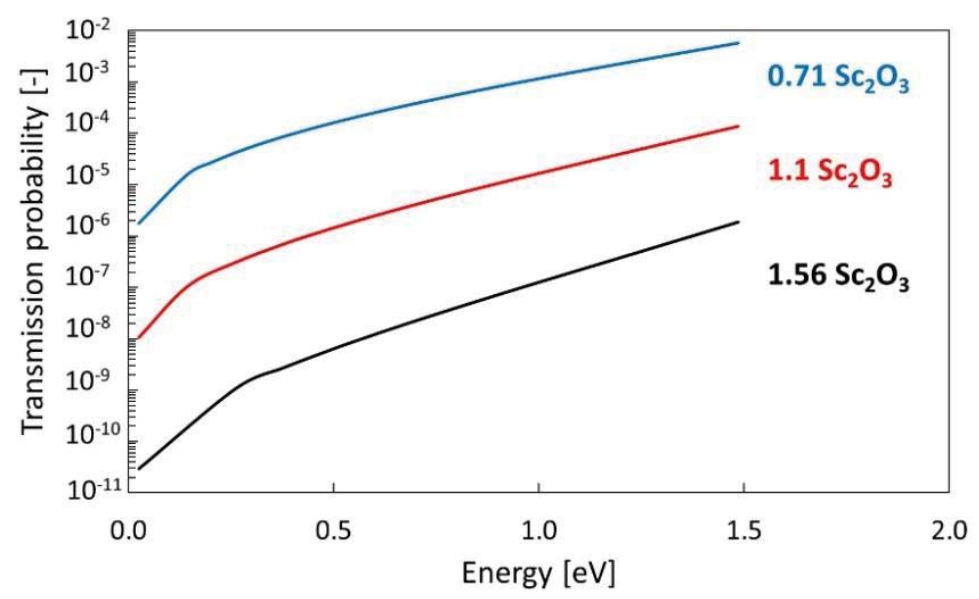

b)

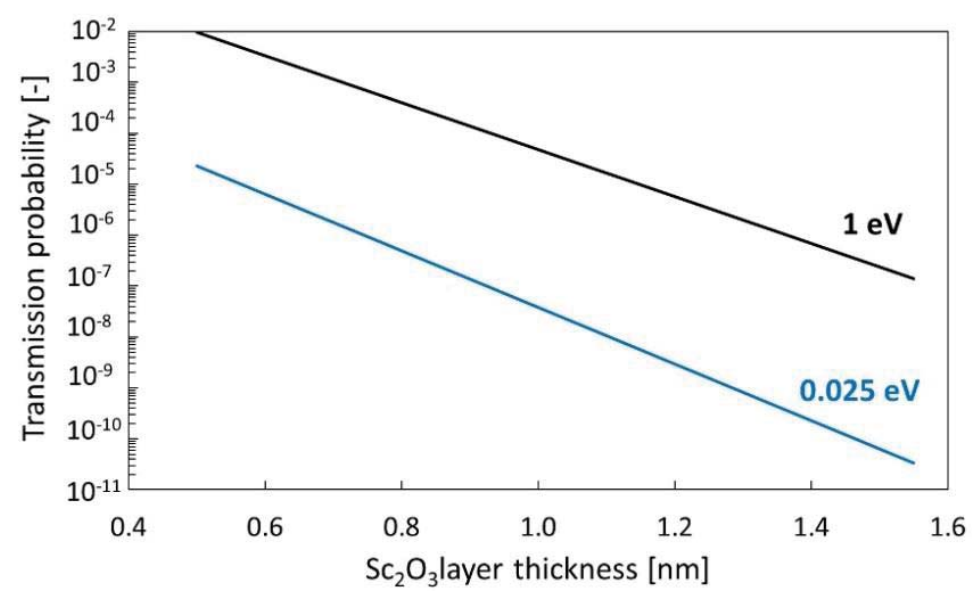

Figure 4-5. Transmission probability as a function of energy of electrons tunneling from $\mathrm{Ru}$ to $\mathrm{Sn}$ for different $\mathrm{Sc}_{2} \mathrm{O}_{3}$ barrier thicknesses (a) and as a function of $\mathrm{Sc}_{2} \mathrm{O}_{3}$ layer thickness for 1 and $0.025 \mathrm{eV}$ electrons (b). 


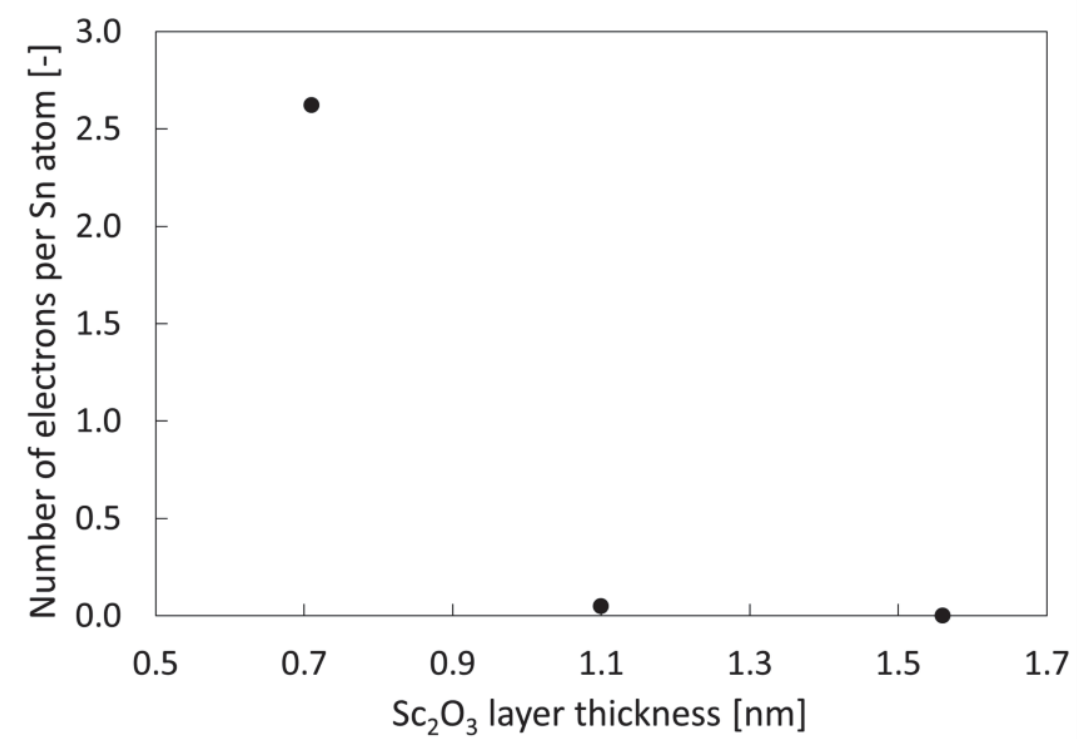

Figure 4-6. Number of tunneling electrons per $\mathrm{Sn}$ atom as a function of $\mathrm{Sc}_{2} \mathrm{O}_{3}$ layer thickness.

\subsection{Conclusions}

Scandium oxide diffusion barrier properties were tested using a MIM structure, consisting of $\mathrm{Ru}, \mathrm{Sc}_{2} \mathrm{O}_{3}$, and $\mathrm{Sn}$. By depositing, and then etching the $\mathrm{Sn}$ layer, it was possible to determine if the $\mathrm{Sn}$ diffused through the $\mathrm{Sc}_{2} \mathrm{O}_{3}$ barrier layer. We observed complete $\mathrm{Sn}$ etching from $0.71,1.1$ and $1.56 \mathrm{~nm}$ of $\mathrm{Sc}_{2} \mathrm{O}_{3}$. This demonstrates

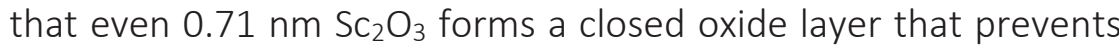
the diffusion of $\mathrm{Sn}$ through to the Ru layer.

The $\mathrm{S} n$ etching time was observed to depend on the $\mathrm{Sc}_{2} \mathrm{O}_{3}$ barrier thickness and increased with increasing $\mathrm{Sc}_{2} \mathrm{O}_{3}$ thickness. This is explained by the formation of a MIM junction between the $\mathrm{Ru}$, $\mathrm{SC}_{2} \mathrm{O}_{3}$ and $\mathrm{Sn}$, where the built-in potential enhances diffusion of electrons from the $\mathrm{Ru}$ and $\mathrm{SC}_{2} \mathrm{O}_{3}$ defect states to the $\mathrm{Sn}$. This diffusion of electrons becomes less efficient for larger barrier thicknesses. We use a simple model to show that for thicker layers of $\mathrm{SC}_{2} \mathrm{O}_{3}$, the etch rate is limited by charge diffusion, while electron tunneling may contribute significantly for thin layers of $\mathrm{Sc}_{2} \mathrm{O}_{3}$. 


\subsection{References}

1. Klenov, D. O.; Edge, L. F.; Schlom, D. G.; Stemmer, S., Extended Defects in Epitaxial $\mathrm{Sc}_{2} \mathrm{O}_{3}$ Films Grown on (111) Si. Applied Physics Letters 2005, 86, 051901.

2. Zhao, C., et al., Ternary Rare-Earth Metal Oxide High-K Layers on Silicon Oxide. Applied Physics Letters 2005, 86, 132903.

3. Shannon, R. D., Dielectric Polarizabilities of lons in Oxides and Fluorides. Journal of Applied Physics 1993, 73, 348-366.

4. Sivasubramani, P., et al., Thermal Stability of Lanthanum Scandate Dielectrics on Si(100). Applied Physics Letters 2006, 89, 242907.

5. Luo, B., et al., Influence of Mgo and $\mathrm{Sc}_{2} \mathrm{O}_{3}$ Passivation on Algan/Gan High-Electron-Mobility Transistors. Applied Physics Letters 2002, 80, 1661.

6. Luo, B., et al., Surface Passivation of Algan/Gan Hemts Using MbeGrown Mgo or $\mathrm{Sc}_{2} \mathrm{O}_{3}$. Solid-State Electronics 2002, 46.

7. Mehandru, R., et al., Algan/Gan Metal-Oxide-Semiconductor High Electron Mobility Transistors Using $\mathrm{Sc}_{2} \mathrm{O}_{3}$ as the Gate Oxide and Surface Passivation. Applied Physics Letters 2003, 82, 2530.

8. Gupta, T., Dielectric Materials In: Copper Interconnect Technology, 2009, p 67-110.

9. Shi, L.; Xia, Y. D.; Xu, B.; Yin, J.; Liu, Z. G., Thermal Stability and Electrical Properties of Titanium-Aluminum Oxide Ultrathin Films as High-K Gate Dielectric Materials. Journal of Applied Physics 2007, 101, 034102.

10. La Fontaine, B. M.; Sporre, J.; Lofgren, R. E.; Ruzic, D. N.; Khodykin, O. V.; Myers, D. W.; Naulleau, P. P., Development of an in-Situ Sn Cleaning Method for Extreme Ultraviolet Light Lithography. 2011, 7969, 796929-796929-9.

11. Pachecka, M.; Sturm, J. M.; van de Kruijs, R. W. E.; Lee, C. J.; Bijkerk, F., Electronegativity-Dependent Tin Etching from Thin Films. AIP Advances 2016, 6, 075222.

12. van Herpen, M. M. J. W.; Klunder, D. J. W.; Soer, W. A.; Moors, R.; Banine, V., Sn Etching with Hydrogen Radicals to Clean Euv Optics. Chemical Physics Letters 2010, 484, 197-199.

13. Soer, W. A.; van Herpen, M. M. J. W.; Jak, M. J. J.; Gawlitza, P.; Braun, S.; Salashchenko, N. N.; Chkhalo, N. I.; Banine, V. Y., AtomicHydrogen Cleaning of Sn from Mo/Si and Dlc/Si Extreme Ultraviolet 
Multilayer Mirrors. J. Micro/Nanolith. MEMS MOEMS 2012, 11, 021118-1.

14. Pachecka, M.; Lee, C. J.; Sturm, J. M.; Bijkerk, F., Tin Etching from Metallic and Oxidized Scandium Thin Films. AIP Advances 2017, 7, 085107.

15. Braginsky, O. V., et al., Removal of Amorphous $\mathrm{C}$ and $\mathrm{Sn}$ on Mo:Si Multilayer Mirror Surface in Hydrogen Plasma and Afterglow. J. Appl. Phys. 2012, 111, 093304.

16. Brongersma, H. H., Low-Energy lon Scattering In: Characterization of Materials; J. wiley \& Sons, 2012.

17. Ziegler, J. F.; Ziegler, M. D.; Biersack, J. P., Srim - the Stopping and Range of lons in Matter (2010). Nuclear Instruments and Methods in Physics Research Section B: Beam Interactions with Materials and Atoms 2010, 268, 1818-1823.

18. Simmons, J. G., Conduction in Thin Dielectric Films. J. Phys. D: Appl. Phys. 1971, 4, 613-657.

19. Simmons, J. G., Generalized Formula for the Electric Tunnel Effect between Similar Electrodes Separated by a Thin Insulating Film. J. Appl. Phys. 1963, 34, 1793-1803.

20. Thissen, P.; Schindler, B.; Diesing, D.; Hasselbrink, E., Optical Response of Metal-Insulator-Metal Heterostructures and Their Application for the Detection of Chemicurrents. New J. Phys. 2010, 12, 113014.

21. Kasprzak, L. A.; Laibowitz, R. B.; Ohring, M., Dependence of the SiSio2 Barrier Height on Sio2 Thickness in Mos Tunnel Structures. J. Appl. Phys. 1977, 48, 4281-4286.

22. Hartman, T. E., Tunneling through Asymmetric Barriers. J. Appl. Phys. 1964, 35, 3283-3294.

23. Speight, J., Lange's Handbook of Chemistry, Sixteenth Edition ed.; McGraw-Hill Education, 2005.

24. P., P. S.; Abernathy, C. R.; Ren, F., Gallium Nitride Processing for Electronics, Sensors and Spintronics; Springer, 2006.

25. Emeline, A. V.; Kataeva, G. V.; Ryabchuk, V. K.; Serpone, N., Photostimulated Generation of Defects and Surface Reactions on a Series of Wide Band Gap Metal-Oxide Solids. J. Phys. Chem. B 1999, 103, 9190-9199. 


\section{Chapter 5}

\section{Adsorption and dissociation of}

\section{$\mathrm{CO}_{2}$ on $\mathrm{Ru}(0001)$}

The adsorption and dissociation of carbon dioxide on a Ru(0001) single crystal surface was investigated by reflection-absorption infrared spectroscopy (RAIRS) and temperature programmed desorption (TPD) spectroscopy for $\mathrm{CO}_{2}$ adsorbed at $85 \mathrm{~K}$. RAIRS spectroscopy shows that the adsorption of $\mathrm{CO}_{2}$ on a $\mathrm{Ru}(0001)$ single crystal is partially dissociative, resulting in $\mathrm{CO}_{2}$ and $\mathrm{CO}$. The $\mathrm{CO}$ vibrational mode was also observed to split into two distinct modes, indicating two general populations of CO present at the surface. Furthermore, a time-dependent blue-shift is observed, which is characteristic of increasing CO surface coverage. TPD showed that coverages of up to $0.3 \mathrm{ML}$ were obtained, and no evidence for chemisorption of oxygen on Ruthenium was found.

\subsection{Introduction}

The transformation on of carbon dioxide $\left(\mathrm{CO}_{2}\right)$ into more valuable compounds (carbon monoxide, methanol, oxalate, organic acids, methane, hydrocarbons) requires activation by a catalyst. ${ }^{1}$ Among ionic liquids, proteins, organic compounds, semiconductors 2, transition metals are studied widely as catalysts, due to their relatively high efficiency. Thus, the interaction of $\mathrm{CO}_{2}$ with metal and metal oxide surfaces is of importance in understanding a number of relevant surface catalytic processes on an atomic scale. ${ }^{1,3-4}$ 
Reaction of $\mathrm{CO}_{2}$ dissociation products with hydrogen to produce hydrocarbons is attractive as a potential net-zero emissions fuel cycle. However, for such a cycle to be efficient, the catalysis of $\mathrm{CO}_{2}$ dissociation and the reverse water gas shift reaction is required. While metallic ruthenium is known to catalyze the reverse water gas shift reaction, its interaction with $\mathrm{CO}_{2}$ has not, to our knowledge been the subject of investigation. ${ }^{5-8}$ The chemisorption and reaction of $\mathrm{CO}_{2}$ on metal oxides, including $\mathrm{RuO}_{2}$, and metallic alloys, including $\mathrm{Ru}$, are well-studied processes. ${ }^{1,3}$ Moreover, the adsorption of $\mathrm{CO}_{2}$ on other single-crystal metal surfaces has been extensively studied. For the surfaces like $\mathrm{Fe}, \mathrm{Ni}, \mathrm{Re}, \mathrm{Al}$ or $\mathrm{Mg}$, it was observed that the adsorption of $\mathrm{CO}_{2}$ is partially dissociative, with $\mathrm{CO}_{2}$ decomposing to $\mathrm{CO}$ and $0 .{ }^{9-13}$ The dissociation of $\mathrm{CO}_{2}$ proceeds via the formation of negatively charged $\mathrm{CO}_{2}^{-}$on $\mathrm{Ni}, \mathrm{Fe}, \mathrm{Cu}, \mathrm{Re}$, which may then dissociate into $\mathrm{CO}$ and $\mathrm{O}^{1}{ }^{1}$

These experiments are often complicated by the low desorption temperature of $\mathrm{CO}_{2}$. In many cases ( $\mathrm{Rh}, \mathrm{Pd}, \mathrm{Pt}, \mathrm{Fe}, \mathrm{Cu}, \mathrm{Re}$ ) $\mathrm{CO}_{2}$ does not stably adsorb to the surface for temperatures above $100 \mathrm{~K}$, and desorbs from the surface for temperatures that are relatively low: $130 \mathrm{~K}(\mathrm{Re})$, and $135 \mathrm{~K}(\mathrm{Pd})$, with $\mathrm{Ni}$ being an exception at $220 \mathrm{~K} .{ }^{1}$ Additionally, surface purity is a very important factor in $\mathrm{CO}_{2}$ adsorption and reaction on metals. Alkali adatoms, for example, increase the binding energy of adsorbed $\mathrm{CO}_{2}$, and promote the partial dissociation of $\mathrm{CO}_{2}$ into $\mathrm{CO}+\mathrm{O}$.

Many surface studies have been performed using scanning tunneling microscopy (STM), low energy electron diffraction (LEED), and X-ray photoelectron spectroscopy (XPS). STM provides valuable insight into the morphology and short-range order of surface adsorbed species ${ }^{14-16}$, however, it can be challenging to resolve some chemical reactions, such as partial dissociation $\left(\mathrm{CO}_{2} \rightarrow \mathrm{CO}+\mathrm{O}\right)$. LEED is sensitive to ordered overlayer structures and XPS is sensitive to chemical changes at the surface, but, the relatively high energy of the electron and X-Ray irradiation can lead 
to surface modifications that may be difficult to separate from the changes of interest. ${ }^{17-22}$

TPD studies, on the other hand, provide a direct measurement of the surface binding energy, and allow the surface coverage to be absolutely calibrated. RAIRS measurements allow the growth and decay of vibrational modes to be studied in situ. These changes provide evidence for changes in molecular population density, molecular orientation, and the environment in which molecules are adsorbed to the surface. By combining TPD and RAIRS, it is often possible to draw quantitative conclusions that would be otherwise elusive. Moreover, due to the low energy of the radiation in RAIRS, in situ studies are highly unlikely to modify the surface during measurement.

In this article, we present the results of TPD and RAIRS studies of $\mathrm{CO}_{2}$ adsorption and dissociation on a $\mathrm{Ru}(0001)$ single crystal surface at $85 \mathrm{~K}$. Additionally behavior of absorbed species after increasing surface temperature to $120 \mathrm{~K}$ was studied.

\subsection{Methods}

A ruthenium (0001) single crystal with a diameter of $11 \mathrm{~mm}$ and thickness of $\sim 3 \mathrm{~mm}$ (Surface Preparation Laboratories, The Netherlands) was used for $\mathrm{CO}_{2}$ adsorption and dissociation studies. The sample was mounted on a 3-axis positioning manipulator in an ultra-high vacuum (UHV) chamber with a base pressure of $10^{-10}$ mbar. The temperature of the sample was controlled by a Eurotherm temperature controller with active heating and liquid nitrogen cooling. A K-type thermocouple was spot-welded to the side of the crystal and used to monitor the sample temperature. The system was equipped with facilities for TPD and RAIRS measurements. A Hiden Analytical 3F/PIC quadrupole mass spectrometer (QMS) was used for thermal desorption measurements. To ensure that the signal was dominated by desorption from the crystal surface, the QMS was mounted inside 
a differentially pumped housing which was placed approximately $1 \mathrm{~mm}$ from the crystal surface during measurements. TPD measurements were performed by heating the crystal surface at a constant rate of $2 \mathrm{~K} / \mathrm{s}$ in the range $85-600 \mathrm{~K}$ and at a rate of $10 \mathrm{~K} / \mathrm{s}$ from 600 to 1580 K. For RAIRS measurements, a Bruker Vertex 70v Fourier transform infrared (FTIR) spectrometer, employing a liquid nitrogen cooled mercury-cadmium-telluride (MCT) detector was used. Background and sample scans were recorded by co-adding 256 scans with a resolution of $4 \mathrm{~cm}^{-1}$.

The crystal surface was subjected to a cleaning process, consisting of oxygen cleaning, annealing, and Ar ion sputtering. In the first step, carbon was removed by sample oxidation at $1300 \mathrm{~K}$ with an $\mathrm{O}_{2}$ background pressure of $1 \times 10^{-7}$ mbar. Afterwards, $\mathrm{Ar}$ ion sputtering ( $2 \mathrm{keV})$, with an argon pressure of $2 \times 10^{-6}$ mbar was performed. Finally the sample was annealed at $1300 \mathrm{~K}$ and flashed to $1580 \mathrm{~K}$. Sputtering and annealing were repeated until no carbon monoxide peak was observed on the TPD spectrum, and until a repeatable water TPD spectrum was achieved. ${ }^{23}$

Carbon dioxide, with a purity of $99.998 \%$ (residual gasses: $\mathrm{O}_{2}$ 2 ppm, $\mathrm{N}_{2} 8$ ppm, hydrocarbons 3 ppm, $\mathrm{H}_{2} \mathrm{O} 1$ ppm, $\mathrm{CO} 1$ ppm) was used for the experiments. Carbon dioxide was dosed on the $\mathrm{Ru}(0001)$ surface, held at a temperature of $85 \mathrm{~K}$, using a retractable quartz dosing tube, placed $1 \mathrm{~cm}$ from the crystal to minimize the increase in the background pressure. A pinhole was mounted between the gas supply and the tube doser, such that a pressure in the mbar range in the dosing system results in effective pressures in the $10^{-8}$ mbar range in front of the crystal surface. The relatively high pressure in the dosing system minimizes possible contaminations from walls of the gas lines. Since $\mathrm{CO}_{2}$ does not stably adsorb at the lowest achievable temperature of $85 \mathrm{~K}$, calibration of the dose is not straightforward. Therefore, gas doses are specified as pressure used in the dosing system times exposure time. The surface coverage, which is the more important 
parameter, is determined by calibrating the total amount of $\mathrm{CO}_{2}$ detected via TPD against reference water TPD spectra (see Section 3.3 for details).

It is known that $\mathrm{CO}_{2}$ adsorption on metal surfaces strongly depends on dosing time, pressure, surface temperature, as well as presence of contaminants on the surface. ${ }^{1}$ This results in some additional uncertainty in the initial coverage for identical dosing conditions. To avoid incorporating this uncertainty into our study, we draw quantitative results from time-series data taken from the same experiment, rather than comparing between experiments.

\subsection{Results and discussion}

\subsection{1. $\mathrm{CO}_{2}$ adsorption on $\mathrm{Ru}(0001)$}

To ensure that all vibrational features were clearly identified, RAIRS spectra were first obtained from a Ru(0001) surface that was dosed with a large amount (dosing pressure approximately 5 mbar for less than 1 minute) of $\mathrm{CO}_{2}$ (see Figure 5-1). Five dominant vibrational modes were detected at frequencies that correspond closely to those reported in literature and their attributions are summarized in Table 5-1. ${ }^{24-25}$ The only exception is the feature at $675 \mathrm{~cm}^{-1}$, which we attribute to the $\left(v_{2}\right) \mathrm{O}=\mathrm{C}=\mathrm{O}$ bend mode, but we note that this is more commonly reported to be at $660 \mathrm{~cm}^{-1} .^{24,26-27}$ As shown in Figure 5-1, the peak at $2343 \mathrm{~cm}^{-1}$ is broadened and several separate peaks between 2283 and $2455 \mathrm{~cm}^{-1}$, are observed. Such broadening is common for thick layers, and, especially for layers that are interacting with a substrate. ${ }^{25}$ In the following experiments, much less than a monolayer of $\mathrm{CO}_{2}$ was dosed $(1,2$ and $3 \mathrm{mbar}$ ) and only the $\mathrm{v}_{3}$ stretch $(2343 \mathrm{~cm}-1)$ and $\left(\mathrm{v}_{2}\right) \mathrm{O}=\mathrm{C}=\mathrm{O}$ bend mode $(675 \mathrm{~cm}-1)$ were observed. These vibrational modes consist of a single peak each, in line with previous literature reports. The center frequency of the two modes did not change for different $\mathrm{CO}_{2}$ coverages. Taken together with the consistent shape 
of the TPD spectra for different coverages (see below), we conclude that the structure of the adsorbed $\mathrm{CO} 2$ does not change significantly in this coverage range.

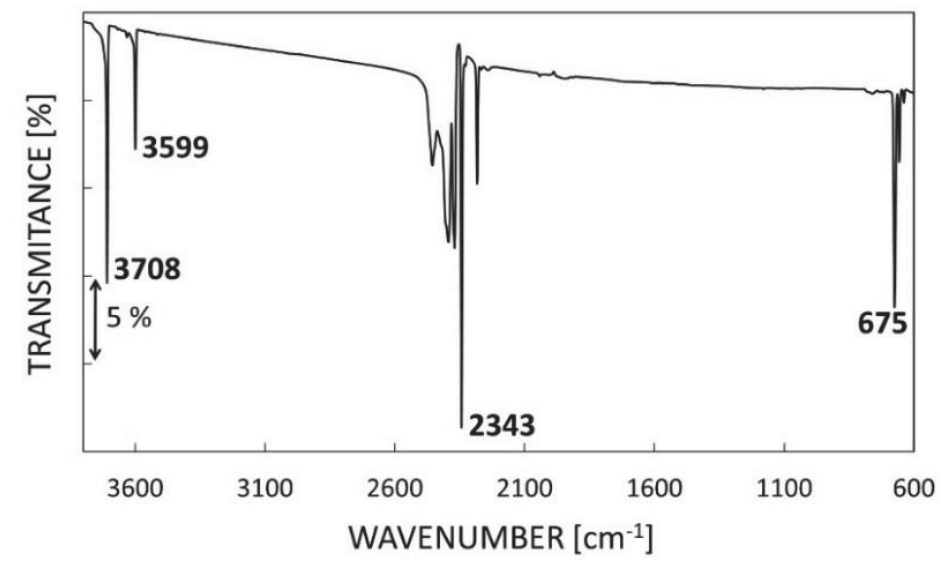

Figure 5-1. Reflection-absorption infrared spectrum of $\mathrm{CO}_{2}$ adsorbed on $\mathrm{Ru}(0001)$ at $85 \mathrm{~K}$.

$\mathrm{CO}_{2}$ adsorption on $\mathrm{Ru}(0001)$ surface was additionally studied with TPD. Carbon dioxide already starts desorbing from the Ru(0001) surface at $85 \mathrm{~K}$, moreover, the desorption peak is rather broad and extends beyond $120 \mathrm{~K}$ (see Figure 5-2), thus we expect some of the $\mathrm{CO}_{2}$ to desorb from the surface during dosing.

Table 5-1. Assignment of RAIRS peaks of $\mathrm{CO}_{2} / \mathrm{Ru}(0001)$ after Ref. ${ }^{24}$ : $v$ indicates a stretch vibration, with $v_{1}$ for symmetric and $v_{3}$ for asymmetric stretch.

\begin{tabular}{cc}
\hline Peak $\left[\mathrm{cm}^{-1}\right]$ & Assignment \\
\hline 3708 & $\left(\mathrm{v}_{1}+\mathrm{v}_{3}\right)$ combination \\
3599 & $\left(2 \mathrm{v}_{2}+\mathrm{v}_{3}\right)$ combination \\
2343 & $\left(\mathrm{v}_{3}\right)^{12} \mathrm{C}=\mathrm{O}$ stretch \\
675 & $\left(\mathrm{v}_{2}\right) \mathrm{O}=\mathrm{C}=\mathrm{O}$ bend \\
\hline
\end{tabular}




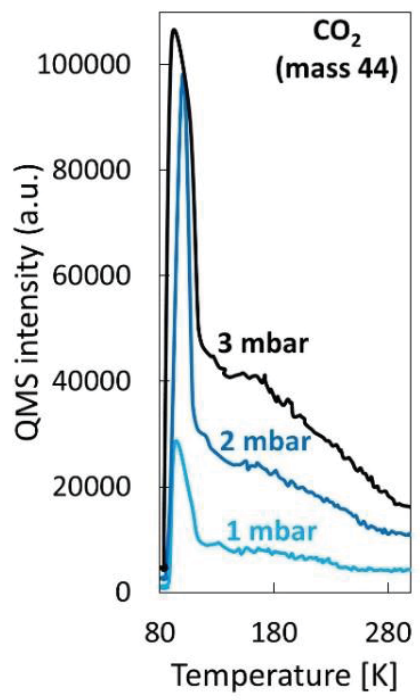

Figure 5-2. Desorbed peaks of $\mathrm{CO}_{2}$ from TPD measurement after $\mathrm{CO}_{2}$ dosed at $85 \mathrm{~K}$ onto the surface for 10 minutes with different pressures in the dosing system (1, 2 and 3 mbar).

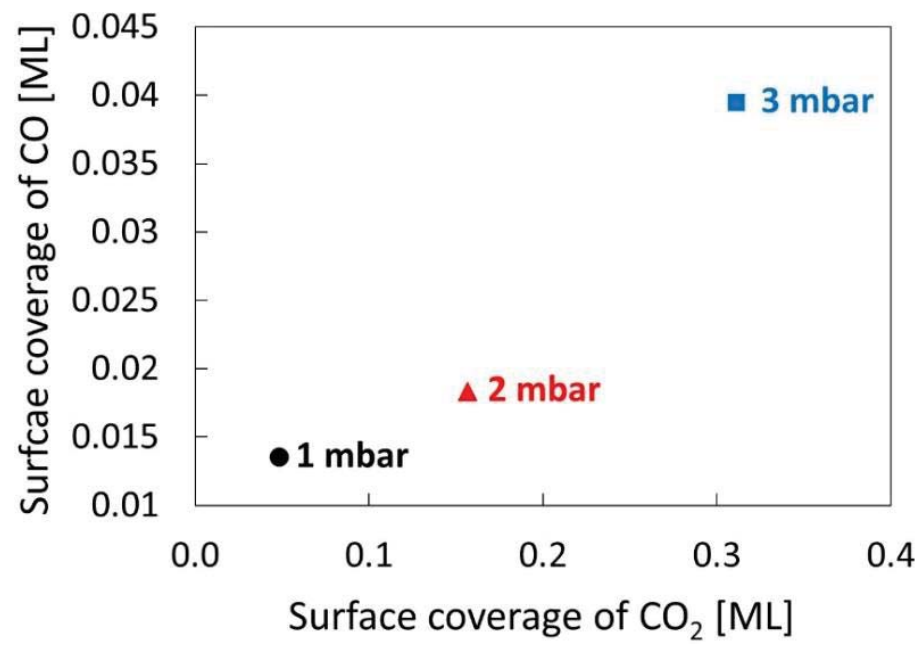

Figure 5-3. Surface coverage of $\mathrm{CO}$ as a function of $\mathrm{CO}_{2}$ dosed onto the $\mathrm{Ru}(0001)$ surface in the pressure of 1,2 and $3 \mathrm{mbar}$.

To exclude the influence of the instability of $\mathrm{CO}_{2}$ on our measurements, we dose $\mathrm{CO}_{2}$ for 10 min with different pressures ( 1 , 
2 and 3 mbar) in the dosing system, which corresponds to different surface coverage $\left(0.05,0.2\right.$ and 0.3 of a $\mathrm{ML}$, respectively) of $\mathrm{CO}_{2}$. The surface coverage was estimated using a reference water TPD spectrum for calibration purposes. Based on the water TPD ${ }^{28}$, we can estimate water coverage, and then taking into account the sensitivity of the mass spectrometer we calculated amount of $\mathrm{CO}$, $\mathrm{CO}_{2}$ and $\mathrm{H}_{2}$ (section 5.3.3) on the surface. After dosing, the two main contributions to the TPD spectrum are $\mathrm{CO}_{2}$ (at $105 \mathrm{~K}$ ) and $\mathrm{CO}$ (at $480 \mathrm{~K}$ ). Figure 5-3 shows the relation between the $\mathrm{CO}$ observed at the surface and the $\mathrm{CO}_{2}$ dosed onto the surface. Carbon dioxide and $\mathrm{CO}$ surface coverages are below $1 \mathrm{ML}$, thus we expect dose dependence coverage. As we will show later, the surface coverage of $\mathrm{CO}$ is clearly above the measured background (see Figure 5-9 for comparison), and depends on the $\mathrm{CO}_{2}$ dose.

\subsection{2. $\mathrm{CO}_{2}$ dissociation on $\mathrm{Ru}(0001)$}

To study that rate at which $\mathrm{CO}_{2}$ partially dissociates on the $\mathrm{Ru}(0001)$ surface, $\mathrm{CO}_{2}$ was dosed onto the surface for 10 minutes at a pressure of $1 \mathrm{mbar}$, after which the surface was monitored with RAIRS for 50 minutes (including dosing time). Directly after that, the sample surface was heated to $120 \mathrm{~K}$ and RAIRS measurements were obtained after cooling to $85 \mathrm{~K}$. The change in the $\mathrm{CO}$ and the $\mathrm{CO}_{2}$ ( $\mathrm{v}_{3}$ stretch and $\mathrm{v}_{2} \mathrm{O}=\mathrm{C}=\mathrm{O}$ bend modes) over time is presented in Figure $5-4 a$ and $b$.

To quantify the changes in $\mathrm{CO}_{2}$ and $\mathrm{CO}$ coverage, the intensity of the asymmetric stretching modes of $\mathrm{CO}_{2}$ and $\mathrm{CO}$ were used, although it should be noted that RAIRS spectra are generally not quantitative. Figure 5-4 shows that the $\mathrm{CO}_{2} \mathrm{~V}_{3}$ mode slowly decreases with time, moreover, it is also red-shifted from 2343 to $2341 \mathrm{~cm}^{-1}$. For low coverages of CO, like those used in this work, it is known that intensity of the asymmetric stretch mode scales approximately with coverage ${ }^{29}$, thus, we assume that all the changes in the spectra are due to changes in coverage. Our analysis 
shows that the intensity changes correspond to a reduction in $\mathrm{CO}_{2}$ coverage from 0.05 to $0.03 \mathrm{ML}$, as shown in Figure 5-5. Moreover, it can be seen that approximately half of the $\mathrm{CO}_{2}$ loss is due to desorption from the surface, and the remaining loss is due to dissociation into $\mathrm{CO}$. Similar behavior was observed in $\mathrm{CO}_{2}$ adsorption on $\mathrm{Ni}(100)$ studies 10-11, 30, where it was shown that adsorption of $\mathrm{CO}_{2}$ (100L) on $\mathrm{Ni}(100)$ results in $\mathrm{CO}_{2}$ and $\mathrm{CO}$ desorption from the surface. Based on evidence from EELS experiments, the existence of a "bent" $\mathrm{CO}_{2}$ configuration was proposed as a precursor to dissociative adsorption. A vibrational mode at $1620 \mathrm{~cm}^{-1}$ was assigned to an asymmetric stretching mode of a bent $\mathrm{CO}_{2}$ species, while peaks at 670 and $2350 \mathrm{~cm}^{-1}$ originate from the vibrational modes of linear, undistorted $\mathrm{CO}_{2}$.

Although the presence of peaks at 660 and $2343 \mathrm{~cm}^{-1}$ was observed after adsorption of $\mathrm{CO}_{2}$ on $\mathrm{Ru}(0001)$, no evidence for a vibrational mode at $1620 \mathrm{~cm}^{-1}$ was found. Only after increasing the dose and flux of $\mathrm{CO}_{2}$, by using a higher dosing pressure, a mode at $1580 \mathrm{~cm}^{-}$ ${ }^{1}$ was detected. We speculate that this mode may be due to the asymmetric stretch of distorted $\mathrm{CO}_{2}$, but we cannot definitively assign it. Due to the low amounts of CO formed on Ru(0001) and the reported instability of bent $\mathrm{CO}_{2}$, the coverage of this species might be too low to be reliably detected. Transition metals with full $\mathrm{d}$-band are known to be less active than metals with unpaired d-electrons, thus dissociative adsorption is more likely on $\mathrm{Ru}$, as evidenced by the reported behavior of $\mathrm{CO}_{2}$ on $\mathrm{Fe}, \mathrm{Ni}$, and $\mathrm{Re} .{ }^{1,31} \mathrm{In}$ contrast, $\mathrm{CO}_{2}$ does not partially dissociate on evaporated $\mathrm{Cu}$ films at 195 and $273 \mathrm{~K}$, as well as on $\mathrm{Cu}(110)$ and $\mathrm{Cu}(111)$ surfaces, which was attributed to the full d-bands. ${ }^{1}$ 
a)

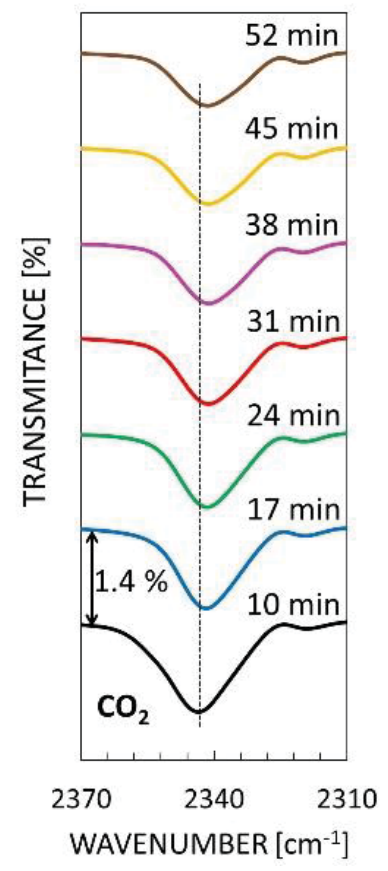

b)

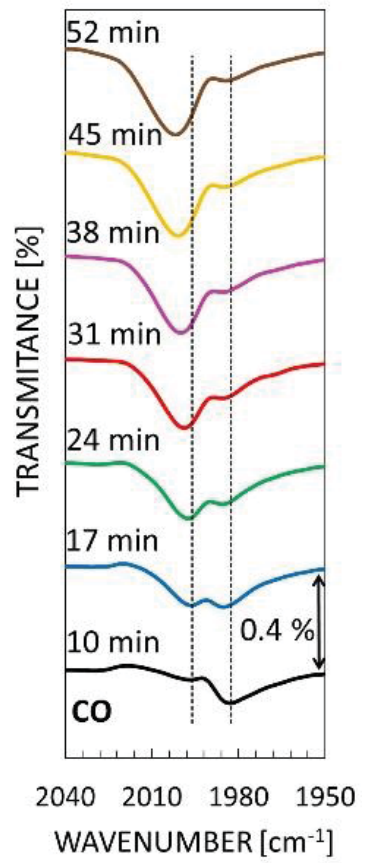

Figure 5-4. Reflection-absorption infrared spectrum of $\mathrm{CO}_{2}$ stretch mode (a) and $\mathrm{CO}$ (b) for different delay times, after dosing $\mathrm{CO}_{2}$ onto a Ru(0001) surface at $85 \mathrm{~K}$. Dashed lines indicate the peak positions for "10 min" measurement at $85 \mathrm{~K}$.

The CO vibrational mode, on the other hand, shows a more complicated behavior. The single vibrational mode splits into two. The higher energy mode consistently increases with time, and blueshifts from 1996 to $2002 \mathrm{~cm}^{-1}$ as the amount of CO increases. ${ }^{29}$ At the same time, the lower energy mode (at $1983 \mathrm{~cm}^{-1}$ ) does not grow consistently, but first increases and then decreases. The peak is first blue-shifted to $1986 \mathrm{~cm}^{-1}$, then red-shifts to $1985 \mathrm{~cm}^{-1}$ (see Figure 5-4 for a comparison). To distinguish the changes in intensity of these modes, the peaks (including $\mathrm{CO}_{2}$ stretch mode) were fit with Gaussians and the changes in areas of the peaks are presented in Figure 5-6. 


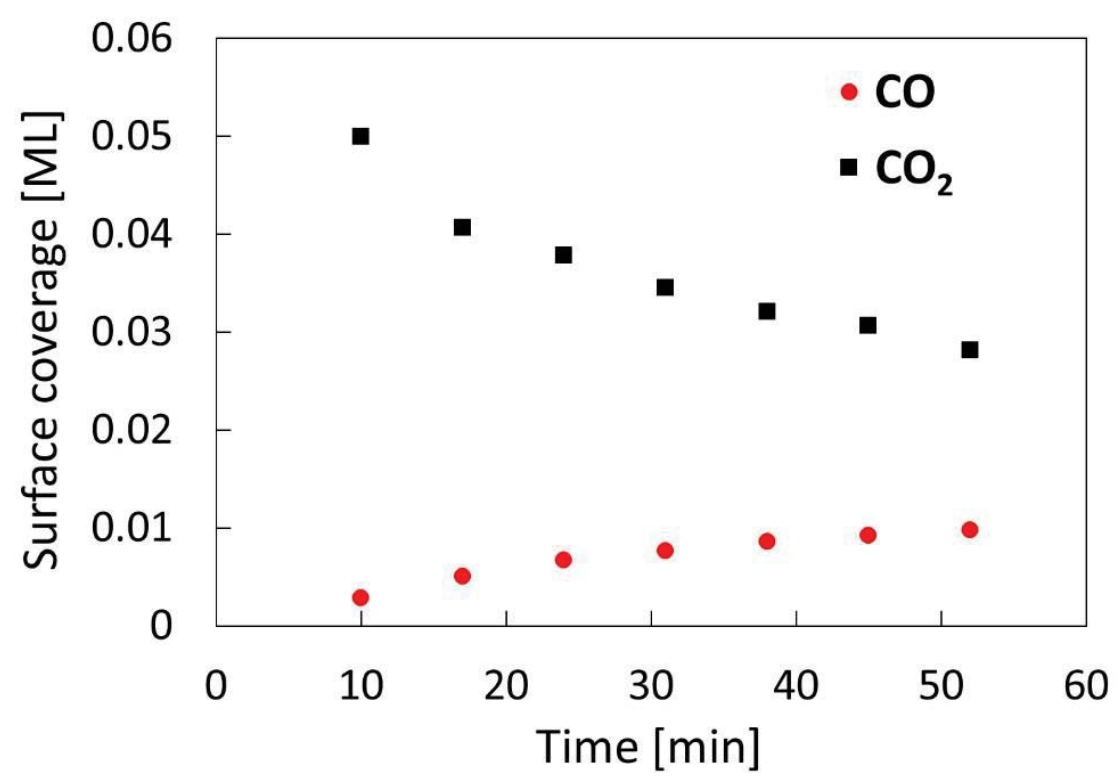

Figure 5-5. Integrated area of the $\mathrm{CO}$ and $\mathrm{CO}_{2}$ ( $v_{3}$ stretch mode) peaks converted into $\mathrm{ML}$ coverage after dosing onto $\mathrm{Ru}(0001)$ surface. Numbers are just indicative.

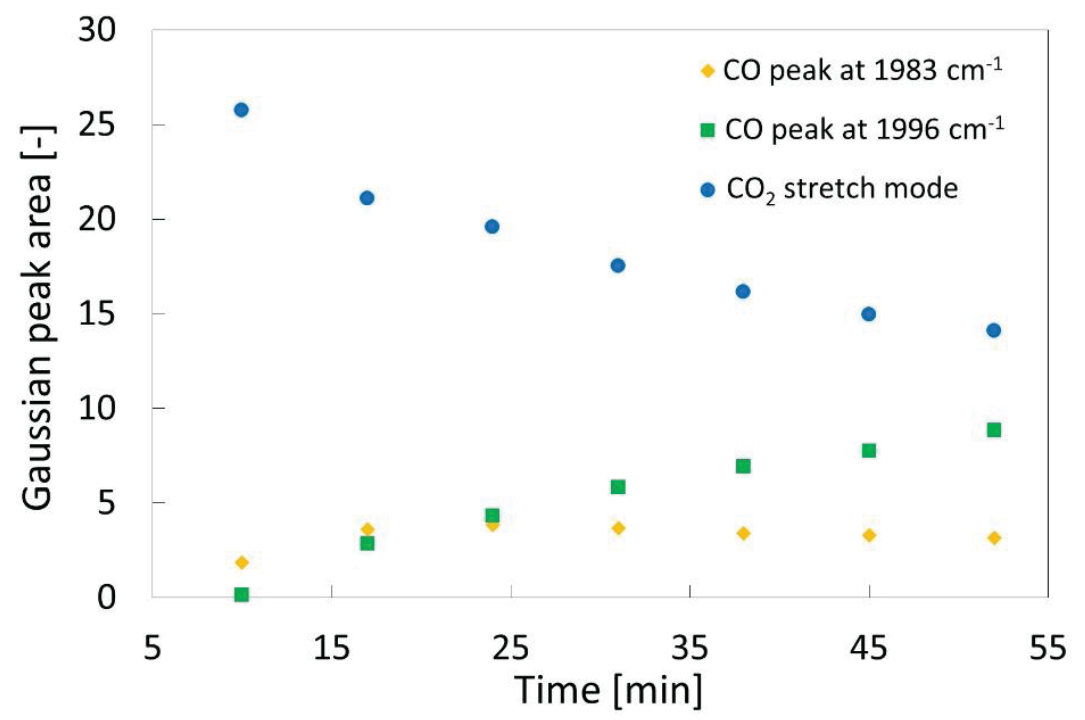

Figure 5-6. Peak areas after fit with Gaussians for $\mathrm{CO}_{2}$ stretch mode and two $\mathrm{CO}$ modes, after $10 \mathrm{~min} \mathrm{CO}_{2}$ dose at $1 \mathrm{mbar}$. 
It can be seen in Figure 5-6 that the area of the lower energy CO mode first increases and afterwards saturates, or even slowly decreases. On the other hand, the higher energy CO mode increases as the $\mathrm{CO}_{2}$ mode decreases. These spectral changes suggest that there are two CO populations. There are a number of possible explanations for the splitting of the vibrational mode: there may be two different binding energies, due to $\mathrm{CO}$ binding at two different sites. One site could be associated with nearby $\mathrm{CO}_{2}$, while the other is associated with $\mathrm{CO}$ that is not associated with $\mathrm{CO}_{2}$. Another possible explanation is that the dissociation of $\mathrm{CO}_{2}$ results in chemisorbed oxygen with the $\mathrm{CO}$ vibrational frequency shifted due to its proximity. A final possibility is that the CO binds to $\mathrm{CO}_{2}$ or $\mathrm{CO}$ rather than the Ru surface.

In our case, the surface coverage is rather low, making the latter case rather unlikely. Furthermore, as can be seen below, there is no evidence that the oxygen dissociation product chemisorbs stably to ruthenium. Therefore, we propose that the CO adsorbs at two different sites with two different binding energies, possibly due to the proximity of $\mathrm{CO}_{2}$. Only the higher energy vibrational mode is strongly dependent on the concentration of $\mathrm{CO}_{2}$, which might be associated to the strengthening of the $\mathrm{C}-\mathrm{O}$ bond (peak at $1996 \mathrm{~cm}^{-}$ ${ }^{1}$ ) and a weakening of the bond between the surface and CO (peak at $\left.1983 \mathrm{~cm}^{-1}\right) .32$

\subsubsection{CO adsorption from the residual background gasses on $\mathrm{Ru}(0001)$}

To avoid mistaking $\mathrm{CO}_{2}$ partial dissociation for $\mathrm{CO}$ adsorption from background, the adsorption of $\mathrm{CO}$ from the background was measured. After cleaning the Ru(0001) surface, the surface was flashed to $600 \mathrm{~K}$ to remove any residual $\mathrm{CO}$. The sample was then cooled to $85 \mathrm{~K}$ and RAIRS measurements were performed after delays of 25 and $50 \mathrm{~min}$ (see Figure 5-7). A peak at $1990 \mathrm{~cm}^{-1}$, corresponding to $\mathrm{CO}$ adsorbed to the surface is observed. ${ }^{28}$ It can 
be seen that the peak increases with time. Moreover, a slight blueshift from 1990 to $1988 \mathrm{~cm}^{-1}$ is observed.

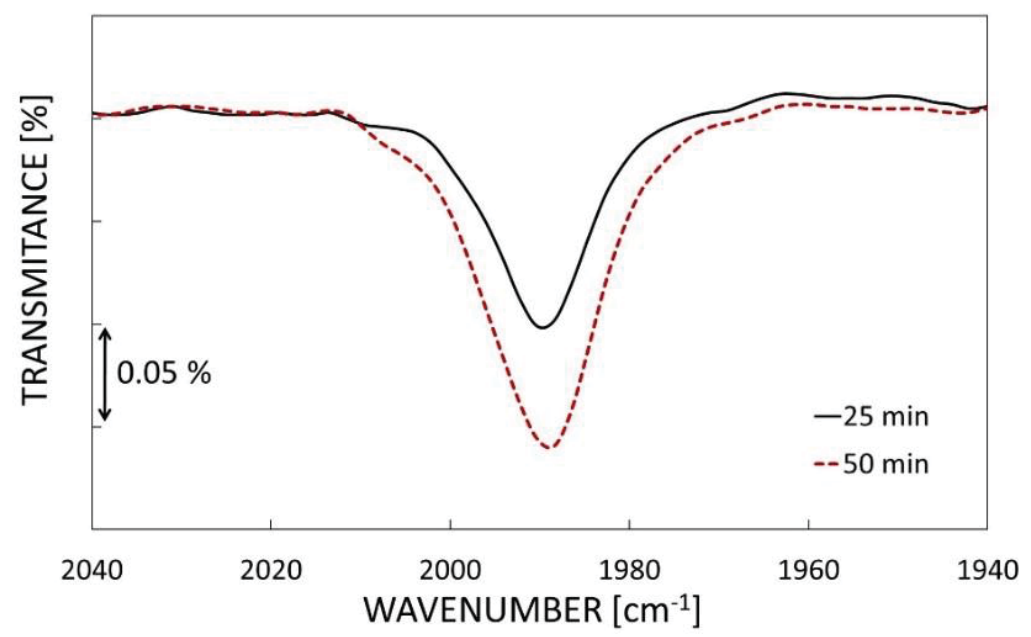

Figure 5-7. Background $\mathrm{CO}$ adsorption on Ru(0001) surface after 25 and 50 minutes of delay at a temperature of $85 \mathrm{~K}$.

To estimate the amount of $\mathrm{CO}$ adsorbing on the surface, TPD measurements were performed under the same conditions. TPD was performed immediately after the surface was cooled to $85 \mathrm{~K}$ and after delays of 25 and 50 minutes after heating to $600 \mathrm{~K}$ and cooling to $85 \mathrm{~K}$. As shown in Figure 5-8, the TPD spectrum showed that the surface coverage of $\mathrm{H}_{2}, \mathrm{H}_{2} \mathrm{O}$, and $\mathrm{CO}$ (Figure 5-8a, b and c, respectively) increases with time.

The surface coverage of $\mathrm{CO}, \mathrm{H}_{2}$ and $\mathrm{H}_{2} \mathrm{O}$ due to background gases are presented on Figure 5-9. There is no significant amount of water on the clean sample, but after exposing to ambient for 50 min, the amount of water increased to approximately 0.004 of a monolayer. A small amount of $\mathrm{CO}(0.001 \mathrm{ML})$ deposits onto the surface very quickly (faster than water), but only grows slowly (8 times slower than water) after that. Hydrogen grows fastest, from $0.003 \mathrm{ML}$ to $0.017 \mathrm{ML}$. A comparison between the growth of 
the $\mathrm{CO}$ peak after $\mathrm{CO}_{2}$ dosing with the growth of $\mathrm{CO}$ from background is presented on Figure 5-10 and in Table 5-2.

a)

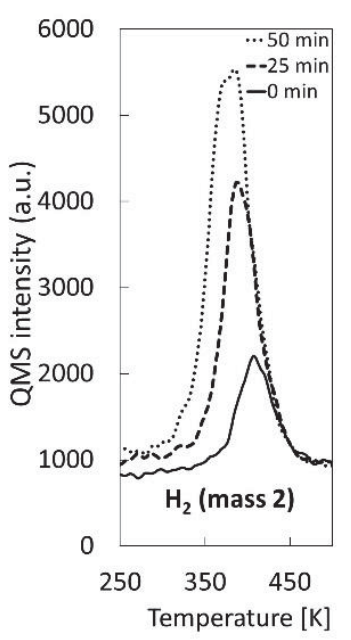

b)

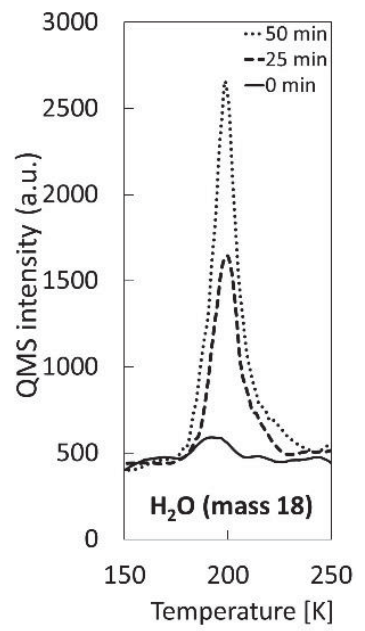

c)

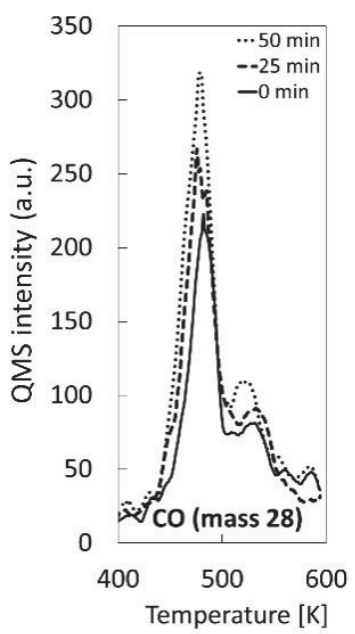

Figure 5-8. TPD of species adsorbed from residual background at a sample temperature of $85 \mathrm{~K}$. No other masses detected.

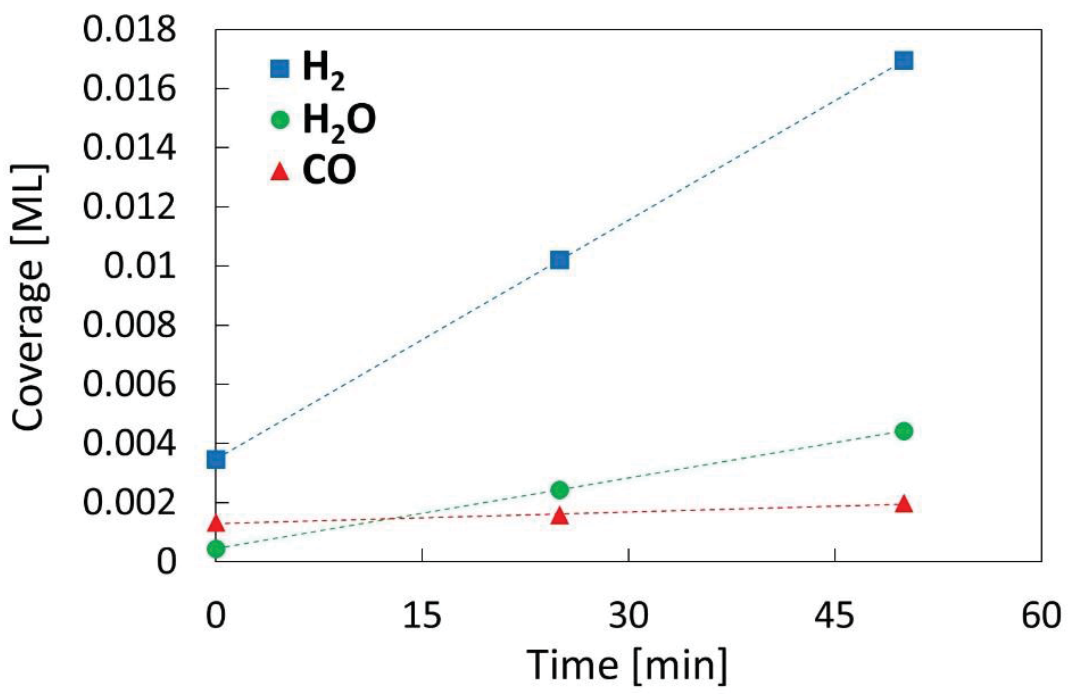

Figure 5-9. Surface coverage of $\mathrm{CO}, \mathrm{H}_{2} \mathrm{O}$ and $\mathrm{H}_{2}$ on $\mathrm{Ru}(0001)$ due to background gases. 
Table 5-2. CO surface coverage in ML from the background residual gases and after $\mathrm{CO}_{2}$ dose onto the surface.

\begin{tabular}{c|cc}
\hline \multirow{2}{*}{$\begin{array}{c}\text { Time } \\
\text { [min] }\end{array}$} & \multicolumn{2}{|c}{ CO surface coverage in $\mathrm{ML}$} \\
\cline { 2 - 3 } & Background & $\begin{array}{c}\text { With } \mathrm{CO}_{2} \\
\text { dose }\end{array}$ \\
\hline 25 & 0.0016 & 0.005 \\
50 & 0.002 & 0.008 \\
\hline
\end{tabular}

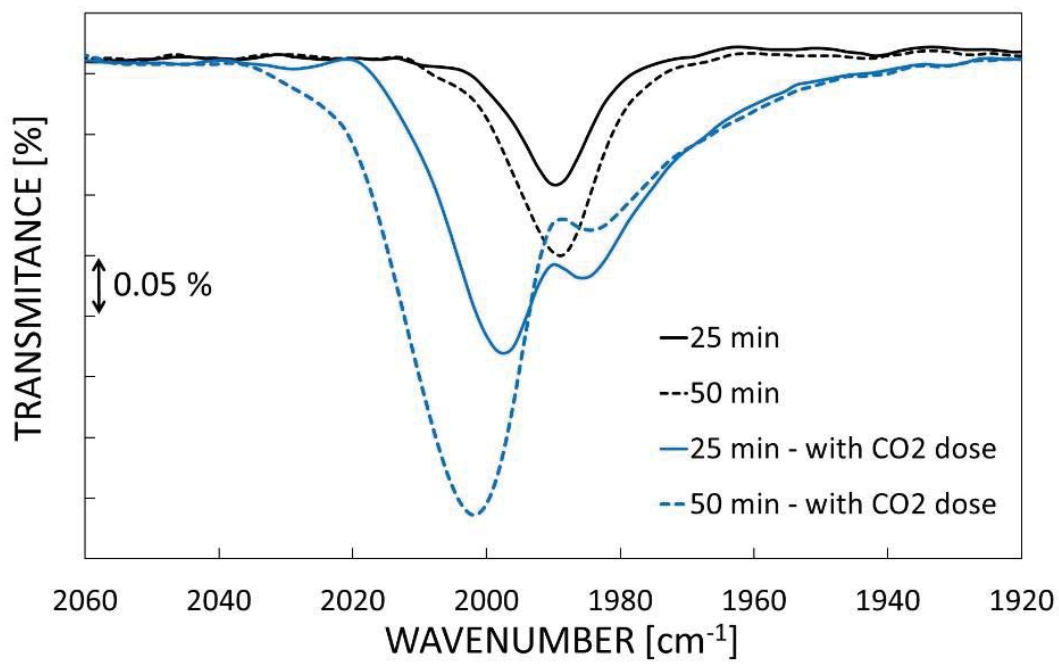

Figure 5-10. Comparison of the reflection-absorption infrared spectrum of $\mathrm{CO}$ peak, from the residual background gases and $\mathrm{CO}$ peak after $\mathrm{CO}_{2}$ dosing, after 25 and 50 min delay.

It is clear that the CO peak grows four times more on a surface that is dosed with $\mathrm{CO}_{2}$ compared to the natural adsorption from background gases. Furthermore, it can be seen from Figure 5-5 that the growth of the CO peak corresponds very well to the decay of the $\mathrm{CO}_{2}$ peak. This suggests that desorption of $\mathrm{CO}_{2}$ at $85 \mathrm{~K}$ is rather slow and that the changes in the infrared spectra are dominated by partial dissociation. After $\mathrm{CO}_{2}$ dosing onto the surface two $\mathrm{CO}$ peaks at different position are observed, what is indicative of a low and high energy binding site. To determine the stability of those peaks, the surface was annealed above the temperature of the 
main desorption peak of $\mathrm{CO}_{2}$. As stated earlier, the $\mathrm{Ru}(0001)$ surface was dosed with $\mathrm{CO}_{2}$ (1 mbar, 10 minutes), and after 50 minutes, was heated to $120 \mathrm{~K}$. After cooling to $85 \mathrm{~K}$, a RAIRS spectrum was obtained (see Figure 5-11).

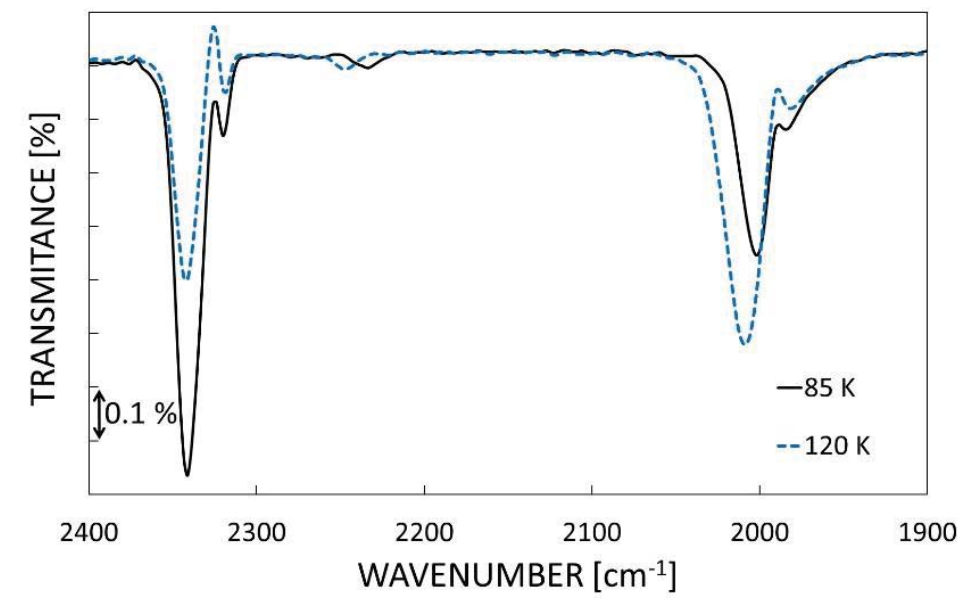

Figure 5-11. Reflection-absorption infrared spectrum after $10 \mathrm{~min}$ $\mathrm{CO}_{2}$ (1mbar) dosing onto the $\mathrm{Ru}(0001)$ and 50 minutes delay time on $\mathrm{Ru}(0001)$ single crystal at $85 \mathrm{~K}$ and after sample annealing to $120 \mathrm{~K}$.

Table 5-3. Surface coverage of $\mathrm{CO}$ and $\mathrm{CO}_{2}$ (after $\mathrm{CO}_{2}$ dose onto the $\mathrm{Ru}(0001)$ surface $50 \mathrm{~min}$ delay) at $85 \mathrm{~K}$ and after annealing to $120 \mathrm{~K}$.

\begin{tabular}{c|cc}
\hline \multirow{2}{*}{$\begin{array}{c}\text { Temperature } \\
{[\mathrm{K}]}\end{array}$} & \multicolumn{2}{|c}{ Indicative surface coverage in $\mathrm{ML}$} \\
\cline { 2 - 3 } & $\mathrm{CO}$ & $\mathrm{CO}_{2}$ \\
\hline 85 & 0.01 & 0.028 \\
120 & 0.016 & 0.014 \\
\hline
\end{tabular}

Table $5-3$ shows that the $\mathrm{CO}_{2}$ coverage is reduced by a factor of two. Complete desorption is not achieved because, as can be seen in Figure 5-2, the $\mathrm{CO}_{2}$ desorption spectrum has a peak at $105 \mathrm{~K}$, followed by a broad feature that extends beyond $120 \mathrm{~K}$. The surface coverage of CO increases from 0.01 to 0.016 of a ML. Interestingly, the overall increase is accompanied by a $23 \%$ reduction in the lower 
energy peak and a $65 \%$ increase in the higher energy peak. In addition to changes in peak intensity, after annealing, the peak positions also change slightly. The higher energy peak blue-shifts from 2002 to $2010 \mathrm{~cm}^{-1}$ and the lower energy peak red-shifts from 1984 to $1980 \mathrm{~cm}^{-1}$. Both shifts are likely to be due to coverage dependent effects. ${ }^{29}$

\subsection{Oxygen TPD}

A remaining question relates to the oxygen radical. Since the generated amount of $\mathrm{CO}$ is very low, it is possible that the oxygen atoms are consumed for forming $\mathrm{CO}$ with residual carbon in the crystal. This should then give a small CO desorption at high temperature, which may be difficult to detect in such small doses. Another option is that oxygen can form water with background $\mathrm{H}_{2}$. Formation of such small amounts of water is not detectable due to presence of background water in the TPD spectrum. Our RAIRS measurements were unable to reliably detect an increase in the $\mathrm{OH}$ stretch mode, but it should be noted that RAIRS is generally not able to detect sub-monolayer amounts of water, since the first monolayer of water on $\mathrm{Ru}$ does not have a significant dipole moment perpendicular to the surface. ${ }^{33} \mathrm{~A}$ third possibility is that the oxygen chemisorbs with the ruthenium surface. To find the role of oxygen chemisorption, the oxygen signal was always recorded in TPD after $\mathrm{CO}_{2}$ adsorption. However, no significant signal at $1580 \mathrm{~K}$ was detected, indicating that ruthenium oxide is not formed during $\mathrm{CO}_{2}$ dissociation, or that the oxygen is consumed for forming $\mathrm{CO}$ from residual carbon that diffuses out of the bulk of the crystal at high temperature.

Furthermore, we also exclude re-association due to

$$
\mathrm{CO}_{2} \stackrel{k_{1}}{\stackrel{k_{2}}{\rightarrow}} \mathrm{CO}+\mathrm{O}
$$

with $\mathrm{k}_{1} \approx \mathrm{k}_{2}$. If this were the case, then, after annealing the ruthenium and removing the majority of $\mathrm{CO}_{2}$, the surface 
concentrations would be out of equilibrium and favor the reverse reaction. However, neither an increase in $\mathrm{CO}_{2}$, nor a decrease in the CO vibrational mode intensity is observed. This implies that $k_{1}>>k_{2}$. Finally, the re-association during TPD can also be excluded because there is no evidence for a significant $\mathrm{CO}_{2}$ desorption peak at the CO desorption temperature.

\subsection{Conclusions}

Our results show that $\mathrm{CO}_{2}$ adsorption on a $\mathrm{Ru}(0001)$ surface results in partial dissociation, with $\mathrm{CO}_{2}$ and $\mathrm{CO}$ present on the surface. RAIRS measurements show that $\mathrm{CO}_{2}$ dissociates into $\mathrm{CO}$ over time. For a $\mathrm{CO}_{2}$ coverage of $0.05 \mathrm{ML}$, dissociation proceeds to a $\mathrm{CO}_{2}$ coverage of $0.03 \mathrm{ML}$, and appears to saturate. Furthermore, the dissociation of $\mathrm{CO}_{2}$ appears to be irreversible. In comparison with previous results reported for $\mathrm{Ni}(110)^{18,30}$, and $\mathrm{Fe}(111)^{9,19,34-35}$, we note that the dissociation of $\mathrm{CO}_{2}$ is qualitatively similar, but has some significant differences. For both $\mathrm{Ni}$ and $\mathrm{Fe}$, partial dissociation is only observed for elevated temperatures, while for Ru(0001), dissociation is already observed at $85 \mathrm{~K}$. Furthermore, in the case of $\mathrm{Ni}$ and $\mathrm{Fe}$, the oxygen is observed to be adsorbed to the surface, while for $\mathrm{Ru}$, there is no evidence of $\mathrm{O}$ adsorption. Finally, on further heating, CO decomposes into carbon and oxygen on Fe, while on Ru, CO desorbs intact. Observed vibrational modes at 660 and $2343 \mathrm{~cm}^{-1}$ correspond to stretch modes of linear, undisturbed $\mathrm{CO}_{2}$, while a vibrational feature that is visible only for higher $\mathrm{CO}_{2}$ coverages at $1580 \mathrm{~cm}^{-1}$, is tentatively assigned to an asymmetric stretching mode of a bent $\mathrm{CO}_{2}$ species.

The adsorption $\left(\mathrm{CO}_{2}\right.$ does not adsorb for temperatures higher than $100 \mathrm{~K}$ ) and desorption temperatures of $\mathrm{CO}_{2}$ on $\mathrm{Ru}$ are relatively low in comparison to those reported for other transition metals. ${ }^{1}$ By annealing the surface at $120 \mathrm{~K}$-just above the peak desorption temperature of $\mathrm{CO}_{2}$-it was observed that the rate of $\mathrm{CO}_{2}$ dissociation was increased and that the $\mathrm{CO}$ restructures to a 
weaker bond between the surface and CO. TPD spectra confirm that the changes in the RAIRS spectrum are due to changes in CO and $\mathrm{CO}_{2}$ coverage. Furthermore, TPD does not show chemisorbed oxygen on the Ru surface, which may be due to $\mathrm{H}_{2} \mathrm{O}$ or $\mathrm{CO}$ formation from residual $\mathrm{H}_{2}$ or $\mathrm{C}$ on the sample.

\subsection{References}

1. Solymosi, F., The Bonding, Structure and Reactions of Co2 Adsorbed on Clean and Promoted Metal Surfaces. J. Mol. Catal. 1991, 65, 337358.

2. Kuhl, K. P.; Hatsukade, T.; Cave, E. R.; Abram, D. N.; Kibsgaard, J.; Jaramillo, T. F., Electrocatalytic Conversion of Carbon Dioxide to Methane and Methanol on Transition Metal Surfaces. J. Am. Chem. Soc. 2014, 136, 14107-14113.

3. Wang, Y.; Lafosse, A.; Jacobi, K., Adsorption and Reaction of Co2 on the Ruo2(110) Surface. J. Phys. Chem. B, 2002, 106, 5476-5482.

4. Mark, M. F.; Maier, W. F., Co2-Reforming of Methane on Supported Rh and Ir Catalysts. J. Catal. 1996, 164, 122-130.

5. Utaka, T.; Okanishi, T.; Takeguchi, T.; Kikuchi, R.; Eguchi, K., Water Gas Shift Reaction of Reformed Fuel over Supported Ru Catalysts. Appl. Catal., A 2003, 245, 343-351.

6. Bricker, J. C.; Nagel, C. C.; Shore, S. G., Reactivities of Ruthenium Cluster Anions: Implications for Catalysis of the Water-Gas Shift Reaction. J. Am. Chem. Soc. 1982, 104, 1444-1445.

7. Graves, C.; Ebbesen, S. D.; Mogensen, M.; Lackner, K. S., Sustainable Hydrocarbon Fuels by Recycling $\mathrm{CO} 2$ and $\mathrm{H} 2 \mathrm{O}$ with Renewable or Nuclear Energy. Renewable Sustainable Energy Rev. 2011, 15, 1-23.

8. Zhao, P.; He, Y.; Cao, D. B.; Wen, X.; Xiang, H.; Li, Y. W.; Wang, J.; Jiao, $\mathrm{H}$. , High Coverage Adsorption and Co-Adsorption of $\mathrm{Co}$ and $\mathrm{H} 2$ on Ru(0001) from Dft and Thermodynamics. Phys. Chem. Chem. Phys. 2015, 17, 19446-19456.

9. Freund, H. J.; Gehner, H.; Bartos, B.; Wedler, G., Co2 Adsorption and Reaction on $\mathrm{Fe}(111)$ : And Angle Resolved Photoemission (Arups) Study. Surf. Sci. 1987, 180, 550-564.

10. McCarty, J.; Falconer, J.; Madix, R. J., Decomposition of Formic Acid on $\mathrm{Ni}(\mathrm{L} 10)$ I.Flash Decomposition from the Clean Surface and Flash 
Desorption of Reaction Products. Journal of Catalysis 1973, 30, 235249.

11. Benziger, J. B.; Madix, R. J., The Decomposition of Formic Acid on Ni (100). Surf. Sci. 1979, 79, 394-412.

12. Asscher, M.; Kao, C. T.; Samorjai, G. A., High-Resolution Electron Energy Loss Spectroscopic Study of Co2, Adsorbed on Re( 0001). J. Phys. Chem. 1988, 92, 2711-2714.

13. Carley, A. F.; Gallagher, D. E.; Roberts, M. W., Activation of Carbon Dioxide at Low Temperatures at Aluminium Surfaces. Surf. Sci. 1987, 183, 263-268.

14. Eren, B.; Zherebetskyy, D.; Patera, L. L.; Wu, C. H.; Bluhm, H.; Africh, C.; Wang, L.-W.; Somorjai, G. A.; Salmeron, M., Activation of Cu(111) Surface by Decomposition into Nanoclusters Driven by Co Adsorption. Surf. Sci. 2016, 351, 475-478.

15. Mongeot de, F. B.; Scherer, M.; Gleich, B.; Kopatzki, E.; Behm, R. J., Co Adsorption and Oxidation on Bimetallic Pt/Ru(0001) Surfaces - a Combined Stm and Tpd/Tpr Study. Surf. Sci. 1998, 411, 249-262.

16. Onishi, H.; Iwasawa, Y., Reconstruction of Tio,( 110) Surface: Stm Study with Atomic-Scale Resolution. Surf. Sci. 1994, 313, 783-789.

17. Kong, D.; Zhu, J.; Ernst, K.-H., Low-Temperature Dissociation of $\mathrm{Co} 2$ on a Ni/Ceo2(111)/Ru(0001) Model Catalyst. J. Phys. Chem. C 2016, 120, 5980-5987.

18. Wambach, J.; Illing, G.; Freund, H. J., Co2 Activation and Reaction with Hydrogen on $\mathrm{Ni}$ ( 110): Formate Formation. Chem. Phys. Lett. 1991, 184, 239-244.

19. Behner, H.; Spiess, W.; Wedler, G.; Borgmann, D.; Freund, H. J., Electron Energy Loss Study of the Electronically Excited States of Adsorbedco2: Case Study Co2/Fe. Surf. Sci. 1987, 184, 335-344.

20. Diemant, T.; Schuttler, K. M.; Behm, R. J., Ag on Pt(111): Changes in Electronic and Co Adsorption Properties Upon Ptag/Pt(111) Monolayer Surface Alloy Formation. Chem. Phys. Chem. 2015, 16, 2943-2952.

21. Wang, W.; Li, L.; Zhou, Q.; Pan, J.; Zhang, Z. L.; Tok, E. S.; Yeo, Y.-C., Tin Surface Segregation, Desorption, and Island Formation During Post-Growth Annealing of Strained Epitaxial Ge1-Xsnx Layer on Ge(001) Substrate. Appl. Surf. Sci. 2014, 321, 240-244.

22. Böttcher, A.; Niehus, H., Formation of Subsurface Oxygen at Ru(0001). J. Chem. Phys. 1999, 110, 3186-3195. 
23. Madey, T. E.; Faradzhev, N. S.; Yakshinskiy, B. V.; Edwards, N. V., Surface Phenomena Related to Mirror Degradation in Extreme Ultraviolet (Euv) Lithography. Appl. Surf. Sci. 2006, 253, 1691-1708.

24. Gerakines, P. A.; Schutte, W. A.; Greenberg, J. M.; Dishoeck van, E. $\mathrm{F} .$, The Infrared Band Strengths of $\mathrm{H} 2 \mathrm{O}$, $\mathrm{Co}$ and $\mathrm{Co} 2$ in Laboratory Simulations of Astrophysical Ice Mixtures. Astron. Astrophys. 1995, 296, 810-818.

25. Smith, A. L., The Coblentz Society Desk Book of Infrared Spectra 2ed., 1982.

26. Liu, Z. M.; Zhou, Y.; Solymosi, F.; White, J. M., Spectroscopic Study of K-Induced Activation of Co, on Pt( 111). Surf. Sci. 1990, 245, 289-304.

27. Liu, Z. M.; Zhou, Y.; Solymosi, F.; White, J. M., Vibrational Study of Co2- on K-Promoted Pt(111). J. Phys. Chem. 1989, 93, 4383-4385.

28. Liu, F.; Sturm, J. M.; Lee, C. J.; Bijkerk, F., Extreme Uv Induced Dissociation of Amorphous Solid Water and Crystalline Water Bilayers on Ru(0001). Surf. Sci. 2016, 646, 101-107.

29. Pfnür, H.; Menzel, D., High Resolution Vibrational Spectroscopy of Co on Ru(Oo1): The Importance of Lateral Interactions. Surf. Sci. 1980, 93, 431-452.

30. Bartos, B.; Freund, H. J., Adsorption and Reaction of $\mathrm{Co}$, and $\mathrm{Co}, / \mathrm{O}$ Co-Adsorption on $\mathrm{Ni}(110)$ : Angle Resolved Photoemission (Arups) and Electron Energy Loss (Hreels) Studies. Surf. Sci. 1987, 179, 5989.

31. Collins, A. C.; Trapnell, B. M. W., Co2 Chemisorption on Evaporated Metal Films. Trans. Faraday Soc. 1957, 53, 1476-1482.

32. Zeinalipour-Yazdi, C. D.; Willock, D. J.; Thomas, L.; Wilson, K.; Lee, A. F., Co Adsorption over Pd Nanoparticles: A General Framework for Ir Simulations on Nanoparticles. Surf. Sci. 2016, 646, 210-220.

33. Clay, C.; Haq, S.; Hodgson, A., Intact and Dissociative Adsorption of Water on Ru(0001). Chem. Phys. Lett. 2004, 388, 89-93.

34. Behner, H.; Spiess, W.; Wedler, G.; Dorgmann, D., Interaction of Carbon Dioxide with Fe( 110), Stepped Fe( 110) and Fe(111). Surf. Sci. 1986, 175, 276-286.

35. Yoshida, K.; Samorjai, G. A., The Chemisorption of Co, Co2, C2h2, C2h4, H2 and Nh3 on the Clean Fe( 100) and (111) Crystal Surfaces. Surf. Sci. 1978, 75, 46-60. 


\section{Valorization}

Our systematic investigation on Sn etching from different surface materials has very good predictive power and facilitates the choice of materials for EUV and di-electric materials applications.

Knowledge of the Sn etching process provides information on the influence of oxidized capping material in comparison to metallic surfaces. Also, the influence of the underlayer on surface binding can be qualitatively estimated via the electronegativity model, and checked by $\mathrm{Sn}$ etching studies. That information allows rational choices to be made for, not only the layer material, but also for its thickness and composition.

The use of CO may reduce the concentration of hydrogen at the optical surface. $\mathrm{CO}$ binds stronger than $\mathrm{H}$ to the Ru surface, so it can displace $\mathrm{H}$ from the metal surface. Moreover, $\mathrm{CO}$ reacts with $\mathrm{H}$ to form hydrocarbons which further reduces the surface $\mathrm{H}$ concentration. However, achieving a constant CO coverage of all the optical surfaces in an EUVL tool will require a significant amount of $\mathrm{CO}$ to be delivered to the system. Knowing that $\mathrm{CO}$ is highly toxic makes usage of large quantities of it unsafe and uneconomic. That is why CO should be introduced/ delivered to the surface in a different way. Our hypothesis was that $\mathrm{CO}_{2}$, irradiated with EUV will produce $\mathrm{CO}$ and, consequently lead to high $\mathrm{CO}$ surface coverage. However, this proved to be inaccurate. Instead, the adsorption of $\mathrm{CO}_{2}$ on a Ru surface results in partial dissociation, with $\mathrm{CO}_{2}$ and $\mathrm{CO}$ present on the surface. Thus, no EUV is needed to activate $\mathrm{CO}_{2}$ dissociation into $\mathrm{CO}$, and $\mathrm{CO}$ can be delivered to the Ru surface via a small partial pressure of $\mathrm{CO}_{2}$. This process is not aggressive, thus, the total concentration of $\mathrm{CO}$ in the vacuum system will remain very low. Knowledge of $\mathrm{CO}_{2}$ absorption and dissociation on $\mathrm{Ru}$ surface is the first step towards using a good understanding of the 
surface chemistry to control surface reactions on EUV optical surfaces via the partial pressure of background gasses. 


\section{Summary}

The physics and chemistry of Sn etching from optical and dielectrical surfaces must be understood in order to ensure that cleaning is complete and that the process does not damage the surface of the elements. We proposed the use of the relative electronegativities of the surface material and $S n$ to predict the degree to which electrons are available for bonding. This allows the success or failure of Sn etching from a thin metallic surface material to be predicted. It was found that Sn can be completely etched from transition metals with electronegativity values that are lower than or equal to $\mathrm{Sn}\left(\boldsymbol{\chi}_{\mathrm{Sn}}-\boldsymbol{\chi}_{\mathrm{M}} \geq 0\right)$. We observed incomplete $\mathrm{Sn}$ etching when Sn was initially deposited onto materials with an electronegativity value higher than that of $\operatorname{Sn}\left(\boldsymbol{\chi}_{\mathrm{Sn}}-\boldsymbol{\chi}_{\mathrm{M}}<0\right)$. This shows that electronegativity is a useful predictor for hydrogen etching of Sn from metal surfaces. Furthermore, for high electronegativity surfaces, which we predict to prevent complete etching, the remaining amount of $\mathrm{Sn}$ after etching depends on the electronegativity of the surface onto which Sn was deposited. This indicates that even $\mathrm{S} n$ that is separated from the surface by several atomic layers is still influenced by the surface.

Metals with high electronegativities form weak oxides, such as ruthenium, while those with low electronegativity form strong oxides (e.g., scandium and aluminium). This leaves open the question of the role of surface oxidation in tin adhesion. To investigate the influence of oxidation, the removal of Sn from metallic and oxidized Sc thin films was studied. We have shown that tin can be fully etched from a metallic Sc surface as well from Sc thin films with complete and incomplete oxidation. Furthermore, our results show that the presence of $\mathrm{Sc}_{2} \mathrm{O}_{3}$ on a Sc thin film significantly slows the etch rate. For Sn etching from oxidized Sc, 
we propose that etching is slowed by electrons being trapped at defect sites in the $\mathrm{Sc}_{2} \mathrm{O}_{3}$ layer. This effect is strengthened when Sc metal is present below the $\mathrm{Sc}_{2} \mathrm{O}_{3}$, due to the built-in electric field spanning the oxide, generated by the difference in work function between Sc and Sn.

In this thesis, catalytic dissociation of $\mathrm{CO}_{2}$ was studied as a precursor for hydrogen control studies. Carbon dioxide adsorption and dissociation on a Ru single crystal surface was studied. Our results show that $\mathrm{CO}_{2}$ adsorption on a $\mathrm{Ru}(0001)$ surface results in partial dissociation, with $\mathrm{CO}_{2}$ and $\mathrm{CO}$ present on the surface. Furthermore, the dissociation of $\mathrm{CO}_{2}$ appears to be irreversible and is already observed at $85 \mathrm{~K}$. The observed vibrational modes at 660 and $2343 \mathrm{~cm}^{-1}$ correspond to stretch modes of linear, undisturbed $\mathrm{CO}_{2}$, while a vibrational feature, which is visible only for higher $\mathrm{CO}_{2}$ coverages, at $1580 \mathrm{~cm}^{-1}$ is tentatively assigned to an asymmetric stretching mode of a bent $\mathrm{CO}_{2}$ species. The adsorption and desorption temperatures of $\mathrm{CO}_{2}$ on $\mathrm{Ru}$ are relatively low. By annealing the surface at $120 \mathrm{~K}$-just above the peak desorption temperature of $\mathrm{CO}_{2}$-it was observed that the rate of $\mathrm{CO}_{2}$ dissociation was increased and that the $\mathrm{CO}$ restructures to a weaker bond between the surface and $\mathrm{CO}$. The partial dissociation of $\mathrm{CO}_{2}$ is an important first step, since $\mathrm{CO}$ and $\mathrm{H}$ may react to form water and volatile hydrocarbons. This may then reduce the hydrogen concentration at the surface, which slows hydrogen penetration into the mirror.

Scandium oxide $\left(\mathrm{Sc}_{2} \mathrm{O}_{3}\right)$ is a possible candidate for high-k dielectric applications. However, the stability of the dielectric layer is also very important: metal atoms from the gate electrode should not penetrate into or through the oxide layer. In this thesis, metal diffusion studies were carried out to test if $\mathrm{Sc}_{2} \mathrm{O}_{3}$ layers of various thicknesses act as a diffusion barrier. Scandium oxide diffusion barrier properties were tested using a MIM structure, consisting of $\mathrm{Ru}, \mathrm{SC}_{2} \mathrm{O}_{3}$, and $\mathrm{Sn}$. We observed complete $\mathrm{Sn}$ etching from 0.71, 1.1 
and $1.56 \mathrm{~nm}$ of $\mathrm{Sc}_{2} \mathrm{O}_{3}$. It was demonstrated that even $0.5 \mathrm{~nm} \mathrm{S \textrm {S } _ { 2 } \mathrm { O } _ { 3 }}$ forms a closed oxide layer that prevents the diffusion of $\mathrm{Sn}$ through to the Ru layer. The Sn etching time was observed to depend on the $\mathrm{Sc}_{2} \mathrm{O}_{3}$ barrier thickness and increased with increasing $\mathrm{Sc}_{2} \mathrm{O}_{3}$ thickness. This is explained by the formation of a MIM junction between the $\mathrm{Ru}, \mathrm{Sc}_{2} \mathrm{O}_{3}$ and $\mathrm{Sn}$, where the built-in potential enhances diffusion of electrons from the $\mathrm{Ru}$ and $\mathrm{Sc}_{2} \mathrm{O}_{3}$ defect states to the $\mathrm{Sn}$. This diffusion of electrons becomes less efficient for larger barrier thicknesses. We use a simple model to show that, for thicker layers of $\mathrm{Sc}_{2} \mathrm{O}_{3}$, the etch rate is limited by charge diffusion, while electron tunneling may contribute significantly for thin layers of $\mathrm{SC}_{2} \mathrm{O}_{3}$. 


\section{Samenvatting}

De fysische en chemische eigenschappen van het etsen van kleine hoeveelheden tin $(\mathrm{Sn})$ is van belang voor diverse optische en diëlektrische oppervlakken. Het etsproces dient in detail te worden gekarakteriseerd, zodat volledig etsen kan worden bereikt zonder dat schade wordt toegebracht aan het oppervlak.

Op basis van de elektronegativiteit van het oppervlaktemateriaal en het $\mathrm{Sn}$ hebben we een schatting gemaakt van de sterkte van de $\mathrm{Sn}$-binding. Dit geeft een directe indicatie van het etsen van $\mathrm{Sn}$ van een dun metaaloppervlak. Dit promotie-onderzoek laat zien dat volledig etsen mogelijk is wanneer de elektronegativiteit van het

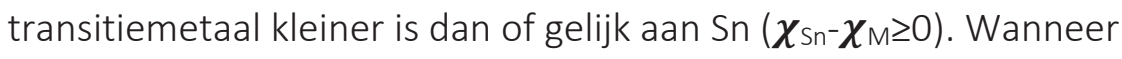
de elektronegativiteit groter is dan die van $\operatorname{Sn}\left(\boldsymbol{\chi}_{\mathrm{Sn}}-\boldsymbol{\chi}_{\mathrm{M}}<0\right)$, is volledig etsen niet mogelijk. Het onderzoek toont aan dat de elektronegativiteit een goede indicator is voor het Sn-etsgedrag van waterstofradicalen aan een metaaloppervlak. Daarnaast verwachten we voor sterk elektronegatieve oppervlakken dat de overgebleven hoeveelheid $\mathrm{Sn}$ na het etsen afhangt van de elektronegativiteit van het oppervlak waarop het $\mathrm{Sn}$ is aangebracht. Daarbij wordt de elektronegativiteit beïnvloed door meerdere atoomlagen.

Metalen met een hoge elektronegativiteit vormen zwakke oxides, bijvoorbeeld ruthenium, terwijl metalen met een lage elektronegativiteit sterke oxides vormen (zoals scandium en aluminium). Hierbij is de vraag welke rol oppervlakte-oxidatie speelt bij de binding van tin. Om deze processen te onderzoeken is de invloed onderzocht van het tin-etsen van metallische en geoxideerde Sc-samples. We laten zien dat tin volledig geëtst kan worden van het Sc-oppervlak, onafhankelijk van de oxidatiegraad. Daarbij laten de resultaten zien dat de aanwezigheid van $\mathrm{Sc}_{2} \mathrm{O}_{3}$ op 
het Sc-oppervlak de etssnelheid vertraagt. We verwachten dat het etsen vertraagd wordt doordat elektronen binden met defectlocaties in de $\mathrm{Sc}_{2} \mathrm{O}_{3}$-laag. Dit effect wordt nog versterkt wanneer Sc-metaal onder de $\mathrm{Sc}_{2} \mathrm{O}_{3}$-laag aanwezig is, vanwege het elektrische veld over het oxide als gevolg van het verschil in de werkfunctie tussen Sc en Sn.

In dit proefschrift werd verder katalytische dissociatie van $\mathrm{CO}_{2}$ bestudeerd als een voorloper voor waterstofstudies aan oppervlakken. Koolstofdioxide-adsorptie en -dissociatie zijn onderzocht op een Ru monokristallijn oppervlak. Onze resultaten laten zien dat $\mathrm{CO}_{2}$-adsorptie op een $\mathrm{Ru}(0001)$ oppervlak leidt tot partiële dissociatie, waarbij zowel $\mathrm{CO}_{2}$ als $\mathrm{CO}$ op het oppervlak aanwezig zijn. Daarnaast is de dissociatie van $\mathrm{CO}_{2}$ irreversibel en al zichtbaar bij $85 \mathrm{~K}$. De geobserveerde vibrationele modes van 660 en $2343 \mathrm{~cm}^{-1}$ corresponderen met lineaire strek modes $\mathrm{CO}_{2}$, terwijl een vibrationele mode van $1580 \mathrm{~cm}^{-1}$ geassocieerd kon worden met een asymmetrische gekromde $\mathrm{CO}_{2}$-configuratie. De adsorptie- en desorptietemperaturen van $\mathrm{CO}_{2}$ op Ru zijn relatief laag. Door het oppervlak te verhitten tot $120 \mathrm{~K}$, net boven de piekwaarde van de desorptietemperatuur, wordt de dissociatiesnelheid van $\mathrm{CO}_{2}$ verhoogd en de CO vormt een zwakkere binding met het oppervlak. De partiële dissociatie van $\mathrm{CO}_{2}$ vormt een belangrijke eerste stap in het proces, omdat $\mathrm{CO}$ en $\mathrm{H}$ kunnen reageren tot water en gasvormige koolwaterstoffen. Dit kan de waterstofconcentratie op het oppervlak verlagen en zo de waterstofpenetratie in de spiegel vertragen.

Scandiumoxide $\left(\mathrm{S}_{2} \mathrm{O}_{3}\right)$ is een mogelijke kandidaat voor hoge-k diëlektrische toepassingen. De stabiliteit van de diëlektrische laag is echter ook erg belangrijk: metaalatomen van de gate-elektrode mogen niet in of door de oxidelaag dringen. In het kader van dit proefschrift werd onderzoek gedaan naar metaaldiffusie om te testen of $\mathrm{SC}_{2} \mathrm{O}_{3}$-lagen kunnen werken als diffusiebarrière. De diffusiebarrière-eigenschappen van verschillende diktes 
scandiumoxide werden getest met behulp van een MIM-structuur, bestaande uit $\mathrm{Ru}, \mathrm{Sc}_{2} \mathrm{O}_{3}$ en $\mathrm{Sn}$. We observeerden volledige $\mathrm{Sn}$-ets van $0,71,1,1$ en 1,56 $\mathrm{nm} \mathrm{Sc} 2 \mathrm{O}_{3}$. Er werd aangetoond dat zelfs 0,5

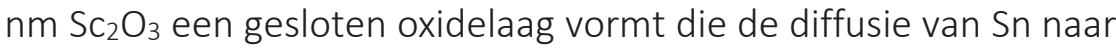
de Ru-laag voorkomt. Er werd waargenomen dat de Sn-etstijd afhing van de $\mathrm{SC}_{2} \mathrm{O}_{3}$-barrièredikte en toenam met toenemende $\mathrm{SC}_{2} \mathrm{O}_{3}$-dikte. Dit kan worden verklaard door de vorming van een MIM-junctie tussen de $\mathrm{Ru}, \mathrm{Sc}_{2} \mathrm{O}_{3}$ en $\mathrm{Sn}$ lagen, waar de ingebouwde potentiaal de diffusie van elektronen van de defecten in de Ru en $\mathrm{Sc}_{2} \mathrm{O}_{3}$ lagen naar het $\mathrm{Sn}$ verbetert. Deze diffusie van elektronen wordt minder efficiënt bij grotere barrièrediktes. We gebruiken een eenvoudig model om aan te tonen dat de etssnelheid voor dikkere lagen $\mathrm{Sc}_{2} \mathrm{O}_{3}$ wordt beperkt door ladingsdiffusie, terwijl elektronentunneling significant kan bijdragen bij dunne lagen $\mathrm{Sc}_{2} \mathrm{O}_{3}$. 


\section{Acknowledgement}

First and foremost, I would like to thank my supervisor prof.dr. Fred Bijkerk for providing me the opportunity to carry out this PhD research. I appreciate his time and contributions to making my PhD time productive and stimulating.

I have been fortunate to have Chris Lee as my daily supervisor, it is impossible to put my appreciation into words. Thank you for your great guidance, bright ideas and always challenging me.

I want to thank Marko Sturm for AFM, XPS measurements, his tireless explanations, and contributions to my papers. I would like to acknowledge Theo van Oijen for sample preparation.

I would also like to express my gratitude to Wim van der Zande, Edgar Osorio and Maarten van Kampen from ASML, for useful discussions and support.

I am truly grateful to Goran Milinkovic, Luc Stevens, John de Kuster, and Ruben Kok for all their support. They helped me with lab administration, experiments and building setups.

Many thanks go to my paranymfs Olena Soroka, Baibhav Mund as well as my direct colleagues An Gao, Feng Liu, Ani Chandrasekaran, and Rogier van den Bos, a group of young, enthusiastic and supportive people. I really enjoyed the working atmosphere both in the lab and the office that you helped create.

Also my thanks go to Carin Krijgen and Jacqueline Emmerich for all the administrative work.

Paulina Jackiewicz and Wojciech Jackiewicz, thank you for your great input into my work in the form of setup drawings.

My family has always been supportive and encouraging during my PhD. Especially, I would thank my parents who always believed in me and supported me in all my pursuits. 
Last but not least, I would like to thank my husband Demian Rozendaal for always being there to listen and help during this time.

Thank you all!

M. Pachecka

Eindhoven

June 13, 2018 


\section{About the author}

Małgorzata Pachecka was born on $22^{\text {nd }}$ of April 1987 in Siedlce, Poland. In 2006 she started her studies at Warsaw University of Life Sciences and in 2010 she received a B.Sc. degree in Food Technology and Human Nutrition with a major in Food Engineering and Process Management. Two years later she pursued an M.Sc. degree at the same faculty and same major. In parallel (from 2007) she studied Chemical and Process Engineering at Warsaw University of Technology with a major in Chemical Engineering and pursued a B.Sc. degree in 2011 and M.Sc. degree in 2012. During her studies she carried out several internships at different companies, including Silliker Polska Sp. (Warsaw, Poland) and Wetsus, Centre of Excellence for Sustainable Water Technology (Leeuwarden, The Netherlands). In December 2012 she started her PhD research in Chemistry and Physics of EUV optics at the Nanolayer Surfaces and Interfaces (nSI) Group of the FOM Institute Differ. In 2013 the Group relocated and became part of the later founded Industrial Focus Group XUV Optics, within the MESA+ Institute for Nanotechnology. During her PhD period she worked closely with the ASML Research Department, and carried out most of her research in the ASML Research Laboratory. The PhD research was part of the NanoNextNL Program and it was supervised by Prof.dr. F. Bijkerk, with daily supervision of Dr. C.J. Lee. A selection of the results are presented in this thesis. 